\title{
V JORNADA DE INVESTIGACIÓN 2017
} DIVISIÓN DE PEDIATRÍA

\section{Pontificia Universidad Católica de Chile Jueves 30 de Marzo 2017 \\ Aula Magna Manuel José Irarrázaval}

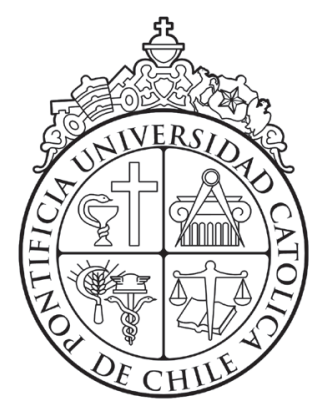

\section{Comité de Investigación}

\author{
Dr. Álvaro González \\ Dr. José Antonio Castro \\ Dr. Alejandro Martínez
}

Dr. Arturo Borzutzky

Dra. Nicole Le Corrè

Dr. Jaime Cerda

Dra. Marcela Ferres

Dra. Carolina Serrano

Dra. M. Ángeles Beytia

Dra. Pamela Zúñiga

Dr. Matías Luco

Dra. Carolina Valdebenito

Dr. Ricardo Uauy

Dr. Paul Harris
Jefe de la División de Pediatría

Presidente de la Comisión de Investigación

Secretario de la Jornada de Investigación

Coordinador de Investigación de Residentes de Pediatría
Coordinador de Investigación de Residentes de Pediatría
Asesor de Metodología de la Investigación
Representante de Infectología
Representante de Gastroenterología
Representante de Neurología
Representante de Hemato/Oncología
Representante de Neonatología
Representante del Hospital Sotero del Rio.
Miembro Honorario
Miembro Honorario




\section{Simposio de epigenética en pediatría}




\section{INTRODUCCIÓN A LA EPIGENÉTICA:}

\section{Función endotelial en la Restricción de Crecimiento Intrauterino como modelo de estudio.}

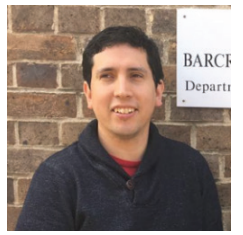

\section{DR. BERNARDO JAVIER KRAUSE LEYTON}

Investigador Adjunto, Departamento de Neonatología Laboratorio de Programación y Epigenética Perinatal Facultad de Medicina Pontificia Universidad Católica de Chile

La restricción del crecimiento intrauterino (RCIU) es una enfermedad perinatal que afecta la trayectoria de crecimiento fetal, llegando a estar bajo el percentil 10 del peso esperado para la edad gestacional. En este contexto, la evidencia actual apoya fuertemente que alteraciones en el crecimiento intrauterino y durante los primeros años de vida, presentan una fuerte influencia en el riesgo de padecer enfermedades crónicas que en muchos casos pudiera ser mayor que la carga genética del paciente. La persistencia y reproducibilidad de los fenotipos asociados a alteraciones en el desarrollo temprano sugieren la participación de mecanismos moleculares que registran dichas modificaciones (i.e. mecanismos epigenéticos) generando una "reprogramación" celular y fisiológica. Los mecanismos moleculares considerados epigenéticos incluyen metilación del DNA, modificaciones post-traduccionales de histonas, modificación de cromatina dependiente de ATP, y RNAs no codificantes. En base a estos antecedentes nuestro grupo ha explorado la presencia de cambios en la metilación del DNA a nivel endotelial en placentas humanas y arterias de cobayos en edad fetal y adulta, como marcadores epigenéticos asociados a la RCIU. Así mismo, hemos develado la interacción entre la síntesis de óxido nítrico y la activación de modificaciones en histonas como un mecanismo regulador de la función endotelial a corto plazo. Si bien los resultados apoyan la presencia de alteraciones en marcas epigenéticas resultantes de la RCIU, se hacen necesarios estudios adicionales para develar los alcances funcionales a nivel vascular de estos cambios, así como oportunidades de intervención y prevención.

\section{EPIGENÉTICA Y ASMA}

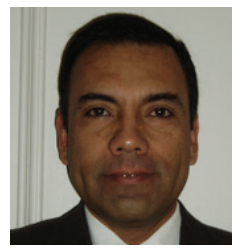

\section{DR. JOSÉ CASTRO-RODRÍGUEZ}

Pediatra Broncopulmonar

Profesor Asociado, Departamento de Cardiología y Neumología Pediátrica Laboratorio de Programación y Epigenética Perinatal Facultad de Medicina

Pontificia Universidad Católica de Chile

Las enfermedades alérgicas y el asma son el resultado de complejas interacciones entre la predisposición genética y factores ambientales. El asma es una de las enfermedades crónicas más prevalentes en niños. En esta presentación se revisarán algunos mecanismos epigenéticos que factores ambientales como: la exposición a alérgenos, tabaco, bacterias, componentes microbianos, dieta, obesidad y estrés; ejercen durante la vida intrauterina e infancia precoz favoreciendo así el desarrollo de las enfermedades alérgicas y el asma.

FONDECYT \# 1141195 "Early risk of asthma in children exposed to in-utero maternal obesity. An epigenetic-mediated programming of immune function"

\section{EPIGENÉTICA Y OBESIDAD:}

\section{La obesidad materna define el estado metabólico y los marcadores inflamatorios del recién nacido en la vida temprana: mecanismos epigenéticos}

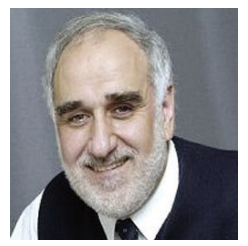

\section{DR. RICARDO UAUY}

Departamento de Neonatología

División de Pediatría y División de Obstetricia

y Ginecología Escuela de Medicina,

Pontificia Universidad Católica de Chile.

La evidencia indica que la exposición a diversas condiciones ambientales en etapas tempranas de la vida puede inducir alteraciones persistentes en el epigenoma. Los estudios epigenómicos en sujetos obesos han permitido evaluar el papel de los mecanismos epigenéticos en el origen y desarrollo de la obesidad. La presente revisión aborda estudios que dan cuenta de la asociación entre la obesidad y metilación global del genoma (ADN), analizando el potencial impacto de intervenciones previas y posteriores al nacimiento que afectan la metilación del ADN y la obesidad en etapas más avanzadas de la vida. Estudios realizados principalmente en leucocitos, han logrado identificar sitios del ADN diferencialmente metilados asociados con obesidad. Estudios hasta la fecha no han demostrado que dichos cambios en metilación sean revertidos luego de bajar de peso. Esto contrasta con resultados iniciales en este campo, que sugieren que existirían marcadores epigenéticos presentes desde el nacimiento que permitirían definir el riesgo de obesidad durante el curso de la vida.

La evidencia actual sugiere que algunas marcas epigenéticas son modificables, basándonos en la exposición en la vida intrauterina y también por los hábitos dietarios y de actividad física durante las etapas del crecimiento y en la adultez. Esto sugiere que existe la oportunidad de intervenir durante la gestación o en la vida posnatal temprana, modificando los perfiles epigenéticos desfavorables e idealmente contribuyendo a prevenir la obesidad en los sujetos o poblaciones susceptibles.

CONICYT-PCHA 2014-201463140222, FONDECYT \#1141195, \#1150878 and \#1171406 2017 


\section{Presentaciones orales}




\section{Maternal obesity is associated with metabolic and inflammatory profile of the offspring at birth.}

Jaramillo A, Carrasco K, Muñoz E, Soto G, Uauy R, Castro-Rodríguez JA, Krause BJ, Casanello P.

Departamento de Neonatología, División de Pediatría y División de Obstetricia y Ginecología, Escuela de Medicina, Pontificia Universidad Católica de Chile.

The effect of maternal obesity on the metabolic and inflammatory state of their offspring at birth remains to be fully defined. The aim of this study was to compare offspring cord blood insulin, leptin, adiponectin and cytokines from normal weight and obese mothers, and relate these to maternal and neonatal biological characteristics. A group of healthy pregnant women, obese (BMI $>30 \mathrm{~kg} / \mathrm{m} 2)$ and normal weight $(18,5$ and $24,9 \mathrm{~kg} / \mathrm{m} 2)$ at $<14 \mathrm{wks}$ gestation were recruited at the time of delivery (36-41 wks) after signing an informed consent. Cord blood samples were obtained at birth on all healthy neonates with birth weight $>2500 \mathrm{~g}$. Umbilical cord plasma served to determine concentration of insulin, leptin, cytokines (Milliplex ${ }^{\circledast}$ Human Cytokine/Chemokine and Human Adipokine, Merck Millipore, Billerica, MA, USA), and adiponectin (ELISA, HMW \& Total Adiponectin ELISA. ALPCO, USA). Distribution of variables was assessed with Shapiro Wilk test. The comparisons between groups was done using t-student and Chi2 tests. Pearson served to assess correlations between variables. Multiple linear regression models were used to examine the association between the neonatal outcomes and maternal BMI. $p$-value $<0,05$ was considered statistically significant. Offspring from obese mothers had higher birth weight ( $3560 \mathrm{~g}$ vs. $3426 \mathrm{~g}$ ) and concentrations (log(pg/ $\mathrm{mL})$ ) of insulin $(10,85$ vs. 9,91), leptin $(95,01$ vs. 77,14$)$, adiponectin (33,68 vs. 28,69$)$, TNFa $(4,13$ vs. 3,96$)$ and IL 12 p40 (7,53 vs. 7,09), at birth. Maternal variables were associated with increase cord plasma leptin, adiponectin, TNFa and IL12p40 in the offspring, at birth. Maternal obesity in early pregnancy was associated with higher concentrations of insulin, leptin, adiponectin, TNFa and IL12p40 in their offspring at birth.

Presentado en: Congreso Iberoamericano DOHaD

Fuente de financiamiento: CONICYT-PCHA /Doctorado Nacional/ 2014-201463140222 y FONDECYT \#1141195

\section{Caracterización clinica de los primeros seis casos de tifus de los matorrales identificados en Chiloé, Chile, 2015-2016.}

\author{
Velásquez Katia'; Andrés Hernández; ; Thomas Weitzel²; López \\ Javier ${ }^{3}$; Martínez-Valdebenito Constanza ${ }^{4}$, Teresa Azócar ${ }^{4}$; \\ Yasna Montero', Abarca Katia ${ }^{4}$. \\ ${ }^{1}$ Hospital San Carlos de Ancud, ${ }^{2}$ Clinica Alemana, Universidad del \\ Desarrollo, ${ }^{3}$ Hospital Veterinario Puente Alto, ${ }^{4}$ Depto. de Enfermedades \\ Infecciosas e Inmunología Pediátricas, Facultad de Medicina, Pontificia \\ Universidad Católica de Chile.
}

INTRODUCCION. El tifus de los matorrales (TM) es una rickettsiosis causada por Orientia tsutsugamushi, endémica en el Sudeste Asiático y la Región Pacífico Occidental, relevante por la posibilidad de complicaciones y letalidad de alrededor de $10 \%$ sin terapia apropiada. Durante un estudio clínico multicéntrico que buscó infecciones emergentes causadas por rickettsias en Chile, identificamos casos de TM en la isla Chiloé, representando los primeros casos en Sudamérica. OBJETIVOS. Describir las manifestaciones clínicas y las actividades de riesgo relacionadas a la adquisición de casos de TM en Chiloé. MÉTODOS. Todos los pacientes fueron participantes del estudio clínico que se presentaron al hospital de Ancud con cuadros febriles sin causa identificada. Se confirmaron por la detección de los genes 16S RNA, 47kDa y 56kDa de O. tsutsugamushi en sangre, buffy coat y/o escara; o por la seroconversión de IgG anti-O. tsutsugamushi por IF (Fuller Lab) o ELISA, títulos elevados de IgG en muestra única, o ELISA IgM positiva. RESULTADOS. Entre enero de 2015 y abril de 2016 identificamos 6 pacientes con TM, 2 de ellos confirmados por PCR y 4 por serología. Los seis pacientes eran provenientes de Ancud sin antecedentes de viajes, 5 varones, edades 30-62 años, un diabético, resto previamente sanos. Uno se presentó en enero de 2015, el resto entre enero y marzo de 2016. Presentaron fiebre (6), calofríos (6), cefalea (6), escara (6) (4 en extremidades inferiores), exantema (5), sudoración nocturna (5), mialgias/artralgias (4), linfadenopatías (4), odinofagia (3) y dolor abdominal (1). En el laboratorio PCR elevada (6), rango 18-120 (corte 5), transaminasas aumentadas (4/5), leucocitos $\leq 4500$ (3), plaquetas $<150.000$ (3). Las posibles actividades de riesgo durante el periodo de incubación fueron cortar o cargar leña (5) o trabajar en el campo (1). Recibieron doxiciclina 5, todos evolucionaron con 
mejoría de los síntomas y signos. CONCLUSIONES. Se presenta la primera serie chilena de TM, enfermedad emergente en la isla de Chiloé. En nuestra serie, la presentación consistió en un cuadro febril agudo, con molestias constitucionales intensas, exantema y escara. En los exámenes se encontró aumento de PCR y de transaminasas y una leve plaquetopenia. Los casos se presentan en verano y en personas de zonas rurales con exposición a leña o labores agrícolas; la respuesta al tratamiento con doxiciclina fue rápida. Los clínicos deben estar atentos a posibles casos de TM, en esta u otras regiones, para instaurar terapia apropiada y evitar evoluciones desfavorables.

Presentado en: Congreso Chileno de Infectología

Fuente de financiamiento: FONDECYT

\section{Hospital-based prospective multinational multicenter surveillance of kawasaki diseable(KD) in children from 20 latin american(LA) countries: success, obstacles and challenges of the rekamlatina network}

Rolando Ulloa-Gutierrez ${ }^{* 1}$, Andrea Salgado², Adrián Collia ${ }^{3}$, Luis Martín Garrido-García ${ }^{4}$, Marco A Yamazaki- Nakashimada ${ }^{5}$, Dora Estripeaut $^{6}$, Lourdes Dueñas ${ }^{7}$, Patricia Saltigeral ${ }^{8}$, Greta Miño ${ }^{9}$, German Camacho- Moreno ${ }^{10}$, Enrique Faugier-Fuentes ${ }^{11}$, Virgen Gómez $^{12}$, Olguita del Aguila ${ }^{13}$, Francisco Rodríguez ${ }^{14}$, Martha Alvarez-Olmos ${ }^{15}$, Lucila Martínez-Medina ${ }^{16}$, Marco T Luque $^{17}$, Heloisa H de Sousa Marques ${ }^{18}$, Luisa B Gámez González ${ }^{19}$, Kathia Luciani $^{20}$, Mildred Zambrano ${ }^{21}$, Carlos Grazioso ${ }^{22}$, Nora Bueno ${ }^{23}$, Lorena Franco ${ }^{24}$, Fernanda Cofré25, Paola Pérez-Camacho ${ }^{26}$, Giannina Izquierdo ${ }^{27}$, Pilar Picart ${ }^{27}$, María Catalina Pirez ${ }^{28,}$ Sandra Beltrán ${ }^{29}$, Mario Melgar ${ }^{30}$, Carlos Daza ${ }^{31}$, Eduardo LópezMedina $^{32}$, Arturo Borzutzky ${ }^{33}$, Adriana $\mathrm{H}$ Tremoulet $^{34}$ and The REKAMLATINA-1 Study Group Members

'Servicio de Infectología Pediátrica, Hospital Nacional de Niños de Costa Rica, San José, Costa Rica, Infectología Pediátrica, Universidad Pontificia de Chile, Santiago, Chile, ${ }^{3}$ Departamento de Pediatria, Sanatorio Mater Dei, Buenos Aires, Argentina, ${ }^{4}$ Cardiología Pediátrica, ${ }^{5}$ Clinical Immunology Department, Instituto Nacional de Pediatría, Distrito Federal, Mexico, ${ }^{\circ}$ Infectología Pediátrica, Hospital del Niño, Ciudad Panama, Panama, 'Hospital Benjamín Bloom, San Salvador, El Salvador, ${ }^{8}$ Servicio de Infectología Pediátrica, Instituto Nacional de Pediatría y Star Médica Hospital Infantil Privado, Distrito Federal, Mexico, 'Infectología Pediátrica, Hospital del Niño "Francisco de Ycaza Bustamente", Guayaquil, Ecuador, ${ }^{10}$ Infectología Pediátrica, Hospital de la Misericordia, Bogotá, Colombia, "Reumatología Pediátrica, Hospital Infantil de México Federico Gómez, Distrito Federal, Mexico, ${ }^{12}$ Depatamento de Enfermedades Infecciosas, Hospital Infantil
"Dr. Robert Reid Cabral", Santo Domingo, Dominican Republic, ${ }^{13}$ Unidad de Infectología Pediátrica, Hospital Edgardo Rebagliati, Lima, Peru, ${ }^{14}$ Inmunología Pediátrica, Hospital de Especialidades Instituto Hondureño de Seguridad Social, Tegucigalpa, Honduras, ${ }^{15}$ Infectología Pediátrica, Fundación Cardio Infantil, Bogotá, Colombia, ${ }^{16}$ Infectología Pediátrica, Centenario Hospital Miguel Hidalgo, Aguas Calientes, Mexico, ${ }^{17}$ Infectología Pediátrica, Hospital Escuela Universitario, Tegucigalpa, Honduras, 18Infectología Pediátrica, Hospital Das Clinicas da Faculdade Medicina da USP, Sao Paolo, Brazil, ${ }^{19}$ Infectología Pediátrica, Hospital Infantil de Chihuahua, Chihuahua, Mexico, ${ }^{20}$ Infectología Pediátrica, Hospital de Especialidades Pediátricas de la Caja del Seguro Social, Ciudad Panama, Panama, ${ }^{21}$ Infectología Pediátrica, Hospital de Niños Dr. Roberto Gilbert Elizalde, Guayaquil, Ecuador, ${ }^{22}$ Infectología Pediátrica, Sanatorio Nuestra Sra. Del Pilar/Hospital General San Juan de Dios, Ciudad Guatemala, Guatemala, ${ }^{23}$ Cardiología Pediátrica, ${ }^{24}$ Reumatología Pediátrica, Hospital Infantil Municipal de Cordoba, Córdoba, Argentina, ${ }^{25}$ Infectología Pediátrica, Hospital Roberto del Río, Santiago, Chile, ${ }^{26}$ Infectología Pediátrica, Fundación Valle del Lili, Cali, Colombia, ${ }^{27}$ Infectología Pediátrica, Hospital de Niños Dr. Exequiel Gonzales Cortés, Santiago, Chile, ${ }^{28}$ Infectología Pediátrica, Hospital Pediátrico Centro Hospitalario Pereira Rossell, Montevideo, Uruguay, ${ }^{29}$ Infectología Pediátrica, Clínicas Colsanitas, Bogotá, Colombia, ${ }^{30}$ Infectología Pediátrica, Hospital Roosevelt, Ciudad Guatemala, Guatemala, ${ }^{31}$ Infectología Pediátrica, Hospital Materno Infantil José Domingo De Obaldía, Chiriquí, Panama, ${ }^{32}$ Infectología Pediátrica, Hospital Universitario del Valle y Centro Médico Imbanaco, Cali, Colombia, ${ }^{33}$ Dpto. Enfermedades Infecciosas e Inmunología Pediátrica, Pontificia Universidad Católica de Chile, Santiago, Chile, ${ }^{34}$ Pediatrics, University of California San Diego, San Diego, CA, United States

Background and aims: Prior to 2013, the regional epidemiology of $\mathrm{KD}$ in LA children was unknown and only individual reports from some countries were available. Our main objective is to describe the main success and challenges of prospective surveillance of KD by REKAMLATINA, the largest non-funded multinational network studying the epidemiology, clinical aspects and treatment of KD. Methods: Ongoing prospective multinational multicenter surveillance study of children with $\mathrm{KD}$ at main pediatric/general referral hospitals from 20 LA countries, period 06-1-2014 to 01-15-2016. Results: 402 patients from 51 hospitals have been enrolled so far. Countries with the most representative data according to their population include Mexico, Costa Rica, Panama, El Salvador, Honduras, Colombia, Ecuador, Dominican Republic and Chile. Other diverse and unexplored aspects of KD have been submitted and presented in 9 research abstracts at international conferences. Main obstacles at many centers include lack of standard echocardiographic descriptions including coronary diameter measurement, z-score determination, and classification of aneurysms into small, medium or giant. Main current challenges include recruiting more 
cardiologists at each site and more number of centers, especially from large and populated countries (Brasil, Venezuela, Peru and Argentina). Conclusions: REKAMLATINA network has become an important model research group to study KD in LA children. However, improvement in awareness, surveillance, and reporting is needed, particularly in Nicaragua, Cuba, and Puerto Rico.

Presentado en: 28th International Congress of Pediatrics Fuente de financiamiento: No declara

\section{Evaluación de Tasas de Defectos de Tubo Neural en la Región Metropolitana de Chile, para los años 2010-2015}

\author{
Mellado $C^{1-2}$, Pardo RA ${ }^{1-3-4}$, Vilca $M^{4}$, Villarroel $L^{5}$ \\ 'Unidad de Genética, Servicio de Pediatría, Complejo Hospitalario \\ Dr. Sotero del Rio. ${ }^{2}$ Unidad de Genética y Enfermedades Metabólicas, \\ Sección de Neurología, Genética y Enfermedades Metabólicas, División \\ de Pediatría, Escuela de Medicina. Pontificia Universidad Católica de \\ Chile. ${ }^{3}$ Sección de Genética, Departamento de Medicina. Hospital \\ Clínico Universidad de Chile ${ }^{4}$ Unidad de Neonatología, Departamento \\ de Obstetricia y Ginecología, Hospital Clínico Universidad de Chile. \\ ${ }^{5}$ Departamento de Salud Pública. Facultad de Medicina. Pontificia \\ Universidad Católica de Chile
}

Los defectos de tubo neural (DTN), son anomalías congénitas prevenibles con medidas de salud pública como la fortificación de alimentos con ácido fólico (FAF). Chile fortifica la harina de trigo con ácido fólico (AF) desde el año 2000, al 2009 el nivel de reducción de la tasa de DTN era de 50\%. Sin embargo por la posible asociación del AF con cáncer se resuelve ese año disminuir el nivel de FAF. El objetivo de este estudio es evaluar el impacto del nuevo nivel de fortificación de la harina de trigo con AF en la prevalencia al nacer de los DTN en Chile. Se realizó un estudio retrospectivo de base hospitalaria en los 11 hospitales públicos de Santiago. Se incluyeron todos los RN vivos y muertos de 500 g o más al momento del nacer. Se registraron todos los casos de DTN durante el periodo post modificación de la norma de FAF (post-FAFM: 2010-2015) y se comparó con el periodo post-FAF (2001-2009). Se evaluó además el periodo post-FAF completo (post-FAFC: 2001-2015) con el periodo previo a la fortificación (pre-FAF: 1999-2000). En el periodo post-FAFM se detectaron 287 casos de DTN, con una tasa de 9,5 por 10.000 recién nacidos totales (RNT). No se encontró diferencias significativas con la tasa para el periodo post-FAF de 8,6 por 10.000 RNT (OR: 1, 1; IC 95\%= $0,96-1,29)$. Tampoco se detectaron variaciones significativas para espina bífida $(\mathrm{OR}=1,17 ; \mathrm{Cl} 95 \%=0,95-1,44)$, anencefalia $(\mathrm{OR}=1,1$;
$\mathrm{Cl} 95 \%=0,86-1,42)$, y encefalocele (OR=0,95; IC 95\% 0,65-1,41). Al comparar las tasas pre-FAF ( 17,1 por 10.000 RNT) vs post-FAFC (8,9 por 10.000 RNT) la reducción global de DTN fue de $48 \%$ (OR= 0,52, IC 95\%: 0,45-0,61), reducción que fue significativa en los 3 DTN estudiados; espina bífida (OR de 0,51;Cl 95\% = 0,41-0,63), anencefalia (OR: 0,52; Cl 95\%=0,4-0,68) y encefalocele (OR: 0,57;IC $95 \%=0,38-0,85)$. La modificación a la norma de fortificación de harina de trigo con ácido fólico efectuada en 2009 no ha tenido impacto en la tasa de DTN en Chile y continua siendo una medida de salud pública efectiva para la reducción de DTN.

Presentado en: Neonatologia

Fuente de financiamiento: Ministerio de Salud de Chile, protocolo ID: 757-248-LE14 (DIPOL)

\section{Solar Radiation Is Inversely Associated With Inflammatory Bowel Disease Admissions In Chile}

Jaime $\mathrm{F}^{{ }^{*}}$, Riutort $\mathrm{MC}^{{ }^{1 *}}$, Alvarez-Lobos $\mathrm{M}^{2}$, Hoyos-Bachiloglu $\mathrm{R}^{3}$, Camargo $C^{4}$, Borzutzky $A^{3,5}$.

'Department of Pediatric Gastroenterology and Nutrition, Division of Pediatrics, School of Medicine, Pontificia Universidad Católica de Chile, Santiago, Chile. '2Department of Gastroenterology, School of Medicine, Pontificia Universidad Católica de Chile, Santiago, Chile. ${ }^{3}$ Department of Pediatric Infectious Diseases and Immunology, School of Medicine, Pontificia Universidad Católica de Chile, Santiago, Chile. ${ }^{4}$ Department of Emergency Medicine and Division of Rheumatology, Allergy, and Immunology, Department of Medicine, Massachusetts General Hospital, Harvard Medical School, Boston, USA. ${ }^{5}$ Millennium Institute on Immunology and Immunotherapy, School of Medicine, Pontificia Universidad Católica de Chile, Santiago, Chile.

Background: A latitude gradient for inflammatory bowel disease (IBD) has been suggested in the northern hemisphere, which may be explained by vitamin $\mathrm{D}$ (VD) deficiency at higher latitudes that have lower solar radiation (SR). VD has multiple biological effects on the immune and gastrointestinal systems and VD deficiency could have a causal role in IBD flares. Chile is a long and slender country spanning latitudes $17^{\circ}$ and $56^{\circ}$ South, with a wide range of SR, providing an excellent opportunity to evaluate the association between regional SR, as a proxy for VD status, and hospital admissions due to IBD. Methods: Using the national hospital discharge database from the Chilean Ministry of Health, we analyzed admissions due to Crohn's disease (CD) and ulcerative colitis (UC) between 2001 and 2012. Children were considered 
those younger than 18 years. Admission rates were calculated per 100,000 inhabitants. Average annual SR intensity data for the different regions was obtained from the Chilean Solarimetric Registry. This study was approved by the Ethics Committee of the Pontificia Universidad Católica de Chile Medical School. Results: Between 2001 and 2012, there were 12,869 admissions due to IBD, (31\% CD, $69 \%$ UC); $57 \%$ of all patients were female. Pediatric hospitalizations accounted for $11 \%$ of all IBD admissions ( $42 \%$ CD, $58 \%$ UC). Median age for IBD admissions was 36 years (IQR 25-51) and for pediatric admissions was 12 years (IQR 7-15). The national admission rates for CD in children was $1.0(95 \% \mathrm{Cl} 0.9-1.1)$ vs 2.5 $(95 \% \mathrm{Cl} 2.4-2.6)$ in adults, $\mathrm{p}<0.001$. The national admission rate for UC in children was $1.4(95 \% \mathrm{Cl} 1.3-1.5)$, and 5.7 (95\%Cl 5.6-5.8) in adults, $p<0.001$. Although an increasing trend for $C D$ over the 12 -year period was not significant in children $(\boldsymbol{\beta}=0.015,95 \% \mathrm{Cl}$ $-0.040-0.069)$, it was for adults $(\boldsymbol{\beta}=0.153,95 \% \mathrm{Cl} 0.096-0.210)$. A significantly increasing trend in UC admission rates throughout the 12-year period was observed $(\boldsymbol{\beta}=0.143,95 \% \mathrm{Cl} 0.099-0.187$ in children; $\boldsymbol{\beta}=0.143,95 \% \mathrm{Cl} 0.108-0.178$ in adults). In terms of latitude, the highest admission rates for pediatric $C D$ and $U C$ as well as adult UC were observed in the southernmost region of Magallanes (latitude 48-56 ${ }^{\circ}$ ), which also is the region with lowest annual SR. Univariate linear regression analysis showed regional SR was inversely associated with IBD admissions in Chile $(\boldsymbol{\beta}=-0.43$, $\mathrm{P}=0.03$ ). Regional poverty, rurality and indigenous population rates were not significantly associated with IBD admissions in univariate linear regressions. A multilinear regression model that included regional $S R$ and rurality rate predicted $C D$ admissions in adults $(R 2=0.45)$, and $U C$ admissions in both children $(R 2=0.62)$ and adults $(\mathrm{R} 2=0.53)$. Conclusions: Regional SR is inversely associated with IBD admission rates in Chile, which are highest at the southernmost region with the lowest SR. Our results support the potential role of VD deficiency on IBD flares.

Presentado en: Congreso Mundial de Gastroenterología y Nutrición Pediátrica

Fuente de financiamiento: Fondecyt 1130615 a A.B. y 1131012 a

M.A-L. e Iniciativa Científica Milenio P09/016-F a A.B.

\section{Estresores parentales en unidad de cuidados intensivos pediatricos.}

\author{
Ramírez M, Clavería C, Molina Y, Cox A, Navarro S \\ 'Enfermera. Unidad de Pacientes Críticos Pediátricos Hospital Clí- \\ nico Red de Salud UC CHRISTUS. Facultad de Medicina, Escuela de
}

Enfermería Pontificia Universidad Católica de Chile, ${ }^{2}$ Médico Cardiólogo e Intensivista Pediátrico, Departamento de Cardiología y Enfermedades Respiratorias, División de Pediatría. Facultad de Medicina Pontificia Universidad Católica de Chile, ${ }^{3}$ Psicólogo, Mg Psicología de la Salud. Facultad de Medicina, Escuela de Enfermería Pontificia Universidad Católica de Chile. Académico Facultad de Psicología Universidad Adolfo lbáñez, ${ }^{4}$ Psicólogo Clínico, Unidad de Pacientes Críticos Pediátricos, Hospital Clínico Red de Salud UC CHRISTUS, ${ }^{5}$ Enfermera-Matrona, Mg Psicología Social. Facultad de Medicina, Escuela de Enfermería Pontificia Universidad Católica de Chile.

La hospitalización de un hijo es una situación que produce un alto nivel de estrés para los padres/madres, especialmente si ésta se produce en Unidades de Pacientes Críticos Pediátricos (UPCP). OBJETIVO: Determinar cuáles son los principales estresores percibidos y que variables se asocian a dicha percepción en cuidadores de pacientes internados en una UPCP. MÉTODO: Estudio cuantitativo, trasversal y correlacional, que contempla el análisis secundario de datos del estudio: Validación de "The parental stressor scale infant hospitalization, al español" (PSSIH modificado). El muestreo fue no probabilístico por conveniencia y constó de 218 cuidadores de niños internados en la UPCP de la Red de Salud UC CHRISTUS, quienes contestaron un cuestionario demográfico y el instrumento PSSIH modificado para medir estresores en el ambiente de la UPCP. RESULTADOS: Se observó que la muestra consideró como más estresantes las dimensiones clínicas del cuidado: imágenes o sonidos, procedimientos e intervenciones y el aspecto del hijo, en tanto las dimensiones relacionadas con la conducta y la comunicación con el equipo clínico resultaron ser las menos estresantes. Se observó además que tener experiencias previas en la UPCP, tener un ingreso programado, ser ingresado por patología cardiaca, tener un único hijo, tener un mayor nivel educacional y no tener pareja se asocian a una mayor percepción de estrés para las distintas dimensiones evaluadas. CONCLUSIÓN: “The parental stressor scale infant hospitalization, al español" utilizado es un instrumento de fácil entendimiento y aplicación, permite detectar los principales estresores percibidos en los cuidadores de pacientes internados en la UPCP.

Presentado en: Congreso de Pediatria e Intensivo Pediátrico 2016 y Congreso de Cardiología y Cirugía Cardiovascular 2016 Fuente de financiamiento: Proyecto de investigación Integración Docente Asistencial, IDA - 201403. Facultad de Medicina, Escuela de Enfermería de la Pontificia Universidad Católica de Chile. 


\section{Presentaciones de pósters}




\section{High risk of coronary artery aneurysms in infants less than 6 months despite timely treatment}

\author{
Salgado $\mathrm{A}^{1,2}$, Ashouri $\mathrm{N}^{2}$, Berry EK ${ }^{2}$, Sun X, Jain $\mathrm{S}^{2}$, Burns $\mathrm{JC}^{2}$, \\ Tremoulet $\mathrm{AH}^{2}$
}

'Unidad de Hematología y Oncología PUC; '2 Department of Pediatrics, University of California, San Diego

Background Incomplete KD, as well as a higher incidence of CAA, has been reported to occur more commonly in infants 6 months (mos), but only small case series have been published. We characterized the KD course in infants 6 mos and compared to outcomes in KD pts $>6$ mos. Methods We retrospectively reviewed the course of 88 subjects 6 mos diagnosed with KD between January 2004 and December 2013 at Children's Orange County (CHOC) and Rady Children's Hospital San Diego (RCHSD) and compared to 632 subjects $>6$ mos at RCHSD. Complete and incomplete KD cases were defined based on the 2004 AHA guidelines. Subjects were classified by coronary artery (CA) status (normal, dilated, or aneurysmal CA based on RCA and LAD measurements) and by Z-score (RCHSD only). IVIG resistance was defined as fever $\geq 38 \mathrm{C}$ at least 36 hours after completion of IVIG. Fisher's Exact test was used for comparisons. Results Of the 88 infants, 62 (70.4\%) were male and 76 (86.3\%) were treated at 10 days of illness. Treatments in the 88 pts were as follows: IVIG responder: 55(62.5\%); IVIG resistant: 13(14.7\%); infliximab for cardiac indications: 16 (18.2\%); late treatment >10days: 2 (2.3\%); not treated: 2 (2.3\%). Infliximab was administered to a total of 27 pts (30.7\%) and was well-tolerated with rash as the only adverse event in 1 pt. Worst CA status was "normal" in 37 (42.1\%), dilated in 29 (32.9\%), aneurysm in 15 (17.1\%) and giant aneurysm in 7 (7.9\%) pts. Of the 48 pts at RCHSD who presented within the first 10 days of illness, only 26 (54.2\%) had a Z-score $<2.5$. Of these 26 pts, $7(26.9 \%)$ went on to have a subsequent $Z$ score $\geq 2.5$. Comparing the 6 mos vs. $>6$ mos RCHSD cohorts, there were no significant differences in number of pts treated within the first 10 days of illness (48/53, $90.5 \%$ vs. $545 / 632,86.2 \%)$ or pts having incomplete presentations $(12 / 53$, $22.6 \%$ vs. $106 / 632,16.8 \%)$. Conclusions There were no significant differences in the rate of incomplete KD or rate of diagnosis within the first 10 days of illness in children 6 mos vs. $>6$ mos. Infliximab use in $30.7 \%$ of the 6 mos old pts was safe. Infants 6 mos had a high rate of aneurysms $(22 / 88,25 \%)$ despite timely diagnosis and treatment. Better treatments are needed for this high risk group of KD pts.

Presentado en: Enviado a publicación y aceptado

Fuente de financiamiento: Macklin Foundation- Physician development grant (UCSD)

\section{Zika Virus Infection in a Non Mosquito- Born Transmission Country}

Vizcaya C, Perret C, Martinez-Valdebenito C, Ferres M, Contreras AM and Dabanche J.

Departamento de Infectología, Inmunología y Reumatología Pediátrica, PUC. Laboratorio Infectología Y Virología Molecular. Hospital Militar de Santiago.

Background: Zika virus infection has been introduced to the Americas in 2014 on Easter Island and Brazil. Since then, more than 700.000 autochthonous cases in 35 countries have occurred. Brazil and Colombia have the highest number of cases. Two main complications have been reported; congenital syndrome and Guillain Barré syndrome. Chile hasn't got mosquito born transmission of Zika virus so far. The aim of this study is to describe demographic and clinical features of Zika infection in Chilean travelers, including one sexually transmitted case. Methods: patients with positive Zika test diagnosed in our Diagnostic Virology Laboratory where invited to participate. Those who accepted signed the consent form and a survey questionnaire was sent by e-mail to be completed by them. The questionnaire included demographic and clinical information. Zika diagnosis was performed by either RT-PCR or Zika IgM - IgG. RT-PCR is an in house real time PCR, using the CDC protocol. Serology is an ELISA commercial test by Euroimmune ${ }^{\oplus}$. Results: Twelve patients tested positive, average age 31.4 years (15-51 years), 7 females. Ten patients accepted to participate and answered the questionnaire. Nine were imported cases with mosquito borne transmission, including one pregnant woman and one locally acquired by sexual transmission. Country of exposure was Brazil in 3, Venezuela in 3, Colombia in 2, Haiti in 1 and Chile 1 (sexually transmitted). The onset of symptoms occurred between one day before and 9 days after returning to Chile. The reason for travel was tourism in 4 , business in 3 and 2 for sports competition. The sexually transmitted case was from a symptomatic male to his female partner. The interval between sexual intercourses and the onset of symptoms was between 6 to 12 days. Average duration of the travel was 11 days (3-21 days). Main symptoms were maculopapular rash in $8 / 10$, itching rash $7 / 8$, non purulent conjunctivitis $8 / 10$, Fever $9 / 10$ with an average temperature of $38,1^{\circ} \mathrm{C}(37,5-$ $38,8^{\circ} \mathrm{C}$ ) lasting 3 days in average (1-7 days), arthritis $6 / 10$ with a range of 3-15 days, most frequently involved joints were hands, elbows and knees, headache was present in 8/10 patients, retro auricular swollen lymph nodes were present in $6 / 10$ patients and just 2 patients presented gastrointestinal symptoms. No hospitalizations were required and no prolonged arthritis was described. 
The pregnant woman was in her 28Th week of gestation at the moment of symptoms onset. Diagnosis was performed 2 months after symptoms onset with positive Zika IgM ang IgG serology. The newborn was asymptomatic, with negative Zika RT-PCR and positive IgG and negative IgM at birth. She has normal cerebral ultrasound and follow up serology shows a decrease in lgG title and persistent negative lgM. Conclusion: Zika virus infection is present in Chilean travelers, but also has to be included in the differential diagnosis of patients with suspected symptoms mainly itchy rash, that have not traveled but had contact with travelers to endemic areas.

Presentado en: IDWEEK New Orleans

Fuente de financiamiento: Laboratorio de Infectología Y Virología Molecular

\section{Host factors associated with severity of influenza virus A infection on humans.}

García, T.1, ${ }^{1,23}$, Barrera, A. ', Le Corre, N. ${ }^{1,2}$, Angulo, J. 2,3, Rathnasinghe, R. ${ }^{1}$, Dreyse, J. ${ }^{4}$ Núñez, MJ. ${ }^{1}$, Tapia, K. ${ }^{1,2}$, LópezLastra, M. ${ }^{2,3}$, Ferrés, M. ${ }^{1,2}$, Medina, RA. ${ }^{1,2,3,5}$

'Laboratory of Molecular Virology, Escuela de Medicina , Pontificia Universidad Católica De Chile. ${ }^{2}$ Departamento de Enfermedades Infecciosas e Inmunología Pediátrica, Escuela de Medicina, Pontificia Universidad Católica De Chile. ${ }^{3}$ Millennium Institute on mmunology and Immunotherapy, Pontificia Universidad Católica De Chile. ${ }^{4}$ Departamento de Medicina Intensiva, Escuela de Medicina, Pontificia Universidad Católica De Chile. Department of Medicine, Icahn School of Medicine at Mount Sinai, New York, NY 10029, USA.

Severity of influenza A virus infection depends on virological and host factors, mainly extreme age, pregnancy, immunosuppression and a number of comorbidities. However, it is still unclear what specific molecular factors are at the basis of disease outcome. We have established a clinical study, to conduct a comprehensive system analysis approach to gain information of host factors that affect clinical outcome and address disease severity in the general population in Chile. We analyzed clinical metadata from 85 severe and 59 non-severe patients, evaluated the status of the innate and adaptive immune responses by measuring pro- and anti-inflammatory cytokines during the acute phase of infection using a Multiplex ELISA, and determined humoral responses by hemagluttination inhibition assay. We also evaluated the immune genetic predisposition by evaluating SNPs by qRT-PCR of Interleukin 28B (IL28B; an antiviral cytokine) and the Tumor Necrosis Factor-a (TNF-a; a pro-inflammatory cytokine) genes, which expression level depends on the presence of the SNPs rs12979860/rs8099917 and rs1800629, respectively. The predominant comorbidities found were obesity and chronic cardiovascular diseases (including arterial hypertension). Our current results also show higher expression profiles during the acute phase of the pro-inflammatory cytokines IL-8 and IL-15 and of the anti-inflammatory cytokine IL-10, in severe compare to the non-severe patients, meanwhile seroconvertion/ seroprotection and genetic predisposition did not appear to affect clinical outcome. These results expand our understanding of host factors contributing to the pathogenesis of influenza, which can have an impact on therapeutic and prophylactic interventions targeting those at higher risk of severe disease.

Presentado en: Sociedad de Microbiologia de Chile - SOMICH 2016, Congreso Anual del Centers of Excellence on Infleunza Research and Surveillance 2016

Fuente de financiamiento: Proyecto De Inserción Capital Humano En La Academia 79100014, FONDECYT 1121172, 1161791, and Proyecto Anillo PIA ACT 1408 all from CONICYT; and Program Iniciativa Científica Milenio from the Chilean Ministry of Economy, Development and Tourism grant P09/0

\section{Underrepresented variations as potential virulence markers of human seasonal Influenza A virus}

Almonacid, L.I. ${ }^{1,2^{*}}$, Barrera, $A^{1,4^{*}}$, Halpin, $R^{5}$, Wentworth, $D^{5}$, Tapia, $K^{1}$, Ferres, $M^{3}$, García-Sastre, $A^{5,6,7}$, Melo, $F^{2}$ and Medina, R.A., ${ }^{1,4,6}$

'Laboratory of Molecular Virology. Escuela de Medicina, Pontificia Universidad Católica de Chile. Santiago, Chile. ${ }^{2}$ Molecular Bioinformatics Laboratory, Pontificia Universidad Católica de Chile. Santiago, Chile. ${ }^{3}$ Departamento de Enfermedades Infecciosas e Inmunología Pediatrica. Escuela de Medicina, Pontificia Universidad Católica de Chile. Santiago, Chile. ${ }^{4}$ Millennium Institute on Immunology and Immunotherapy. Santiago, Chile. ${ }^{5}$ Virology, J. Craig Venter Institute, Maryland, USA. 6Department of Microbiology, Icahn School of Medicine at Mount Sinai, New York, NY 10029, USA.

The influenza A virus (IAV) is a respiratory pathogen that circulates in humans yearly. Despite preventive measures and treatments IAV is still a disease that produces high morbidity. IAV has a high mutation rate which is a mechanism for fast genomic evolution of the virus. Residue variations have been characterized as virulence markers; therefore we analyze the genomic variations of influenza genes of infected patients sampled in 2011 and 2013 in Chile. Nasopharyngeal swabs of 23 IAV RT-PCR-confirmed patients with $A(H 1 N 1) p d m 09$ IAV were obtained and their viral genomes sequenced. Samples were taken daily during 7 days after symptoms onset. The severe infection criteria were established according to the 
hospitalization parameters and/or derivation to Critical Care Unit after symptoms onset. All patients except for one were classified as severe. Thirty-six haemagglutinin and forty-two neuraminidase sequences were obtained and phylogenetic trees were built. Sequences from each seasons where mainly grouped into two cluster with the exception of four divergent sequences belonging to patients, p1d1/2011, p15d1/2011, p24/2013 and 31673/2013, where two of them died. Seriated samples tend to group together, except for patients p21/2011, p13/2013, p20/2013 and p25/2013 in the haemagglutinin and p3/2011 and p12/2011 in neuraminidase segment. We examined the amino acids sequences of the viral proteins that were represented at low frequency respect NCBI Flu database. Five variations (A90T, H155Q, A156D, K180I and V544I) were located at functionally annotated sites, where four were within antigenic regions. Patient $\mathrm{p} 25 / 2013$ shows the change K180Q in HA that could be considerer as single-antigenic drift within a single host and with an epidemiologically impact, because this residue is the most common today. Patient $\mathrm{p3} / 2011$ had two novel mutations, E483K in HA and I223M in NA. The position 223 in NA is within the binding pocket, suggesting this could be related to oseltamivir resistance, particularly because this mutation reverted to wild type after treatments was finalized. These variations could contribute to severity by immune escape or antiviral-resistance. Thus, additional analyses of all the viral proteins are needed to elucidate residue changes that might be potential virulence markers during human infection.

Presentado en: XXXVIII Congreso Chileno de Microbiología - 2016 Fuente de financiamiento: Funding: Proyecto De Inserción Capital Humano En La Academia 79100014, FONDECYT 1121172, 1161791, and Proyecto Anillo PIA ACT 1408 all from CONICYT; and Program Iniciativa Científica Milenio from the Chilean Ministry of Economy, Development and Tourism gr

\section{Epigenetic programming of vascular function by fetal growth trajectory: the placenta as the black box}

Casanello P, Hernandez C, Carrasco-Wong I, Muñoz E, Uauy R, Krause B.

Departamento de Neonatología, División de Pediatría \& División de Obstetricia y Ginecología, Escuela de Medicina, Pontificia Universidad Católica de Chile.

Introduction: The association of low and excessive fetal weight with cardiovascular risk are in the central interest of DOHaD. Aim: Due to the key role of endothelium in the umbilical vascular function we have studied markers of endothelial epigenetic heterogeneity in endothelium from umbilical arteries (HUAEC) and veins (HUVEC) from intrauterine growth restricted (IUGR), adequate for gestational age (AGA) and large for gestational age (LGA) fetuses. Methods: In HUAEC from IUGR, AGA and LGA fetuses the expression of eNOS, Arg2, NOX4, GPX1, SOD1, Nrf2 and HO1 was determined under basal, hypoxia and oxidative stress conditions. The methylation status (by pyrosecuencing) of the promoter of these genes as well as histone modifications (H3K4 Me2/H3K4 Me3/H3K9 Me2/H3K9 $\mathrm{Ac} / \mathrm{H} 4 \mathrm{~K} 12 \mathrm{Ac}$ ) was determined by ChIP. Knockdown of DNMT1 was performed to study methylation-dependent changes. Results: In IUGR and LGA-derived HUAEC there is an increase in the basal expression of eNOS. The mRNA of Arg2 and eNOS are induced by hypoxia in AGA-HUAEC but no change is observed in IUGR or LGA-HUAEC. Both eNOS and NOX1 showed significant changes in the methylation status at their promoter region in IUGR and LGA. ChIP showed an important amount of opened chromatin markers (H3K9 Ac, H4K12 Ac) in the NOS3 promoter. Knockdown of DNMT1 modified the expression of eNOS in IUGR and LGA compared to AGA, and this was associated to changes in methylation in CpG -352 from TSS in NOS3 gene. Conclusion: In summary both extreme phenotypes (IUGR and LGA) show changes in some key endothelial genes. These changes are associated to epigenetic marks of vascular programming in fetuses in both extremes of the growth curve.

Presentado en: Fetal \& Neonatal Physiological Society Fuente de financiamiento: Fondecyt 1120928-1130801, CONICYT, Chile

\section{Secuenciación completa de genoma en cepas chilenas de Staphylococcus aureus meticilino resistente adquirido en la comunidad: desafíos y oportunidades}

Andrea Salgado', Felipe Sepúlveda², Felipe Melis², Germán Marchandon ${ }^{2}$, Javiera Quintana ${ }^{3}$, Marusella Lam¹, Patricia García', Juan A. Ugalde²

${ }^{1}$ Escuela de Medicina, Pontificia Universidad Católica de Chile, Santiago, Chile ${ }^{2}$ Centro de Genética y Genómica, Facultad de Medicina, Clínica Alemana Universidad del Desarrollo. ${ }^{3}$ Novalact Life Sciences SpA

Introducción. No existe una definición universalmente aceptada para $S$. aureus meticilino resistente comunitario (SAMR-AC), y las técnicas moleculares convencionales para su tipificación analizan secuencias cortas que representan $<1 \%$ del genoma completo. Objetivos. Evaluar el uso de secuenciación completa del genoma (SCG) 
y datos clínicos para la caracterización de cepas chilenas enviadas a la vigilancia de SAMR-AC Material y métodos. Se secuenciaron 58 aislados enviados a la vigilancia de SAMR-AC. Se revisaron las fichas clínicas, perfil de sensibilidad y el informe emitido por el ISP. Se tipificó el multilocus de secuencias, SCCmec, búsqueda de genes que codifican para la leucocidina de Panton-Valentine(PVL), predicción genotípica de sensibilidad antibióticos y se asignó un posible origen comunitario versus hospitalario en base a la comparación con genomas de referencia. Resultados. 60,3\% de los aislados fueron clasificados como SAMR-AC. 44,8 \% de los aislados portaban PVL. No se encontró un clon dominante, los ST más frecuentes fueron el ST72 (25,8\%) seguido del ST8 (20,6\%), y 20,6\% de los aislados tuvieron ST únicos. Discusión. Nuestra colección de genomas se diferencia de resultados previamente publicados, por su bajo porcentaje de cepas PVL (+), la ausencia de un clon dominante y la presencia de ST72. Nuestros hallazgos establecen la necesidad de establecer estudios más detallados a futuro.

Presentado en: Enviado a publicación

Fuente de financiamiento: El financiamiento de este proyecto proviene del programa FONDECYT de Iniciación número \#11145666 (JAU)

\section{Risk Prediction of Bronchopulmonary Dysplasia in Very Low Birth Weight Infants}

Marshall G, Valenzuela D, Tapia JL, et al

'Departamento Salud Pública de la Pontificia Universidad Católica, 2Escuela de Medicina de la Pontificia Universidad Católica, ${ }^{3}$ Unidad de Neonatología de la División de Pediatría de la Pontificia Universidad Católica de Chile

Background: Bronchopulmonary Displasia (BPD) is the main chronic respiratory morbidity in surviving very low birth weight infants (VLBWI) and has been associated to adverse respiratory and neurodevelopmental outcomes. Despite the huge advances in neonatal care its incidence has not been decreased. Risk prediction models may be helpful in order to identify VLBWI with high risk of developing BPD and are susceptible to therapeutic and/or preventive strategies. Objective: The aim of this study is to construct prediction models of moderate to severe BPD, defined as oxygen dependency at 36 weeks of corrected GA, and for BPD/Death in VLBWI at three postnatal ages: perinatal (at birth), 72 hours and 2 weeks of life. Design/Methods: Observational multicentric cohort study using information obtained from the Neocosur Neonatal Research Network database (27 southamerican centers). Data was prospectively collected by online data entry with predefined diagnostic criteria. The study included 17237 of a total of 18055 inborn infants with BW between 500 to $1500 \mathrm{~g}$ born during 2001 to 2015. Infants with major malformations or who died in the delivery room were excluded. In order to construct the predictive models for BPD at each postnatal age, variables were selected using forward logistic regression model considering their specific contribution. The predictive value of the model was evaluated by area under the receiver operating characteristic curve (AUC- ROC). Results: Of the 17237 included VLBWI, 2684 (15.6\%) presented with moderate/ severe BPD, and 6690 (38.8\%) presented with BPD or death. The results of the AUC-ROC for each predictive model with the variables with higher contribution to the respective model are presented in tables 1 and 2. As observed BW, gestational age and the need of intubation at birth were the most important contributors to the BPD perinatal model, whereas lenght of oxygen therarapy and ventilation had a higher contribution in the later model. As observed in the figure, the predictive power of the models increased at later ages. Conclusion(s): In this large population of VLBW infants, we were able to construct models with very high predictive power for BPD and for BPD or death at 3 postnatal ages. This predictive power increased with advancing postnatal age.

Presentado en: Parcialmente, resultados iniciales fueron presentados en Congreso Nacional de Neonatología

Fuente de financiamiento: No declara

\section{Hallazgos en broncoscopía flexible en niños traqueostomizados. 9 años de experiencia en un centro de referencia de enfermedades respiratorias crónicas.}

Astudillo C, Villarroel G, Farías P, Moya A, Briceño L y Méndez M.

Departamento de Cardiología y Enfermedades Respiratorias Pediátricas. División de Peditría de la Pontificia Universidad Católica de Chile.

La broncoscopía flexible es una herramienta fundamental para el diagnóstico y tratamiento de enfermedades que afectan a las vías respiratorias, siendo un procedimiento con bien tolerado y con baja incidencia de complicaciones. En la literatura, hay escasa información respecto a su utilidad en el manejo y seguimiento de pacientes pediátricos traqueostomizados. Objetivo: Describir hallazgos de 9 años de experiencia en la realización de broncoscopías flexibles y complicaciones durante el procedimiento en este grupo seleccionado de pacientes. Materiales y método: Retrospectivo. Revisión de informes de broncoscopía realizadas en pacientes traqueostomizados internados en el Hospital Josefina Martínez entre enero de 2007 y diciembre de 2015. La broncoscopía se 
realizó de acuerdo a nuestro protocolo y bajo sedación - analgesia. Aprobado por el Comité de Ética del SSMSO. Los datos fueron tabulados en la hoja de cálculo excel y analizados con Stata 23.0. Resultados. Se realizaron y analizaron 154 procedimientos en el periodo 2007-2015. Fueron 90 hombres, con una edad promedio de 33 meses, la mayoría de los pacientes tenía apoyo de ventilación mecánica y la evaluación de la vía aérea fue la principal indicación del procedimiento. El principal hallazgo descrito fueron las malacias, tanto traqueomalacia o broncomalacia en 63 informes correspondiente al 40,1\%. Se presentaron complicaciones en el 36,3\% de los procedimientos, siendo las caídas de saturación bajo $90 \%$ las reportadas con mayor frecuencia. Conclusiones. El principal hallazgo reportado en pacientes pediátricos traqueostomizados sometidos a broncoscopía flexible fue traqueomalacia y broncomalacia. Las complicaciones fueron reportadas en $36,3 \%$ de los informes.

Presentado en: Congreso Pediatría y Congreso Internacional ERS Fuente de financiamiento: No declara

\section{Leptin is associated with serum aldosterone in paediatric subjects, independently of body mass index, blood pressure and plasma renin activity.}

Martinez-Aguayo, $A^{1}$; Seiltgens, $C^{1}$; Campino, $C^{2,3}$; Vecchiola, $A^{2,3}$ ; Carvajal, $\mathrm{CA}^{2,3}$; Baudrand, $\mathrm{R}^{2}$; García, $\mathrm{H}^{1}$; Bancalari, $\mathrm{R}^{1}$; Loureiro, $\mathrm{C}^{1}$; Grob, $\mathrm{F}^{1}$; Tapia-Castillo, $\mathrm{A}^{2}$; Valdivia, $\mathrm{C}^{2}$; Fuentes, $\mathrm{C}^{2,3}$; Lagos, $\mathrm{CF}^{2,3,4}$; Solari, $\mathrm{S}^{5}$; Allende, $\mathrm{F}^{5}$; Fardella, $\mathrm{CE}^{2,3}$

'División de Pediatría, Pontificia Universidad Católica de Chile. Santiago, Chile 2Departamento de Endocrinología, Pontificia Universidad Católica de Chile. Santiago, Chile ${ }^{3}$ Instituto Millenium en Inmunología e inmunoterapia, Departamento de Genética Molecular y Microbiología, Pontificia Universidad Católica de Chile. Santiago, Chile ${ }^{4}$ Facultad de Ciencia, Universidad San Sebastián. Santiago, Chile ${ }^{5}$ Departamento de Laboratorios Clínicos; Facultad de Medicina, Pontificia Universidad Católica de Chile. Santiago, Chile

Background: Leptin is considered to play an important role in the development of hypertension in obesity. The excessive synthesis of aldosterone contributes to the development and progression of metabolic and cardiovascular dysfunctions. Leptin is a newly described regulator of aldosterone synthesis that acts directly on adrenal glomerulosa cells to increase CYP11B2 expression and enhance aldosterone production in human adrenal cells lines and in animal models. Objective: to analyze if there is association between leptin with serum aldosterone (SA), as well as with blood pressure (BP), plasma renin activity (PRA), trans-tubular potassium gradient (TTKG), fractional excretion of sodium (FENa) and $24 \mathrm{~h}-\mathrm{Na} / \mathrm{K}$ urine ratio. Design: Cross sectional study. Subject and methods: We studied 79 subjects between 6.1 and 18 years old (mean, 13.2 years; 42 females); 37 were normal weight, 18 were overweight, and 24 were obese. After overnight fasting: anthropometric parameters, SA, PRA, plasma and 24-h-urine electrolytes were measured and TTKG, $\mathrm{FENa}$ and $24 \mathrm{~h}-\mathrm{Na} / \mathrm{K}$ urine ratio were calculated. For variables without normal distribution Spearman correlation was used, and log transformation was calculated previously to partial correlation analyses. Results: Leptin was directly associated with SA (Rho=0.275; $\mathrm{P}=0.016$ ). None association was found between leptin with systolic and diastolic blood pressure $(\mathrm{P}=$ 0.657 and $P=0.869$, respectively) and $P R A(P=0.197)$. Moreover, after controlling by age, body mass index z-score (BMI-z), log 10 PRA and $\log 1024 \mathrm{~h}-\mathrm{Na} / \mathrm{K}$ urine ratio, the association between log10 leptin and log10 SA increase (Partial correlation $=0.367$ $\mathrm{P}=0.002$ ). In other hand, $\mathrm{SA}$ was associated with PRA ( $R \mathrm{ho}=0.400$ $\mathrm{P}<0.001)$ and TTKG (Rho=0.330; $\mathrm{P}=0.037)$; and negative associated with $\mathrm{FENa}(\mathrm{Rho}=-0.246 ; \mathrm{P}=0.035)$ and $24 \mathrm{~h}-\mathrm{Na} / \mathrm{K}$ urine ratio (Rho= $-0.276 ; \mathrm{P}=0.014)$. Conclusion: In paediatric subjects, leptin was associated with serum aldosterone. This association was independently of the effect of age, BMI-z, PRA and blood pressure. Our clinical results agree with the recently described effect between of leptin upon aldosterone secretion in human adrenal cells lines and in animal models

Presentado en: ESPE 2016

Fuente de financiamiento: Supported by Fondecyt 1160695 , 1150437 and 1160836, CORFO 13CTI-21526-P1 and IMII P09/016F(ICM) Chilean Grants. 


\section{Primera evidencia de Orientia tsutsugamushi en la comuna de Tortel, región de Aysen, Chile}

Mario Calvo', Gerardo Acosta², Mauricio Soto³, Javier López Constanza Martínez ${ }^{5}$, Teresa Azócar ${ }^{5}$, Thomas Weitzel ${ }^{6}$, Katia Abarca ${ }^{5}$.

Clínica Alemana de Valdivia y Facultad de Medicina, Austral de Chile'; Instituto de Medicina Preventiva Veterinaria, Facultad de Ciencias Veterinarias, Universidad Austral de Chile²; Instituto de Ciencias Ambientales y Evolutivas, Facultad de Ciencias, Universidad Austral de Chile; ; Hospital Veterinario Puente Alto, Santiago ${ }^{4}$; Facultad de Medicina y Laboratorio Infectología y Virología Molecular, Pontificia Universidad Católica de Chile ${ }^{5}$; Clínica Alemana, Universidad del Desarrollo 6

INTRODUCCION: Recientemente se ha confirmado la presencia de infecciones por Orientia tsutsugamushi, agente causal de tifus de los matorrales, en la isla de Chiloé (Región de Los Lagos), constituyéndose Chile en el primer país que documenta presencia de esta infección transmitida por ácaros fuera del área del Sudeste Asiático y Región Pacífico Occidental donde es endémica. En marzo del 2016 se presentó un caso compatible con tifus de los matorrales en un investigador de Valdivia después de haber realizado un trabajo en terreno en la comuna de Tortel, a $18 \mathrm{~km}$ de la localidad de Caleta Tortel (Región de Aysén). OBJETIVO: Identificar infección por O. tsutsugamushi en un paciente con sintomatología compatible con tifus de los matorrales y su equipo profesional después de una posible exposición durante un trabajo en terreno cerca de Caleta Tortel. MÉTODOS: Se incluyeron a las seis personas que trabajaron en un estudio en terreno con posible contacto a vectores de O. tsutsugamushi en la Región de Aysén, entre el 22 de febrero y el 6 de marzo de 2016. Se registraron síntomas y signos y se tomaron dos muestras de sangre con al menos 4 semanas de intervalo. Se realizó PCR de O. tsutsugamushi en sangre y en escara al sujeto sintomático (genes $16 \mathrm{~S}$ RNA, 47kDa y $56 \mathrm{kDa}$ ) y serología IgG por IF (Fuller, EEUU), IgM e IgG por ELISA (InBios, EEUU) a todos. RESULTADOS: Un sujeto presentó fiebre, cefalea, exantema y escara en tobillo, cuadro iniciado dos días después de haber regresado a Valdivia; los síntomas mejoraron rápidamente en relación a terapia con azitromicina. Los demás permanecieron asintomáticos. El estudio molecular del sujeto sintomático fue negativo, pero mostró exámenes serológicos débilmente positivos (IF títulos de 256, IgM e lgG por ELISA débilmente positivas). De los 5 sujetos asintomáticos, 2 presentaron tests serológicos positivos (IF a títulos de hasta 512, IgM por ELISA débil), 2 débilmente positivos (IF hasta 256, IgM e IgG por ELISA negativas) y 1 negativo para todos los ensayos. CONCLUSIONES: La zona endémica de O. tsutsugamushi en el sur de Chile, fuera de Chiloé, es desconocida. Por lo tanto, la vigilancia de pacientes febriles y en persones con riesgo alto de exposición es de gran importancia en esta zona del país. Presentamos los datos preliminares de un grupo laboral de 6 personas con alto riesgo de exposición a ácaros en la XI Región, en el que se presentó un caso compatible con tifus de los matorrales (fiebre, exantema y escara) y evidencia serológica de una posible exposición a O. tsutsugamushi sin confirmación molecular, en este paciente y en 4 de 5 personas asintomáticas. Son necesarios más estudios para definir la extensión del agente en Chile y precisar la utilidad de cada ensayo serológico en nuestro medio.

Presentado en: Congreso Chileno de Infectología

Fuente de financiamiento: FONDECYT

\section{Protocolo de manejo hídrico y metabólico en el paciente con hipotermia corporal}

Mena P, Maccioni A, Astudillo P

Neonatologia Hosp Sotero del Rio, becada Neonatologia, becado de Pediatria

Introducción: En pacientes con encefalopatía hipóxico isquémica (EHI) en tratamiento con hipotermia corporal, se produce retención hídrica e hiponatremia, hipo e hiperglicemia, hipocalcemia y recientemente reportado hipomagnesemia. No hay recomendaciones específicas en la literatura para manejo de estos trastornos. Objetivos: Evaluar un protocolo de manejo dirigido a minimizar las alteraciones hidroelectrolíticas y metabólicas, con restricción de agua libre y volumen total según peso de nacimiento, estricto control de glicemia y magnesemia (Mg), suplementando con $\mathrm{Mg}$ menor de 1,8 mg/dl. Metodología: Implementación de un protocolo de manejo hídrico y metabólico en pacientes en hipotermia corporal desde Febrero hasta Septiembre 2016. Se comparó la evolución del grupo sometido a protocolo (GP) v/s un grupo histórico (GH) hospitalizado en los años 2014-2015. Los datos se comparan con test de Fisher, test de student y Kruskall Wallis, p 0,05. Se analizaron con Epi Info 7 y SISA. Resultados: Se recopilaron 11 casos en GP y 16 casos en $\mathrm{GH}$. Entre ambos grupos no hay diferencias significativas en peso nacimiento, edad gestacional, $\mathrm{pH}$ y exceso base en gases de cordón o de paciente, pero GH tiene menor APGAR a los 1, 5 y 10 minutos e ingresa de forma más precoz a hipotermia. Se observó que el volumen diario aportado es significativamente menor en GP que en GH. La evolución por día de peso y natremia fue similar, observándose aumento de peso en ambos grupos. La diuresis fue 
similar los primeros 3 días, pero fue mayor en GH 3,3 (1,1) v/s GP 2,3 $(0,8) \mathrm{ml} / \mathrm{kg} / \mathrm{h}, \mathrm{p} 0,02$ al cuarto día de vida. Creatinina máxima sin diferencias significativas. En GP la glicemia estuvo más frecuentemente en los valores planificados y se usaron significativamente menores cargas de glucosa, hasta 1,6 mg/Kg/min. Un caso del GH requirió insulina. La hipomagnesemia se observó en 10 de 11 casos en GP y en el único caso en que se controló en GH. La presentación fue principalmente entre las 6 y 36 horas de vida, y en todos los casos se normalizó con aporte de de sulfato $\mathrm{Mg} 25 \%$, si bien recurrió en dos casos. La hipocalcemia fue más frecuente en $\mathrm{GH}$ y no parece relacionada a mayor gravedad de evolución. De los 10 pacientes en total en que se suplementó con $\mathrm{Mg}, 2$ requirieron aporte de $\mathrm{Ca}$ y de los 15 que no fueron suplementados con $\mathrm{Mg}, 9$ requirieron $\mathrm{Ca}$ ( $p$ 0,057). Conclusiones: El objetivo de reducir la hiponatremia y retención hídrica durante la hipotermia requiere mayor intervención: cumplimiento de protocolo, mayor restricción de agua libre y manejo de acuerdo si hay SSIADH o falla prerrenal. La estabilidad de glicemia mejora con la aplicación de un protocolo de control y modificación de la carga. La hipomagnesemia es muy frecuente (91\%), similar a lo descrito en la literatura, debiéndose controlar y corregir dado su rol neuroprotector (disminuye daño mitocondrial y muerte neuronal). Llama la atención la menor frecuencia de hipocalcemia y necesidad de suplemento de calcio en el GP, lo que podría estar relacionado con el manejo de la hipomagnesemia y podría tener un rol en disminuir el daño neuronal, lo que es una hipótesis a verificar. Nota: el estudio será presentado con el agregado de los nuevos casos

Presentado en: VI Congreso Chileno de Neonatologia

Fuente de financiamiento: --

\section{Organización de un banco de leche para prematuros: logros y dificultades}

Mena P, Arenas D, Lavandero G, Nilo ME, Ahumada Q M, Neonatologia Hosp Sotero del Rio,

Introducción: Iniciar un banco de leche para prematuros ha sido una prolongada aspiración, considerando la importancia que la disponibilidad de leche materna tiene para los prematuros. Durante el año 2015 se terminó la prohibición ministerial de donación a bancos de leche que estableció la norma de VIH el año 2005. Con lo que la era posible organizar un banco de leche. Implementar un banco de leche donada para la alimentación de prematuros de muy bajo peso de nacimiento y a pacientes con trastornos gastrointestinales o cardiopatías cianóticas es un objetivo fundamental del cuidado neonatal Objetivos Relatar el proceso de implementación, gestión, logros y dificultades del desarrollo de un banco de leche para prematuros en Chile Metodología Durante el año 2015 se adquirió el equipamiento, se adaptó un espacio físico para la zona de pasteurización, se crearon normas de funcionamiento y registros adecuados con revisión de todas las estructuras correspondientes del hospital, se inició una marcha blanca para entrenar en el proceso y se inicia el banco el 20 de noviembre de 2015. Se registran los volúmenes de leche donados, procesados, analizados, pasteurizados y administrados en ese periodo. Se crea una página web y un correo para el contacto con potenciales donantes. Se establece un registro de trazabilidad sobre el destino de cada leche procesada. El control de adecuación bacteriológica se realiza por análisis de acidez de la leche con el sistema Dornic que descarta la leche con Dornic mayor de 8 para su procesamiento. El control post-pasteurización se realiza por análisis de una muestra en agar sangre que debe resultar en 0 colonias. Resultados Entre Diciembre de 2015 y Junio de 2016 de un total de 241,25 litros recibidos en donación (entre septiembre y junio), ingresaron al proceso de análisis y pasteurización: 207,566 litros de leche donada (100\%) Fueron desechados por aspecto físico y olor 3,635 litros (1,75\%) por alteración en el análisis de Dornic $94.625(45,6 \%)$ y descartados por cultivo positivo 4,900 I (2,46 \% ) que corresponde a dos procesos de pasteurización, obteniéndose un volumen de leche para administrar de 104,506 L (50,3\%) . 46 prematuros, recibieron un promedio de 2,2 I de leche donada, durante su hospitalización. Los aspectos que fueron críticos durante el período fueron: reclutar madres donantes, transporte de leche desde el hogar al hospital, pérdida de un volumen considerable de leche por alteración de la evaluación del Dornic y necesidad de mayor capacitación en técnica adecuada a la madre donante. Conclusiones En base a la experiencia inicial se considera que la capacitación de la madre con una óptima técnica de extracción, eliminando los primeros ml de extracción es fundamental para minimizar la pérdida de importante volumen por Dornic alterado. Optimizar el sistema de transporte y de captación de donantes es una tarea continua en el banco de leche.

Presentado en: VI Congreso Chileno de Neonatologia Fuente de financiamiento: Hospital Dr Sotero del Río

\section{Gene expression of epidermal tape stripping samples to assess response to vitamin $D$ supplementation in children with severe atopic dermatitis: a pilot study.}

Cabalin C, Pérez-Mateluna G, Iturriaga C, Cristi F, Silva- Valenzuela S, Vera-Kellet C, Cossio ML, Camargo CA, Borzutzky A.

Departamentos de Enfermedades Infecciosas e Inmunología Pediátrica y Dermatología, Escuela de Medicina, Pontificia Universidad Católica de Chile. Department of Emergency Medicine and Division of Rheumatology, Allergy, and Immunology, Department of Medicine, 
Massachusetts General Hospital, Harvard Medical School, Boston, USA. Background: Skin biopsy studies demonstrate that skin affected by atopic dermatitis (AD) shows changes in protein expression of the skin barrier, inflammatory cytokines and antimicrobial peptides. The tape stripping technique is a novel non-invasive sampling method of the stratum corneum of the skin that permits the analysis of different molecules through molecular biology techniques. We applied this novel technique to explore potential mechanisms for the reportedly beneficial effect of vitamin $D(V D)$ supplementation on the severity of $A D$ in some children. Objective: To implement a new combined protocol of non-invasive tape stripping and RNA extraction from epidermal samples and analyze the effect of VD supplementation on Vitamin D Receptor (VDR), Cathelicidin Antimicrobial Peptide (CAMP) Vascular Endothelial Growth Factor (VEGF), and Thymic Stromal Lymphopoietin (TSLP) mRNA expression in the skin of children with severe AD. Methods: In an ancillary study of the VIDATOPIC trial, samples of lesional and non-lesional skin from 6 children with severe $A D$ were collected through tape stripping technique before and after 6 weeks of oral VD supplementation. We extracted total RNA from samples and measured the expression of VDR, CAMP, VEGF and TSLP genes through RT-PCR. We applied the 2(-Delta Delta $C(T)$ ) method to analyze the relative change of expression between lesional and non-lesional skin in each subject before and after VD supplementation. Results: At baseline, mean SCORAD of the 6 children was $60 \pm 10$ and serum $250 H D$ was $48 \pm 22 \mathrm{nmol} / \mathrm{L}$. After 6 weeks of VD supplementation, $25 \mathrm{OHD}$ increased to $99 \pm 20 \mathrm{nmol} / \mathrm{L}$ $(P<0.05)$. Tape stripping was well tolerated in all patients. Tape stripping samples yielded between 2 and 30 ng of RNA for each site. Although statistical power was limited, relative mRNA expression of VDR non-significantly increased after VD supplementation from $0.46 \pm 0.28$ to $1.10 \pm 0.61(P=0.13)$. mRNA expression of other genes did not appear to change: $C A M P(0.87 \pm 0.22$ to $2.14 \pm 2.90$; $P=0.41)$, VEGF $(0.98 \pm 0.24$ to $1.20 \pm 0.36 ; P=0.41)$ and TSLP $(1.60 \pm 2.00$ to $1.68 \pm 2.40$; $\mathrm{P}=0.80$ ). Conclusions: This pilot study suggests that the analysis of mRNA relative expression from tape stripping of stratum corneum samples may permit a direct but non-invasive evaluation of skin biomarkers in AD patients. Further studies of mRNA expression in tape stripping samples are needed to evaluate the effects of VD supplementation on epidermal gene relative expression.

Presentado en: $9^{\text {th }}$ Georg Rajka International Symposium of Atopic Dermatitis 2016

Fuente de financiamiento: Fondo de Desarrollo Científico y Tecnológico Regular Proyecto Número 1130615

\section{Caracterización de pacientes chilenos con alergia alimentaria por hipersensibilidad inmediata en un centro terciario de salud.}

Feuerhake T, Morales PS, Talesnik E, Linn K, Thöne N, Borzutzky A.

Departamento de Enfermedades Infecciosas e Inmunología Pediátrica, Escuela de Medicina, Pontificia Universidad Católica de Chile.

Introducción: Las alergias alimentarias (AA) han experimentado un aumento en su prevalencia a nivel global. Estudio poblacional previo de AA de hipersensibilidad inmediata en escolares chilenos estimó una prevalencia de 5,5\% en este grupo etáreo. Sin embargo, aún existe escasa información acerca de las características clínicas y los alimentos involucrados en pacientes chilenos. Objetivos: Describir las características clínicas de pacientes chilenos con AA de hipersensibilidad inmediata atendidos en un centro terciario de salud. Material y métodos: Revisión retrospectiva de fichas clínicas de pacientes atendidos por especialistas en inmunología y alergia de la Red de Salud UC Christus entre años 2006 y 2016. Resultados: Se incluyó un total de 282 pacientes. El 89\% correspondió a menores de 18 años, con media de $2,7 \pm 4$ años y $62 \%$ fueron hombres. La edad media para mayores de 18 años fue de $31,7 \pm 10$ años y $69 \%$ fueron mujeres. En cuanto a comorbilidad alérgica, $43 \%$ presentaba rinitis alérgica, $35 \%$ dermatitis atópica y $27 \%$ asma bronquial. El $62 \%$ tenía familiares de primer grado con enfermedades alérgicas y un $19 \%$ historia familiar de AA. Las manifestaciones clínicas más frecuentes fueron urticaria (90\%), angioedema (57\%), disnea (30\%) y vómitos (21\%). Un 40\% tenía historia compatible con anafilaxia. Los alimentos más frecuentemente involucrados como causantes de AA confirmada por estudio de laboratorio fueron huevo (33\%), leche de vaca (25\%), maní (17\%), mariscos (5\%), nuez (5\%), tomate $(4 \%)$, trigo $(3 \%)$, palta $(2 \%)$, legumbres $(2 \%)$ y pescados (2\%). Conclusiones: El presente estudio caracteriza las AA de hipersensibilidad inmediata en una serie grande de pacientes chilenos. Los alimentos causantes de AA en Chile son similares a los descritos en otros países, aunque destaca la presencia de AA a tomate y palta, poco habituales en series internacionales. La incidencia de anafilaxia es frecuente destacando la necesidad de contar con autoinyectores de adrenalina en Chile.

Presentado en: XXVII Congreso Internacional Sociedad Chilena de Alergia e Inmunología.

Fuente de financiamiento: NA 


\section{Effect of vitamin D supplementation on the severity of atopic dermatitis in children: the VIDATOPIC randomized controlled trial.}

Borzutzky A, Cifuentes L, Silva-Valenzuela S, Vera-Kellet C, Iturriaga C, Perez-Mateluna G, Cristi F, Cabalin C, HoyosBachiloglu R, Navarrete-Dechent C, Niklitschek S, Carrasco JE, Cossio ML, Le Roy C, Camargo CA.

Departamentos de Enfermedades Infecciosas e Inmunología Pediátrica, Pediatría, Dermatología, Gastroenterología y Nutrición Pediátrica, Escuela de Medicina, Pontificia Universidad Católica de Chile. Department of Emergency Medicine and Division of Rheumatology, Allergy, and Immunology, Department of Medicine, Massachusetts General Hospital, Harvard Medical School, Boston, USA.

Background: Observational studies have shown vitamin D (VD) deficiency is common among patients with atopic dermatitis (AD) and is associated with increased severity. However, results of randomized trials of VD supplementation in AD patients are equivocal. Objective: To determine the efficacy of VD supplementation to decrease clinical severity of AD. Methods: A randomized, double-blind, placebo-controlled trial was conducted in Santiago, Chile. We randomly assigned 101 children aged 2-17 years with active AD (SCORAD 10-103) to weekly oral vitamin D3 (VD3) or placebo for 6 weeks. Patients were recruited between May and October of 2014. Blocked randomization was used with stratification by AD severity. Weekly dose of VD3 was adjusted by age: $8000 \mathrm{IU}$ for ages 2-5.9 years; $12000 \mathrm{IU}$ for ages 6-11.9 years; and $16000 \mathrm{IU}$ for ages 12-17.9 years. The primary endpoint was improvement in SCORAD index at 6 weeks. Analysis was performed by intention-to-treat. Results: Mean age was $6.3 \pm 4.0$ years and baseline SCORAD was $32 \pm 29$. Age, gender, baseline SCORAD, eosinophil count and total IgE levels were not significantly different between groups. At baseline, $57 \%$ of children were VD deficient ( $<50 \mathrm{nmol} / \mathrm{L}$ ): $25 \mathrm{OHD}$ was $47 \pm 20 \mathrm{nmol} / \mathrm{L}$ in supplementation arm and $46 \pm 21 \mathrm{nmol} / \mathrm{L}$ in placebo group ( $\mathrm{P}=0.86$ ). A total of 99 children ( $98 \%$ ) completed the 6-week follow-up assessment. Change in 25OHD at 6 weeks was $+43.4 \pm 34.5 \mathrm{nmol} / \mathrm{L}$ with VD3 supplementation and $+2.3 \pm 21.2 \mathrm{nmol} / \mathrm{L}$ with placebo $(P<0.001)$; however, $46 \%$ of subjects taking placebo increased 25OHD at week 6 . Change in SCORAD at 6 weeks was not different between VD and placebo groups (- $5.3 \pm 11.6$ vs. $-5.5 \pm 9.9$, $\mathrm{P}=0.91)$. There were no significant between-group differences in changes of total IgE, eosinophil count, or $\mathrm{S}$. aureus colonization rate. Subgroup analysis by age, baseline $25 \mathrm{OHD}$, or atopic status did not reveal between-group differences in SCORAD change. Rate of adverse events and use of medical co-intervention during trial also did not differ between groups. When reanalyzing data by change in 25OHD, regardless of treatment assignment, subjects with increased 25OHD between baseline and 6 weeks had significant improvement in SCORAD ( $-7.1 \pm 9.8$ vs $1.8 \pm 12.1, \mathrm{P}=0.02)$, eczema extension $(P<0.01)$ and pruritus $(P<0.01)$ compared to those with stable or decreased 25OHD. Conclusions: Among children with $A D$, weekly VD supplementation improved VD status but did not improve $A D$ severity significantly better than placebo, with both groups showing improvement. However, a longitudinal increase in $25 \mathrm{OHD}$ concentration, regardless of treatment assignment, was associated with a significant reduction in AD severity. (ClinicalTrials. gov number NCT01996423)

Presentado en: 9th Georg Rajka International Symposium of Atopic Dermatitis 2016

Fuente de financiamiento: Fondo de Desarrollo Científico y Tecnológico Regular Proyecto Número 1130615

\section{Lack of association of the PTPN22 gene C1858T polymorphism with atopic dermatitis in Chilean children.}

Perez-Mateluna G, Cristi F, Bustos MF, Iturriaga C, Seiltgens C, Iruretagoyena $\mathrm{M}$, Borzutzky $\mathrm{A}$.

Departamentos de Enfermedades Infecciosas e Inmunología Pediátrica, Pediatría, Reumatología, Escuela de Medicina, Pontificia Universidad Católica de Chile. Department of Emergency Medicine and Division of Rheumatology, Allergy, and Immunology, Department of Medicine, Massachusetts General Hospital, Harvard Medical School, Boston, USA.

Background: The PTPN22 gene, located on the long arm of chromosome 1, encodes lymphoid tyrosine phosphatase (Lyp), a protein that participates in inhibiting T-cell activation. The PTPN22 gene C1858T polymorphism has been associated with increased incidence of multiple autoimmune diseases. Atopic dermatitis (AD) is characterized by overactive $T$-cell responses and autoimmune phenomena against epidermal proteins have been observed in AD. In addition, $A D$ has been associated with autoimmune diseases such as celiac disease, vitiligo, and alopecia areata, but the association with the PTPN22 gene C1858T polymorphism has not been evaluated in AD. Objective: The aim of this study was to evaluate the association of the PTPN22 gene C1858T gene polymorphism with AD in children. Methods: The study included 99 children with $A D$ and 85 healthy non-atopic controls (HC). Genotyping of the rs2476601 (C1858T) PTPN22 gene polymorphism was performed using TaqMan SNP genotyping assay by Real Time PCR (RT-PCR). Severity of AD was assessed by SCORAD. Results: Mean age was $6.3 \pm 4.0$ years for $A D$ 
and mean age was $6.2 \pm 3.8$ years for $\mathrm{HC}(\mathrm{P}=0.84) 52 \%$ were male in $A D$ and $48 \%$ in $H C(P=0.66)$. In children with $A D$ mean SCORAD was $32 \pm 29$. The $\mathrm{C} 1858 \mathrm{~T}$ allele frequencies of cases and controls showed no deviation from Hardy-Weinberg equilibrium. Genotypes CC, CT, and TT of the PTPN22 C1858T polymorphism presented frequencies of $78.8 \%, 20.2 \%$ and $1 \%$, respectively, in the AD group, and $83.7 \%, 12.8 \%$, and $2.3 \%$ in the control group ( $P=0.35$ ). Comparison of the distribution of PTPN22 C1858T alleles among patients with $A D$ and $H C$ revealed no statistically significant differences ( $\mathrm{OR}=1.49,95 \% \mathrm{Cl}=0.70-3.20, \mathrm{P}=0.30$ ) for $\mathrm{TT}+\mathrm{CT}$ vs. $\mathrm{CC}$ genotypes). No association was found either between PTPN22 C1858T polymorphism and AD severity assessed by SCORAD ( $P=0.38)$. Conclusions: We found no association between the PTPN22 C1858T polymorphism and AD susceptibility in Chilean children.

Presentado en: $9^{\text {th }}$ Georg Rajka International Symposium of Atopic Dermatitis 2016

Fuente de financiamiento: Fondo de Desarrollo Científico y Tecnológico Regular Proyecto Número 1130615

\section{Structural domains within the $5^{\prime}$ leader of the HIV-1 full length mRNA and the ribosomal protein S25 influence cap- independent translation initiation}

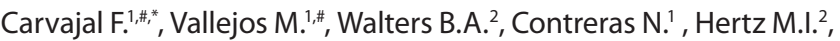
Olivares E.1, Cáceres C.J.1, Pino K.1, Letelier A.1, Thompson S.R.2, and López-Lastra M.?.

'Laboratorio de Virología Molecular, Instituto Milenio de Inmunología e Inmunoterapia, Departamento de Infectología e Inmunología Pediátrica, Escuela de Medicina, Pontificia Universidad Católica de Chile, Marcoleta 391, Santiago, Chile. 2Department of Microbiology, University of Alabama at Birmingham, Birmingham AL, USA. \# Equal contribution.

The $5^{\prime}$ leader of the HIV-1 genomic RNA is a multifunctional region that folds into secondary/tertiary structures that regulate multiple processes during viral replication, including translation initiation, thereby viral protein synthesis. In this work we examine the internal ribosome entry site (IRES) located in the 5 'leader that drives translation initiation of the viral Gag protein under conditions that hinder cap-dependent translation initiation. Through a knock-down approach, we show that full activity of the HIV-1 IRES relies on the presence of the ribosomal protein S25 (eS25). Additionally, a mutational analysis revealed that the HIV-1 IRES is modular in nature, with a core region composed of the PBS, SD and DIS domains. Through mechanistic studies using the scanning-inhibitor drug edeine, we show that once the $40 \mathrm{~S}$ ribosomal subunit is recruited to the IRES, translation initiates without the need of ribosome scanning. These findings elucidate a mechanism of initiation by the HIV-1 IRES whereby a number of highly structured sites present within the HIV-1 5 'leader leads to the recruitment of the 40 S subunit directly at the site of initiation of protein synthesis.

Presentado en: $\mathrm{Si}$

Fuente de financiamiento: FONDECYT 1130270, Project P09/016-F of the Iniciativa Científica Milenio del Ministerio de Economía, Fomento y Turismo to MLL, projects NIH R01GM084547 and 3R01GM084547-01A1S1, and a pilot research project from the UAB, Cancer Center HIV-Associated Malign

\section{LOOP IIId of the HCV IRES is essential for the structural rearrangement of the 40S-HCV IRES complex}

Angulo $\mathrm{J}^{1,2,}$ Ulryck N', Deforges J', Chamond N', Lopez-Lastra $\mathrm{M}^{2}$, Masquida $\mathrm{B}^{3, *}$ and Sargueil $\mathrm{B}^{1, *}$

'CNRS UMR 8015, Laboratoire de cristallographie et RMN Biologiques, Université Paris Descartes, France, ²Laboratorio de Virología Molecular, Instituto Milenio de Inmunología e Inmunoterapia, Centro de Investigaciones Médicas, Escuela de Medicina, PUC, ${ }^{3}$ UMR 7156 Génétique Moléculaire Génomique Microbiologie, CNRS - Université de Strasbourg, Strasbourg, France

As obligatory intracellular parasites, viruses rely on cellular machines to complete their life cycle, and most importantly they recruit the host ribosomes to translate their mRNA. The Hepatitis C viral mRNA initiates translation by directly binding the $40 \mathrm{~S}$ ribosomal subunit in such a way that the initiation codon is correctly positioned in the $\mathrm{P}$ site of the ribosome. Such a property is likely to be central for many viruses, therefore the description of host-pathogen interaction at the molecular level is instrumental to provide new therapeutic targets. In this study, we monitored the $40 \mathrm{~S}$ ribosomal subunit and the viral RNA structural rearrangement induced upon the formation of the binary complex. We further took advantage of an IRES viral mutant mRNA deficient for translation to identify the interactions necessary to promote translation. Using a combination of structure probing in solution and molecular modeling we establish a whole atom model which appears to be very similar to the one obtained recently by cryoEM. Our model brings new information on the complex, and most importantly reveals some structural rearrangement within the ribosome. This study suggests 
that the formation of a 'kissing complex' between the viral RNA and the $18 \mathrm{~S}$ ribosomal RNA locks the $40 \mathrm{~S}$ ribosomal subunit in a conformation proficient for translation.

Presentado en: SI

Fuente de financiamiento: Funding: PICS \#5283 - L.I.A - CNRS; Iniciativa Científica Milenio del Ministerio de Economía, Fomento y Turismo: Proyecto P09/016-F; Laboratoire d'Excellence Project ANR-11-LABX-0057-MITOCROSS

\section{Evolución de pacientes con Hernia Diafragmática Congénita, factores de riesgo de mortalidad y estratificación por riesgo.}

Luco M, Zavala M, Vuletin F, Kattan J

Departamento de Neonatología de la División de Pediatria de la Pontificia Universidad Católica de Chile

Introduction Congenital diaphragmatic hernia (CDH) occurs in $1 / 2500$ births. Since 2003 we run a neonatal ECMO program, attached to the ELSO, and since 2013 our institution is part of an international multicenter study focused on the in-hospital evolution of these patients. The opportunity to report our data has allowed us to compare our results with international series and to stratify them according to risk. Objective Characterize our patients with $\mathrm{CDH}$, and compare our mortality results, based on risk stratification. Materials and Methods CDH patients born between January 2013 and June 2016, that were repaired in our center were included. The data was entered prospectively in the ad hoc CDH Study Group (CDH SG) form. A p value $<0.05$ was considered significant. Results The characteristics of our patients, compared with the reports of the complete series of the CDH SG can be seen in Table 1. In our patients the factors that were associated with a higher mortality were: gestational age, Apgar score at 5 minutes, ECMO, CDH SG risk score and diaphragmatic defect size. Side of the defect, delivery mode, and gender were not. Survivors were maintained on mechanical ventilation for a median of 18 days and were surgically repaired at a median of 8 days. When comparing the characteristics of our population, we could see that they do not differ significantly with the series reported by the CDH SG in most of the variables. When comparing our mortality in the global group as in the group that required ECMO no significant differences were seen with the complete series of the CDH SG patients. When stratifying the population according to the CDH Study Group Risk Score or size of the defect according to the classification of the same group, there were no significant differences in mortality between our patients and the results presented by the $\mathrm{CDH}$ Study Group. Conclusions Our CDH population has similar characteristics to those of the CDH Study Group. The results obtained regarding mortality were similar to those of the CDH Study Group even after being stratified by risk. The collaborative work of different neonatal centers at a national level, together with the development of new technologies and the greater local experience, have allowed to reach a survival rate that is comparable to the centers with the best results in this complex pathology worldwide.

Presentado en: 2nd Latin American ELSO Conference

Fuente de financiamiento: No declara

\section{Use of a validated clinical score for early referral of Congenital Diaphragmatic Hernia to a specialized center in Chile}

Luco M, Kattan J, Santelices F

Departamento de Neonatología de la División de Pediatria de la Pontificia Universidad Católica de Chile

Background. Congenital Diaphragmatic Hernia (CDH) is a significant cause of neonatal mortality. Outcomes vary widely among different patients and centers. An early tool to discriminate which patients would benefit from specific expertise in their management, is needed. By using clinical and echocardiographic parameters, the CDH Study Group (CDHSG), proposed a predictive score to stratify risk into populations of neonates with high, intermediate or low risk of death With this model, patients with higher risk could be selected for transfer to centers with advanced medical therapies. Objectives. To use and validate in our CDH neonates the CDHSG score. To determine a cut off value for predicting survival with no need of ECMO in our population. Design/methods. CDHSG Score was calculated for each neonate admitted with $\mathrm{CDH}$, to our Unit, between January 2013 and January 2016. We excluded all patients with a first cardiac US after their second day of life. The predictive capacity of the CDHSG score was validated by comparing the results of patient's classified in upper, intermediate and lower scores. Based on this, we assessed a score value on which it is advisable to transfer patients at an early stage to a high complexity center with the availability of ECMO. Results. During 33 consecutive months, 60 patients with $\mathrm{CDH}$ were enrolled. They were stratified on low $(n=19)$, intermediate $(n=26)$ and high-risk groups ( $n=15)$; mortality rates were 5, 19 and $73 \%$ for each group respectively. The combined outcome of death or need of ECMO for low risk stage was 5\%, for intermediate 52\%, and for high-risk stage $93 \%$. Differences among groups were statistically different. 
Conclusion. The CDHSG score was efficient in predicting death or need of ECMO in our population. In our setting, we recommend the transfer to an ECMO center of any patient with an intermediate or high CDH SG score as NPV at this cut-off point was $90 \%$.

Presentado en: Pediatric Academic Societies meeting 2016

Fuente de financiamiento: No declara

\section{Cap-independent translation initiation driven by the HIV-1, HTLV-1, and MMTV mRNAs is dependent on hypusine-elF5A.}

Cáceres, C. Joaquín ${ }^{1,2}$, Angulo, Jenniffer', Contreras, Nataly1,2., Pino, Karla1., Vera-Otarola, Jorge1., López-Lastra, Marcelo1.,

'Laboratorio de Virología Molecular, Instituto Milenio de Inmunología e Inmunoterapia, Centro de Investigaciones Médicas, Departamento de Infectología e Inmunología Pediátrica, Escuela de medicina, Pontificia Universidad Católica De Chile. ${ }^{2}$ Programa de Doctorado en Ciencias mención Microbiología, Universidad de Chile/Universidad de Santiago de Chile.

Replication of the human immunodeficiency virus type 1 (HIV-1) is dependent on eIF5A hypusination. EIF5A is the sole cellular protein containing the amino acid residue hypusine [ $\mathrm{N} \varepsilon$-(4-amino-2-hydroxybutyl)lysine]. Hypusine is formed post-translationally on the elF5A precursor by two consecutive enzymatic steps; a reversible reaction involving the enzyme deoxyhypusine synthase (DHS) and an irreversible step involving the enzyme deoxyhypusine hydroxylase $(\mathrm{DOHH})$. In this study we explored the effect of inhibiting $\mathrm{DOHH}$ activity and therefore eIF5A hypusination, on cap-independent translation initiation driven by the 5 'untranslated region of the full length HIV-1 mRNA (HIV-1 IRES). We show that translation initiation mediated by the HIV-1 IRES relies on DOHH protein concentration and on its enzymatic activity. Next we evaluated the impact of elF5A hypusination on the activity of the IRESs of the Human T-cell lymphotropic virus type 1 (HTLV-1), the Mouse Mammary Tumor Virus (MMTV), and Poliovirus (PV). Results show that elF5A hypusination is required for the activity of retroviral IRESs (HIV-1, HTLV-1 and MMTV), but not for the activity of the PV IRES.

Presentado en: si

Fuente de financiamiento: FONDECYT 1130270 And P09/016-F De La Iniciativa Científica Milenio Del Ministerio De Economía, Fomento Y Turismo De Chile. CJC And NC Are Supported By CONICYT Doctoral Fellowships

\section{Biomechanical and functional properties of fetal guinea pig arteries reveal a heterogeneous effects of growth restriction on vascular remodeling}

Cañas D ${ }^{1}$, Herrera EA ${ }^{2,3}$, García-Herrera C ${ }^{1}$, Celentano D ${ }^{4}$, Krause B.J ${ }^{5}$

'Departamento de Ingeniería Mecánica, Facultad de Ingeniería, Universidad de Santiago de Chile (USACH). Av. Bernardo. O 'Higgins 3363, Santiago, Chile. ${ }^{2}$ Programa de Fisiopatología, Instituto de Ciencias Biomédicas, Facultad de Medicina, Universidad de Chile. Av. Salvador 486, Providencia 7500922, Santiago, Chile. ${ }^{3}$ International Center for Andean Studies (INCAS), Universidad de Chile, Baquedano s/n, Putre, Chile. ${ }^{4}$ Departamento de Ingeniería Mecánica y Metalúrgica, Instituto de Ingeniería Biológica y Médica, Pontificia Universidad Católica de Chile. Av. Vicuña Mackenna 4860, Santiago de Chile, Chile. ${ }^{5}$ Departament of Neonatology, Division of Pediatrics, Faculty of Medicine, Pontificia Universidad Católica de Chile. Marcoleta 391, Santiago 8330024, Santiago, Chile.

Aim: Fetal growth restriction (FGR) is associated with a variety of cardiometabolic diseases in adulthood which could involved a remodeling processes of the vascular walls since the fetal period. However, there is no consensus whether this remodeling affects in a similar way the whole vascular system. We aimed to determine the effects of FGR on the vasoactive and biomechanical properties of umbilical and systemic vessels in fetal guinea pigs. Methods: FGR was induced by implanting ameroid occluders at mid-gestation in uterine arteries of pregnant guinea pigs, whilst the control group was exposed to simulated surgery. At the term of gestation, systemic arteries (aorta, carotid and femoral) and umbilical vessels were isolated to determine ex vivo contractile and biomechanical responses (stretch-stress until rupture) on a wire myograph, as well as opening angle and residual stresses. Histological characteristics in tissue samples were measured by van Gieson staining. Results: Aorta and femoral arteries from FGR showed an increased in biomechanical markers of stiffness ( $p<$ $0.01)$, contractile capacity $(p<0.05)$ and relative media thickness $(p<0.01)$, but a reduced internal diameter $(p<0.001)$, compared with controls. There were no differences in the biomechanical properties of carotid and umbilical from control and FGR fetuses, but FGR umbilical arteries had a decreased contractile response to $\mathrm{KCl}(\mathrm{p}<0.05)$ along with a reduced relative media thickness $(p<0.05)$. Conclusion: Altogether, these changes in functional, mechanical and morphological properties suggest that FGR is asso- 
ciated with a heterogeneous pro-constrictive vascular remodeling affecting mainly the lower body fetal arteries. These effects would be set during a pathologic pregnancy in order to sustain the fetal blood redistribution in the FGR, and may persist up to adulthood increasing the risk of a cardiovascular disease.

Presentado en: No

Fuente de financiamiento: Fondecyt 1130801

\section{$\mathrm{N}$-acetyl cysteine, a glutathione precursor, reverts vascular dysfunction and endothelial epigenetic programming in intrauterine growth restricted guinea pigs}

Herrera EA ${ }^{1}$, Cifuentes-Zúñiga $F^{2}$, Figueroa E ${ }^{1}$, Villanueva $C^{1}$, Hernández $C^{2,3}$, Arroyo V ${ }^{2}$, Peñaloza E ${ }^{2}$, Farías $M^{3}$, Uauy R ${ }^{2}$, Casanello $P^{2,3}$, Krause BJ ${ }^{2}$

'Programa de Fisiopatología, Instituto de Ciencias Biomédicas, Facultad de Medicina, Universidad de Chile. Av. Salvador 486, Providencia 7500922, Santiago, Chile. '2Department of Neonatology, Division of Paediatrics, Faculty of Medicine, Pontificia Universidad Católica de Chile. Marcoleta 391, Santiago 8330024, Santiago, Chile. ${ }^{3}$ Division of Obstetrics \& Gynaecology, Faculty of Medicine, Pontificia Universidad Católica de Chile. Marcoleta 391, Santiago 8330024, Santiago, Chile.

In humans, intrauterine growth restriction (IUGR) is associated with vascular dysfunction, oxidative stress and signs of endothelial programming in umbilical vessels. We aimed to determine the effects of maternal antioxidant treatment with $\mathrm{N}$-acetyl cysteine (NAC) on fetal endothelial function and eNOS programming in IUGR guinea pigs. IUGR was induced by implanting ameroid constrictors on uterine arteries of pregnant guinea pigs at mid gestation, receiving half of the sows NAC in the drinking water (from day 34 until term). Fetal biometry and placental vascular resistance were followed by ultrasound throughout gestation. At term, umbilical arteries and fetal aortae were isolated to assess endothelial function by wire-myography. Primary cultures of endothelial cells (EC) from fetal aorta, femoral and umbilical arteries were performed to determine eNOS mRNA levels by qPCR and analyse DNA methylation in Nos3 promoter by pyrosequencing. Doppler ultrasound measurements showed that NAC reduced placental vascular resistance in IUGR $(p<0.05)$ and recovered fetal weight $(p<0.05)$, increasing fetal-to-placental ratio at term ( 40\%) ( $<0.001)$. In IUGR, NAC treatment restored eNOS-dependent relaxation in aorta and umbilical arteries ( $p<0.05)$, normalizing eNOS mRNA levels in EC fetal and umbilical arteries ( $p<0.05)$. IUGR-derived EC had a decreased DNA methylation ( 30\%) at CpG -170 (from the TSS) and this epigenetic signature was absent in NAC treated fetuses ( $p$ $<0.001)$. These data show that IUGR-EC have common molecular markers of eNOS programming in umbilical and systemic arteries and this effect is prevented by maternal treatment with antioxidants.

Presentado en: Fetal and Neonatal Physiological Society, 43rd Annual Meeting

Fuente de financiamiento: Fondecyt 1130801

\section{Congenital Diaphragmatic Hernia Defect Size and Infant Morbidity at Discharge}

Putnam LR, Harting MT, Tsao K, Morini F, Yoder BA, Luco M, Lally P, Lally K

McGovern Medical School at the University of Texas Health Science Center at Houston and Children's Memorial Hermann Hospital, Houston, Texas; bBambino Gesù Children's Hospital, IRCCS, Rome, Italy; CUniversity of Utah School of Medicine and Primary Children's Hospital, Salt Lake City, Utah; and dPontificia Universidad Católica de Chile, Santiago, Chile

BACKGROUND AND OBJECTIVE: Survival for infants with congenital diaphragmatic hernia $(\mathrm{CDH})$ has gradually improved, yet substantial burden of disease remains. Although larger $\mathrm{CDH}$ defect sizes increase mortality, the association between defect size and morbidity has not been reported. Our objective was to evaluate the association of defect size with pulmonary, neurologic, and gastrointestinal morbidity at the time of hospital discharge. METHODS: An international, prospective cohort study was performed. Patient demographics, intraoperative defect size, and clinical outcomes were reviewed. The primary outcome was morbidity at the time of discharge, which entailed supplemental oxygen requirement, abnormal neurologic clinical and radiographic findings, gastroesophageal reflux, supplemental nutrition, or pulmonary-, neurologic-, or gastrointestinal-related medications. RESULTS: A total of 3665 patients were included in the study cohort. Overall survival was $70.9 \%$, and $84.0 \%$ of survivors were discharged from the hospital (16.0\% transferred). Median age at discharge was 38 days (interquartile range [IQR] 23-69) and ranged from 22 (IQR 16-32) days for "A" (smallest) defects to 89 (IQR 64-132) days for "D" (largest) defects $(P<.001)$. Of those discharged from the hospital, $1522(74.2 \%)$ had pulmonary $(n=660,30.2 \%)$, neurologic $(n=$ $446,20.4 \%)$, or gastrointestinal $(n=1348,61.7 \%)$ morbidities, and multiple morbidities were diagnosed in 701 (34.7\%) patients. On multivariable regression analyses incorporating key patient characteristics, defect size was consistently the greatest predictor of 
overall morbidity, hospital length of stay, and duration of ventilation. CONCLUSIONS: Infants with CDH are commonly discharged with $\geq 1$ major morbidities. The size of the diaphragmatic defect appears to be the most reliable indicator of a patient's hospital course and discharge burden of disease.

Presentado en: Publicado en Pediatrics

Fuente de financiamiento: No declara

\section{Variaciones geográficas en necesidades de atención de salud en menores de un año, en Chile}

Gattini D, Gattini C.

\begin{abstract}
${ }^{1}$ Departamento de Gastroenterologia y Nutrición Pediátrica de la Pontificia Universidad Católica de Chile; 2. Escuela de Salud Pública, Universidad de Chile
\end{abstract}

Introducción: Los sistemas de salud tienen por objetivo responder a las necesidades de atención de salud (NAS) de los diversos grupos de la población. La necesidad de atención de salud (NAS) es percibida como una carencia posible de satisfacer. También como una brecha entre una situación actual y una deseable. Es posible aproximarse a estimar estas necesidades midiendo: El riesgo, incidencia/prevalencia de morbi-mortalidad evitable; la brecha entre lo observado y deseado (variación reducible); los servicios asistenciales actualmente provistos y los servicios asistenciales que pueden ser costo-efectivos. Los menores de un año, independiente de su situación de salud, requieren de atención integral destinada a preservar y mejorar el nivel de salud. El progreso de la salud infantil en Chile se relaciona tanto con el desarrollo global y del sistema de salud. Sin embargo, se mantienen desigualdades geográficas relacionadas con determinantes sociales y con la atención de salud. Las áreas con menor desarrollo socioeconómico concentran mayor vulnerabilidad y necesidades de atención de salud, con eventos que son evitables. Objetivo: Evaluar las variaciones geográficas en NAS en menores de un año en Chile según comunas y Servicios de Salud, agrupados según nivel de desarrollo socioeconómico. Métodos: Estudio ecológico descriptivo de variaciones geográficas de la situación y atención de salud en comunas y servicios según nivel socioeconómico, bajo perspectiva de necesidades de atención de salud. Como indicador resumen de nivel socioeconómico, se utilizó el Índice de Desarrollo Socio-Económico comunal (IDSE), bajo metodología similar a la elaboración de IDH: Para estimar NAS según situación de salud se utilizó: bajo peso al nacer, prematurez, malnutrición y tasa de mortalidad infantil (TMI). Como indicador relevante de NAS, se estimó la distribución de la mortalidad infantil a través de Índice de Gini, curva de Lorenz e índice y curvas de concentración. Se comparó la mortalidad en quintiles comunales según IDSE, para los períodos 1990-1994 y 2010-2013. Para estimar NAS como línea de base de servicios se utilizó: cobertura de atención profesional del parto y de vacunaciones, y egresos hospitalarios. Resultados: Se encontró variación significativa inversa en prevalencia de obesidad y en la mortalidad infantil según IDSE. Sin embargo, no se encontró variación significativa en cobertura de vacunas, del parto y egresos hospitalarios anuales, natalidad, prematurez y bajo peso al nacer según IDSE. Se observó una disminución del nivel y variación geográfica de la TMI entre 1990-1994 y 2010-2013. Sin embargo, persisten diferencias significativas entre la TMI de las comunas elite (mayor IDSE) con el resto de comunas del país. Conclusión: La diferencia geográfica y socioeconómica entre NAS materno-infantil, ha disminuido en las últimas dos décadas en relación al progresivo desarrollo socioeconómico y cobertura de servicios de salud, esto implica que el sistema de salud chileno ha logrado una gran cobertura e impacto relacionado con promoción y prevención. Sin embargo, este avance sigue siendo inequitativo, pues persisten brechas significativas en los quintiles de menor IDSE, con mortalidad infantil evitable y por tanto posible de reducir. Las comunas elite, continúan siendo un referente empírico óptimo para estimar niveles posibles de alcanzar en el resto del país. Este tipo de estudio permite destacar la alta importancia de evaluar las variaciones geográficas en NAS, con el fin de orientar a los servicios de salud para responder en forma efectiva a las necesidades existentes en los diversos grupos de la población.

Presentado en: 2015 Presentación Oral Congreso de Pediatria; 2016 Presentación Oral Congreso de Pediatria Social Fuente de financiamiento: No declara

\section{Influencia de la malnutrición por exceso en la evolución de niños menores de dos años hospitalizados por infección respiratoria aguda baja}

Bustos E, Franulic Y, Messina J, Barja S.

Hospital Josefina Martínez. Departamento de Gastroenterología y Nutrición Pediátrica. División de Pediatría, Facultad de Medicina Pontificia Universidad Católica de Chile. Escuela de Nutrición y Dietética, Facultad de Medicina Universidad Finis Terrae.

Introducción: La obesidad se ha asociado a mayor morbimortalidad en adultos que cursan infecciones respiratorias. 
Objetivo: Estudiar si existe asociación entre la malnutrición por exceso (ME) y la evolución clínica en niños menores de dos años hospitalizados por infecciones respiratorias agudas bajas (IRAB). Sujetos y métodos: Estudio retrospectivo con revisión de fichas y registros clínicos de los menores de dos años hospitalizados por IRAB en el Hospital Josefina Martínez durante los períodos de Campaña de Invierno, años 2009 a 2015. Se consignaron datos demográficos, antropometría al ingreso y estado nutricional según referencia OMS 2006. Se caracterizó la evolución según: estadía hospitalaria (días/horas), necesidad y duración (días) de oxigenoterapia y apoyo ventilatorio, uso de corticoides orales y/o antibióticos. Resultados: La muestra quedó constituida por 678 niños de 10,96 $\pm 5,65$ meses de edad, 62,3\% menores de un año, 55\% hombres. El diagnóstico de ingreso más frecuente fue neumonia viral (67\%). Recibió cuidado básico: $54,7 \%$, oxigenoterapia: $98,7 \%$, apoyo ventilatorio: $35,4 \%$, antibióticos: $26,1 \%$, corticoides: $47,5 \%$. En estado nutricional, tenían desnutrición $1,3 \%$, riesgo de desnutrir $8,7 \%$, eutrofia $55,2 \%$, sobrepeso $23,3 \%$ y obesidad $11,5 \%$. Los hombres con malnutrición por exceso (ME) tuvieron mayor frecuencia de neumonia viral $(75,4 \%$ vs $60,2 \%, p=0,014)$, necesidad de cuidado mixto $(27,7 \%$ vs $19,9 \%$, $\mathrm{p}=0,018$ ) y duración del apoyo ventilatorio: Mediana 4,5 (3 a 5,5) vs. 3,0 (2 a 5) días, p=0,007) que los eutróficos. En las mujeres no hubo asociación entre ME y la evolución clínica, pero aquellas con malnutrición por déficit requirieron menos tratamiento corticoidal que las eutróficas ( $28 \%$ vs $54,8 \%, p=0,025)$. Conclusiones: En esta muestra de niños menores de dos años hospitalizados por IRAB, los hombres con malnutrición por exceso evolucionaron con mayor complejidad de cuidado y apoyo ventilatorio más prolongado de que los eutróficos.

Presentado en: No

Fuente de financiamiento: Sin fuente de financiamiento

\section{Alta incidencia de hipotiroidismo congénito con elevación tardía de TSH en recién nacidos de pretérmino}

Gutiérrez $\mathrm{M}^{1}$, Leguizamón $\mathrm{L}^{2}$, Fabres $\mathrm{J}^{2}$, Grob $\mathrm{F}^{3}$.

${ }^{1}$ Residente de Pediatría, ${ }^{2}$ Departamento de Neonatología. ${ }^{3}$ División de Pediatría, Unidad de Endocrinología

INTRODUCCIÓN: El hipotiroidismo congénito $(\mathrm{HC})$ se diagnostica los primeros días de vida en recién nacidos de término a través de la determinación de TSH. El retraso del diagnóstico puede provocar daño neurológico irreversible. Se ha reportado una mayor incidencia de $\mathrm{HC}$ en recién nacidos de pretérmino (RNPT) después del mes de vida. En nuestro país, no se determina TSH en ese momento. El objetivo de este estudio es determinar la incidencia de $\mathrm{HC}$ tardío en RNPT. PACIENTES Y MÉTODOS. Se realizó un estudio prospectivo en RNPT menores de 34 semanas de edad gestacional y/o menores de 1500 gr nacidos en la Red de Salud UC entre junio y octubre de 2016. Se determinó TSH a las 48 hrs y 15 días de vida, al mes y 2 meses de vida. Se solicitó TSH y T4 libre a aquellos con TSH mayor a $15 \mathrm{mui} / \mathrm{ml}$ a las $48 \mathrm{hrs}$ y 15 días; mayor a $10 \mathrm{mui} / \mathrm{ml}$ al mes y mayor a $5 \mathrm{mui} / \mathrm{ml}$ a los 2 meses. Se diagnosticó HC en aquellos pacientes con TSH mayor a $10 \mathrm{mui} / \mathrm{ml}$ a las $48 \mathrm{hrs}$ y 15 días, mayor a $10 \mathrm{mui} / \mathrm{ml}$ al mes y mayor a $5 \mathrm{mui} / \mathrm{ml}$ a los 2 meses. RESULTADOS. Se incluyeron 27 pacientes con edad gestacional de 31 +- 2.2DS. Hubo 2, 16 y 9 RNPT entre las 24 a 28,28 a 32 y 32 a 34 semanas respectivamente. A los 7 y 15 días ninguno fue diagnosticado con HC. Al mes y 2 meses se obtuvo TSH en 14 y 13 pacientes respectivamente, confirmándose el diagnostico en 3 y un paciente respectivamente. La incidencia acumulada de $\mathrm{HC}$ fue 14.8\% (1:7); en menores de 1000gr fue 1:27. La incidencia de HC entre las 28 a 32 semanas y entre las 32 a 34 semanas fue 1:27 y 1:9 respectivamente. No hubo casos en menores de 28 semanas. Todos los confirmados iniciaron tratamiento con levotiroxina. CONCLUSIONES: Reportamos una alta incidencia de HC tardío en RNPT, mayor a la reportada en la literatura. Ésta no se correlaciona con la edad gestacional, probablemente debido al bajo numero de pacientes menores de 28 semanas.

Presentado en: No

Fuente de financiamiento: Concurso Becarios Residentes Año 2016

\section{Comparación entre distintos puntos de corte de parámetros de monitoreo ambulatorio de presión arterial en} pacientes pediátricos de Santiago.

Peredo MS, Carrillo D, Bofill L, Vogel A, Nardiello A, Andrade D

Unidad de Nefrología de la División de Pediatría de la Pontificia Universidad Católica de Chile

Se realizó un estudio analítico transversal con el objetivo de evaluar distintos puntos de corte de normalidad para informe de monitoreo de presión arterial (MAPA). Recomendaciones internacionales consideran el uso de límites de presión arterial normal diferenciando el día y la noche según tablas del Grupo Alemán de Hipertensión Pediátrica, pero no hay trabajos que evalúen aplicabilidad en pacientes pediátricos chilenos. Con este fin se utilizaron datos de 
pacientes que se tomaron MAPA en la Red de Salud UC Christus entre Enero y Julio de 2015, considerando un registro por paciente. Para definir normalidad se compararon las tablas de presión arterial clínica del Fourth Report on Pediatric Hypertension del NHBPEP (2004) y las tablas para MAPA informadas por el Grupo Alemán de Hipertensión Pediátrica (2002). Se excluyeron registros de pacientes que no fueran técnicamente satisfactorios y pacientes con talla menor de 1,15 mt. Se obtuvieron datos de 50 pacientes: 25 hombres (50\%) y 25 mujeres (50\%) con mediana de 11 años RIC (8-14). La indicación de MAPA fue por hipertensión o sospecha de ésta en 48 pacientes (96\%). Comparando estos criterios se obtuvo diferencias estadísticamente significativas para presiones sistólicas y diastólicas, diurnas y nocturnas (todas con $p=0,0002$ a $p<0,0001$ ) y sus sobrecargas sistólicas y diastólicas, diurnas y nocturnas, calculadas según $\mathrm{p} 95$ (todas con $\mathrm{p}=0,002$ a $\mathrm{p}<0,0001$ ). Asimismo, al ocupar las tablas para MAPA del Grupo Alemán se obtiene mayor correlación con coeficientes de Kendall más altos que con las del NHBPEP entre sobrecargas y sus presiones promedio diurnas y nocturnas, con sobrecarga y presiones promedio sistólicas diurnas 0,68 versus 0,6; diastólicas diurnas 0,76 versus 0,69 ; sistólicas nocturnas 0,62 versus 0,57 y diastólicas nocturnas 0,74 versus 0,50 . Por lo tanto y en espera de definiciones de límites basadas en outcomes clínicos es que sugerimos el considerar límites de presión arterial en MAPA diferenciando día de noche, en concordancia con recomendaciones internacionales y con los hallazgos de nuestro trabajo.

Presentado en: II Congreso Nacional de Hipertensión

Fuente de financiamiento: No declara

\section{Implementación de un protocólo de realimentación en niños con infecciones respiratorias bajas y apoyo ventilatorio no invasivo}

Franulic $\mathrm{Y}^{1}$, Farías $\mathrm{N}^{1}$, Bustos $\mathrm{E}^{1}$, Méndez $\mathrm{M}^{2}$, Barja $\mathrm{S}^{3}$.

Departamento de Gastroenterología y Nutrición Pediátrica. División de Pediatría, Facultad de Medicina Pontificia Universidad Católica de Chile. Hospital Josefina Martínez

Introducción: Los niños con infecciones respiratorias bajas agudas (IRAB) que requieren apoyo ventilatorio no invasivo necesitan inicialmente un período variable de ayuno, que puede prolongarse innecesariamente. Objetivo: Desarrollar un protocolo de realimentación para estos pacientes y evaluar su implementación según los plazos propuestos. Método: Estudio prospectivo realizado en niños con IRAB y AVNI, hospitalizados durante la campaña de invierno de 2016 (13/6 al 31/8) en el Hospital Josefina Martínez. Para calcular el volumen a aportar se usó el método de Holliday-Segar. Se desarrolló un protocolo de realimentación y se registró la duración en horas de cada etapa. Se difundió entre todo el personal y estuvo fácilmente disponible de modo impreso. Resultados: Se registró la aplicación del protocolo en 54 pacientes, con mediana de edad de 11,7 meses (3,13 a 57,2), 48\% menores de 1 año, 51\% mujeres. El tiempo estadía fue de 9 días ( 5 a 21), el de oxigenoterapia 6 días (3 a 20) y el de AVNI 5 días (3 a 12). Diagnósticos de alta: Neumonía viral (77,1\%), Bronquiolitis (10,4\%), Otros (12,5\%). La duración del ayuno tuvo mediana de 10 horas (4 a 47,7). Dos niños no lo requirieron, 16 (33,3\%) cumplieron 6 horas, 18 (34,6\%) cumplieron 6-12h, 14 (27\%) 12-24h y en 4 el ayuno duró más de 24h. Se alcanzó $60 \%$ de RDAs por SNG a las $16 \mathrm{~h}$ (8 a 48), logrado a las $12 \mathrm{~h}$ de iniciada SNG por 23 pacientes (42,6\%). La duración total de SNG tuvo mediana de 90 hrs (40 a 210), momento en el cual se logró la alimentación completa por vía oral. Se encontró correlación positiva entre la duración del ayuno y la de AVNI (Rho Spearman $0,32, p=0,026$ ) y de oxigeno (Rho $0,27, p=0,06$ ), así como del logro de realimentación $100 \%$ y estadía (rho 0,41, p=0,02), oxígeno (rho $0,64, p=0,00$ ) y AVNI (rho $0,55, p=0,00$ ). Conclusiones: Fue posible aplicar y registrar el cumplimiento de este protocolo de realimentación en niños con IRAB y AVNI. Fue aceptable en cuanto a duración del ayuno, pero la etapa de alimentación por sonda fue más larga que lo propuesto. Hubo asociación positiva entre ambas duraciones y la evolución de estos pacientes.

Presentado en: No

Fuente de financiamiento: Sin financiamiento

\section{Tracheal suctioning does not prevent meconium aspiration syndrome (MAS).}

Fabres J ', Urzúa S ${ }^{1}$, Campbell S 1', Szyld E ².

'Departamento de Neonatología, División de Pediatría, Pontificia Universidad Católica de Chile. ${ }^{2}$ Pediatrics, University of Oklahoma Health Sciences Center.

Background: Currently, insufficient evidence exists that endotracheal suctioning of infants born through meconium stained amniotic fluid (MSAF) prevents MAS. Over the last 16 years, International Resuscitation Guidelines (IRG) have changed. Prior to 2000, universal suctioning was recommended. After 2000, suctioning was only recommended for depressed newborns. In 2010, it was found that insufficient evidence supported this practice. Finally, in 2015 IRG recommendation for endotracheal suctioning was eliminated. Objective: To evaluate whether there has been a change in tracheal 
suctioning in newborns with MSAF, if the incidence of MAS and other respiratory disorders (ORD) have changed and if the tracheal suctioning is associated with difficulties during transition. Design/ Methods: Single-center study of electronically captured data on all deliveries between 1-1-2007 and 12-31-2015. All live births born through MSAF were included. Two periods were compared, before and after 2010 IRG (2007-2010 vs 2011-2015). The proportion of infants intubated for tracheal suctioning and the incidence of MAS and ORD were compared. The impact of tracheal suctioning on respiratory transition, was evaluated by comparing 1-minute Apgar scores between intubated and non-intubated infants. Statistical significance was estimated using contingency tables and calculating p-values using Fisher's exact or Chi Square test. Results: During the 9 years included in the study, 20,615 babies were born, 2,229 of them (10.8\%) through MSAF. There was no difference between the 2 periods in the incidence of MSAF (10.7 vs $10.9 \%$; $p=0.61$ ). The proportion of newborns born through MSAF that were intubated for tracheal suctioning significantly declined in the second period (31 vs $23 \%$; $p<0.0001$ ). However, the incidence of MAS (1.9 vs $1.3 \%$; $\mathrm{p}=0.29$ ) and of MAS or ORD (2.4 vs $1.8 \% ; \mathrm{p}=0.45$ ) were not different. During both periods, babies intubated for meconium suctioning had a significant higher proportion of a 1-minute Apgar score $\leq 3$ (34.7 vs $4.0 \% ; \mathrm{p}<0.0001)$. Conclusion(s): Tracheal suctioning declined between the 2 periods, consistent with IRG recommendations. This decrease was not followed by an increase in the incidence of MAS or ORD. The higher proportion of a low 1-minute Apgar score in the intubated babies, could represent either the newborn's initial physiological state or the negative impact of this procedure on the newly born infant's transition. These results provide support for the current recommendation of not routinely intubating and suctioning babies born through MSAF to prevent MAS.

Presentado en: No. Se envió a PAS Meeting 2017

Fuente de financiamiento: Sin financiamiento

\section{Helicobacter pylori infection in mothers modifies fecal microbiota in their newborns according to the delivery route.}

Hernandez $C^{1}$, Shin $\mathrm{H}^{2}$, Troncoso $\mathrm{P}^{1}$, Catalano D ${ }^{2}$, Gandonu S ${ }^{2}$, Ortiz M ${ }^{1}$, Serrano C ${ }^{1}$, Dominguez-Bello GM ${ }^{2}$, Harris PR ${ }^{1}$.

${ }^{1}$ Department of Pediatric Gastroenterology and Nutrition, Pontificia Universidad Católica de Chile School of Medicine and ${ }^{2}$ New York University School of Medicine, USA.

Background: Interactions of resident intestinal microbes with the luminal contents and the mucosal surface play important roles in normal intestinal development, nutrition and immunity. Long-standing infections such as gastric $\mathrm{H}$. pylori modify the gastric microbiota and might modify fecal microbiota composition. Objective: To evaluate the fecal microbiota of mother-child pairs and its relation to $\mathrm{H}$. pylori status. Methods: Consecutive mothers and their newborns were recruited in the maternity unit, immediately after delivery. After signing informed consent, we take one stool sample of the mother before hospital discharge and one stool sample of the newborns at home (15 days old). Maternal H. pylori status was evaluated by $\mathrm{H}$. pylori antigen detection (Platinum HpSA, Meridian Diagnostics, Ohio, USA). Collected samples were stored at $-80^{\circ} \mathrm{C}$ until processing. The $\mathrm{V} 4$ region of the $16 \mathrm{~S}$ rRNA gene was sequenced using Illumina MiSeq platform. Sequences were analyzed using the QIIME pipeline. Results: 22 mother-child pairs were recruited and 11 of them have positive maternal $\mathrm{H}$. pylori status (50\%). Thirteen babies were vaginally delivered and 9 were born by C-section. All babies were fully breastfed. H. pylori was not detected in the feces of newborns. The analyses showed that there were differences in the structure of the microbiota by maternal $\mathrm{H}$. pylori status only in infant feces born vaginally (PERMANOVA, $p=0.01$ ). Although with similar bacterial alpha diversity level, infants born vaginally to $\mathrm{H}$. pylori-infected mothers had higher abundance of Enterobacteriaceae and Veilonella (LEfSe analysis, LDA > 3.0-fold). Conclusions: Maternal H. pylori status affects the fecal microbiota composition in babies born by vaginal delivery, but not in babies born by $\mathrm{C}$-section. The results suggest that the effect of the maternal $\mathrm{H}$. pylori on the infant fecal microbiota is mediated by the acquired vaginal microbiota at birth.

Presentado en: V World Congress of Pediatric Gastroenterology, Hepatology and Nutrition 2016.

Fuente de financiamiento: FONDECYT\# 1130387

\section{Aporte del laboratorio en el diagnóstico de la infección por virus zika. Experiencia en un país no endémico}

Perret C', Vizcaya C'1, Medina R'1, Contreras AM, Martínez C, García Ty Ferrés $M^{1}$.

'Depártamento de Enfermedades Infecciosas e Inmunología Pediátrica

La introducción del virus Zika (ZIKV) a América se conoció en mayo de 2015. A fines de ese año Brasil alerta la probable relación entre la epidemia y la microcefalia congénita. Desde entonces se ha presentado circulación autóctona en 42 países en todo el 
continente. Los viajeros están expuestos al viajar a zonas de riesgo. El diagnóstico serológico es difícil dado la reacción cruzada por la similitud antigénica entre ZIKV y virus dengue (DENV), ambos flavivirus. Objetivo: Describir el comportamiento de la PCR de ZIKV. Evaluar reacción cruzada entre serología de ZIKV y DENV y sugerir algoritmo diagnóstico. Metodología: Se analizaron las muestras de pacientes enviados para diagnóstico de dengue o Zika al laboratorio de Infectología y virología molecular de la Pontificia U. Católica de Chile, desde marzo a mayo, 2016. A Todos los pacientes se les realizó IgM dengue y ZIKV. En el caso de ambas IgM positivas se incluyó para análisis solo a aquellos que se pudo determinar el verdadero positivo. Algunos pacientes fueron enrolados para una cohorte de seguimiento clínico y de laboratorio por el período de 2 meses. Para la PCR de ZIKV se utilizó una técnica in house con el protocolo del CDC. Para lgM de dengue se utilizó la técnica de ELISA usando el kit comercial Focus ${ }^{\circledR}$ y para ZIKV la técnica de ELISA con el kit de Euroimmune ${ }^{\circledast}$. Resultados: Se analizaron 35 muestras de pacientes. 16 pacientes fueron IgM (+) DENV y 9 pacientes IgM ZIKV (+). 3 pacientes ZIKV (+) (33\%) también tuvieron IgM DENV (+) estableciéndose como casos verdaderos de ZIKV; En dos de ellos por seroconversión IgG ZIKV e IgG DENV (-) y el tercero por nexo epidemiológico con caso ZIKV confirmado por PCR. A 8 pacientes enrolados en la cohorte de seguimiento se les realizó PCR ZIKV. 5 tuvieron PCR (+), con sensibilidad global de 71\%. En los con PCR con menos de 5 días de enfermedad el 100\% la tuvo positiva. 3 pacientes fueron PCR (-), una de ellos fue IgM (+) para DENV e IgM (-) para ZIKV y 2 de ellos con IgM (+) para ZIKV y DENV y en el seguimiento uno fue ZIKV IgG (+) y DENV IgG (-) y 1 caso con nexo epidemiológico con caso de ZIKV confirmado por PCR. El promedio de días de evolución de los PCR (+) fue de 3,2 días, y el de los PCR negativo fue de 6 días. $P<0,00001$. En 6 pacientes con seguimiento con IgG ZIKV y DENV, ninguna IgG resultó positiva antes de los 14 días, en 2 ambas IgG fueron positivas, una por dengue previo y la otra con absorbancia de ZIKV mucho más alta que la de IgG DENV. Conclusiones: En un país no endémico para la circulación de flavivirus proponemos para diagnóstico inicial de infección por Zika realizar PCR antes de los 5 días de enfermedad dada su sensibilidad cercana al $100 \%$. Pasado esos días IgM ZIKV y DENV dado que la reacción cruzada sería cercana a un tercio. Si IgM ZIKV (+) y DENV (-) se hace el diagnóstico de infección por virus Zika. Si ambos son positivos debería seguirse con IgG ZIKV y DENV a los 14 días de evolución. Seroconversión de IgG ZIKV solamente hace el diagnóstico de Zika. Si ambos son positivos se puede utilizar la diferencia en la absorbancia.

Presentado en: Sociedad Chilena de Infectología

Fuente de financiamiento: Laboratorio de Infectología y Virología Molecular

\section{Resonancia nuclear magnética de cuerpo entero en pacientes con sospecha de enfermedades neuromusculares hereditarias en una cohorte chilena}

Avila Smirnow $D^{1,2,}$ Contreras Olea O ${ }^{3}$, Caicedo Feijoó A ${ }^{4}$, Beytía Reyes $\mathrm{M}^{1,2}$, Gejman Enríquez $\mathrm{R}^{6}$, Rendu J ${ }^{6}$, de Becdelievre $\mathrm{A}^{7}$, Boutron $A^{8}$, Escobar Henríquez $R^{2}$

' Unidad e Neurología del Servicio de Pediatría del Complejo Asistencial Dr. Sotero del Río. ${ }^{2}$ Unidad de Neurología de la División de Pediatría de la Escuela de medicina de la Pontificia Universidad Católica de Chile. ${ }^{3}$ Departamento de Radiología de la Pontificia Universidad Católica de Chile. ${ }^{4}$ Servicio de Imagenología del Complejo Asistencial Dr. Sótero del Río. ${ }^{5}$ Departamento de anatomía patológica de la Pontificia Universidad Católica de Chile. ${ }^{6}$ UF de Biochimie et Génétique Moléculaire du Département de Biochimie Pharmacologie Toxicologie du CHU de Grenoble-Université Grenoble Alpes. 'UF Cardiogénétique et Myogénétique du Centre de Génétique du GH Pitié Salpêtrière. 8 Laboratoire de biochimie du GHU Paris-Sud - Hôpital de Bicêtre

Introducción La resonancia nuclear magnética de cuerpo entero (RNM-CE) es de gran utilidad en el estudio diagnóstico de diversas enfermedades neuromusculares (ENM), sin embargo es aún subutilizada nacional e internacionalmente. Objetivos Describir los hallazgos en RNM-CE en pacientes con sospecha de ENM en el Complejo Asistencial Dr. Sótero del Río (CASR) y la Red de Salud UC-Christus (RSUCC) y su utilidad en la clínica. Métodos Se realizó un estudio colaborativo descriptivo retrospectivo mediante revisión de fichas clínicas en el CASR y la RSUCC. Los pacientes fueron estudiados mediante evaluación clínica, histopatológica y RNM-CE, según indicación clínica, análisis molecular. Se aplicó un protocolo de RNM-CE que incluyó cortes axiales y coronales en T1 y STIR. Se analizaron 45 músculos en cada examen, mediante una escala de severidad (Mercuri). Resultados Entre octubre 2013 y julio 2016, 11 pacientes ( 6 hombres, 5 mujeres) fueron estudiados mediante este protocolo de RNM-CE. La edad promedio fue 11 años (rango 1-19). Los hallazgos imagenológicos, clínicos e histopatológicos permitieron orientar o validar el estudio genético en 6 casos: 3 con estudio genético realizado (genes NEB y CPT2) y 3 con estudio genético en curso (genes RYR1, TPM2, SEPN1). En 2 pacientes las anomalías imagenológicas fueron leves e inespecíficas y en 3 fueron normales, permitiendo excluir etiologías determinadas. Conclusión En la mayoría de los casos la RNM-CE fue de utilidad en el enfrentamiento clínico del paciente, orientando o validando el diagnóstico genético. Pensamos que este examen debiese utilizarse sistemáticamente en el estudio de las ENM hereditarias.

Presentado en: SOPNIA 2016

Fuente de financiamiento: No declara 


\section{Prenatally diagnosed congenital diaphragmatic hernia: Optimal Mode of Delivery?}

Mesas Burgos C, Frencknera B, Luco M, Harting MT, Lally PA, and Lally KP

a Department of Pediatric Surgery, Karolinska Institutet, Stockholm, Sweden, bDepartment of Neonatology, Pontificia Universidad Católica de Chile c Department of Pediatric Surgery, McGovern Medical School at UT Health and Children's Memorial Hermann Hospital, Houston, TX, US

Objective: To evaluate if the delivery mode of infants with prenatally diagnosed congenital diaphragmatic hernia (CDH) affects outcome. Study design: Data from the CDH Study Group database of infants with prenatal diagnosis between 2001-2015 was divided into 4 delivery mode groups: vaginal spontaneous, vaginal induced, elective caesarean (CS) section, emergent caesarean section. Outcomes were analyzed in relation to the time of day of delivery and the gestational age at birth. Results: 3906 cases of prenatally diagnosed $\mathrm{CDH}$ were assessed, with an overall survival of $64 \%$. There were no differences in patient characteristics, requirement for ECMO, length of hospital stay or intubation, requirement for $\mathrm{O} 2$ at 30 days or overall survival. The time of day at birth did not affect outcome. There was no difference in outcome between the different delivery modes at similar GA at birth, with worse outcomes at lower GA. Conclusions: Neither the mode nor time of delivery seem to affect the overall outcome for patients with prenatally diagnosed $\mathrm{CDH}$. Outcome is strongly associated with the GA at birth.

Presentado en: World Federation of Associations of Pediatric Surgeons meeting 2016

Fuente de financiamiento: No declara

\section{Incidencia de alergia alimentaria postransplante de células de cordón umbilical no relacionadas en niños.}

Hernandez AA, N Rojas, F Barriga, M Wietstruck, P Morales, A Borzutzky.

Departamento de Enfermedades Infecciosas e Inmunología Pediátrica y Sección de Hematología y Oncología, División de Pediatría, Escuela de Medicina, Pontificia Universidad Católica de Chile.
Introducción: El desarrollo de alergia alimentaria (AA) posterior a transplante de precursores hematopoyéticos de cordón umbilical (TPHCU) es un fenómeno infrecuente sin etiología clara, probablemente secundario a una reconstitución inmune desregulada. Objetivos: Determinar la incidencia y describir las características clínicas de AA post TPHCU en un centro terciario pediátrico chileno. Material y métodos: Revisión retrospectiva de casos de pacientes pediátricos que recibieron TPHCU entre los años 1996 y 2015. Resultados: Tres de 94 niños desarrollaron AA post TPHCU. Caso 1: Niña de 6 años, sin antecedentes de AA, inicia terapia para leucemia linfoblástica aguda (LLA), por recaída recibe TPHCU. 3 meses postransplante tuvo anafilaxia 20 minutos post ingesta de huevo, IgE específica huevo $55 \mathrm{kU} / \mathrm{L}$. 15 meses postransplante aún evita el alimento implicado. Caso 2: Niña de 13 años, sin antecedentes de AA, tratada por leucemia mieloide aguda, TPHCU por recaída. 3 meses postransplante presenta anafilaxia a los 30 minutos post ingesta de huevo, IgE específica 3,5 kU / L, luego al recibir almendras tuvo vómitos muy intensos a los $15 \mathrm{~min}$ con lgE específica de $26 \mathrm{Ku} / \mathrm{L}$, con lácteos presentó anafilaxia a los $30 \mathrm{~min}$ con IgE especifica de $5.7 \mathrm{Ku} / \mathrm{L}$. 12 meses postransplante se reporta completa tolerancia a huevo y lácteos, aún evita frutos secos. Caso 3: Varón 3 años, sin antecedentes AA, tratado por LLA de muy alto riesgo por lo que recibe TPHCU. 3.5 meses postransplante presenta cuadro de vómitos, dolor abdominal y diarrea a los 30 minutos post ingesta de huevo, IgE específica 3,33 kU/L. 9 meses postransplante logra tolerancia total al huevo. Conclusiones: La incidencia de AA post TPHCU fue de 3.1\%, predominando la alergia al huevo. Esta incidencia en niños es menor a la reportada recientemente en adultos con AA post TPHCU en Japón (6.6\%). Se requieren mayores estudios para dilucidar los factores de riesgo y la patogénesis de esta complicación.

Presentado en: XXVII Congreso Internacional Sociedad Chilena de Alergia e Inmunología

Fuente de financiamiento: NA

\section{Primary immunodeficiency epidemiology in Chile evaluated through ICD-10 coded hospital admissions.}

Poli C, Hoyos-Bachiloglu R, Borzutzky A.

Departamento de Enfermedades Infecciosas e Inmunología Pediátrica, Escuela de Medicina, Pontificia Universidad Católica de Chile. 
Background: The epidemiology and admission trends of primary immunodeficiency (PID) in Chile are unknown. Methods: ICD10-coded PID admissions between 2001-2010 in Chile were reviewed using national hospital discharge databases. Results: During the study period, 5486 admissions due to PID were registered. $58.5 \%$ of patients were male and $66.3 \%$ were $<18$ years. Median length of stay was 1 day (range 1-403 days). Most frequent diagnoses were hypogammaglobulinemia (27.6\%), unspecified immunodeficiency (21.9\%), hemophagocytic lymphohystiocytosis (18.3\%) and CVID (11.2\%). There was a significant increase in PID admission rate and 1 -day admissions during this period $(B=0.2 ; P=0.001$ and $B=33$; $P \leq 0.001$, respectively), however no significant variation was found for $>1$ day admissions $(B=4.8 P=0.18)$. The increasing trend in PID admission rate was significant in patients with private, but not public insurance $(B=0.53 P \leq 0.001$ vs. $B=0.08 P=0.079$, respectively). Conclusions: We report an increasing trend in PID admissions in Chile over a 10-year period. Increase is mainly due to short admissions, possibly accounting for improvements in IVIG access. Higher admission rates in patients with private insurance suggest socioeconomic disparities in access to treatment. The evaluation of ICD-10 coded admissions may prove a useful tool to assess the epidemiology of PID in other countries worldwide.

Presentado en: 2016 CIS Annual Meeting: Immune Deficiency \& Dysregulation North American Conference

Fuente de financiamiento: Millennium Institute on Immunology and Immunotherapy (Chile) grant P09/016-F.

\section{Case-control study of the association of obesity and abdominal obesity with atopic dermatitis in Chilean children.}

Iturriaga C, Bustos MF, Le Roy C, Cifuentes L, Silva- Valenzuela S, Vera-Kellet C, Cristi F, Pérez-Mateluna G, Cabalin C, HoyosBachiloglu R, Camargo CA, Borzutzky A.

Departamentos de Enfermedades Infecciosas e Inmunología Pediátrica, Pediatría, Dermatología, Gastroenterología y Nutrición Pediátrica, Escuela de Medicina, Pontificia Universidad Católica de Chile. Department of Emergency Medicine and Division of Rheumatology, Allergy, and Immunology, Department of Medicine, Massachusetts General Hospital, Harvard Medical School, Boston, USA.

Background: Overweight and obesity have been associated with higher rates of atopic dermatitis (AD), and some investigators have proposed recent increases in obesity as a possible explanation for concurrent increases in AD prevalence. However, studies to date show conflicting results and there is little information on this association in Latin America. Objective:To evaluate the association of nutritional status and abdominal obesity with AD in Chilean children. Methods: We conducted a case-control study in 101 children with AD and 101 healthy controls (HC). Overweight was defined as BMI-for-age Z-score $\geq+1$ and $<+2$ and obesity as BMI-for-age Z-score $>+2$ as per WHO standard definitions. Abdominal obesity was defined as waist circumference/height ratio $(W H R)>0.5$. AD severity was assessed by SCORAD. Eosinophil blood counts, total IgE, and 25-hydroxyvitamin D (25OHD) were measured in children with AD. Results: Median age was 5 years (interquartile range $3-9$ ) in cases and controls ( $P=0.91$ ). $53 \%$ of children with $A D$ and $48 \%$ among $\mathrm{HC}$ were female $(\mathrm{P}=0.48)$. No significant differences in terms of BMI Z-score were found between children with $A D$ and $\mathrm{HC}$ (mean BMI-for-age Z-score $+1.1 \pm 1.3$ vs. $+1.2 \pm 1.2, \mathrm{P}=0.40$ ). Among children with $\mathrm{AD}, 23 \%$ were overweight and $28 \%$ obese, while $28 \%$ of $\mathrm{HC}$ were overweight and $26 \%$ obese $(P=0.44$ and $\mathrm{P}=0.78$, respectively). No children had undernutrition (BMI Z-score $<-2)$. Sixty percent in each group had abdominal obesity $(P=0.95)$. Girls with AD had higher rate of abdominal obesity than $\mathrm{HC}(70 \%$ vs $52 \%$ ), while boys with AD had lower rate of abdominal obesity than $\mathrm{HC}$ (52\% vs 69\%), but neither comparison was statistically significant $(P=0.06$ and $P=0.09$, respectively). Children with $A D$ had slightly lower height-for-age Z-score than $\mathrm{HC}(-0.12 \pm 1.23$ vs. $+0.1 \pm 0.84, P=0.15)$, but this was significant only for children $<8$ years $(-0.19 \pm 1.1$ vs. $+0.23 \pm 0.87, P<0.02)$. Among children with $A D$ $\geq 8$ years, higher BMI Z-score was associated with higher SCORAD (rho=0.38, $\mathrm{P}<0.03$ ), and higher BMI Z-score and WHR correlated with higher eosinophil count ( $r h o=0.35$ and $r h o=0.38$, both $\mathrm{P}<0.05$ ). Higher BMI Z-score and WHR did not correlate with total IgE or 25OHD among children with AD. Conclusions: Chilean children with AD had similar rates of obesity and abdominal obesity rates as healthy controls. In older children, obesity and abdominal obesity were associated with increased AD severity.

Presentado en: $9^{\text {th }}$ Georg Rajka International Symposium of Atopic Dermatitis 2016

Fuente de financiamiento: Fondo de Desarrollo Científico y Tecnológico Regular Proyecto Número 1130615

\section{Cytomrgalovirus inmune response follow up using Quantiferon- $\mathrm{Cmv}^{\circledR}$ in children during the first year after hematopoietic stem cell or solid organ transplantation; preliminary results}

Vizcaya C ${ }^{1}$, Le Corre ${ }^{1}$, Martinez-Valdebenito $C^{1,2}$, Barriga $F^{3}$, Urcelay $\mathrm{G}^{3}$, Contreras $\mathrm{M}^{3}$, Vidal $\mathrm{M}^{3}$, Dellepiane $\mathrm{P}^{3}$, Contreras $\mathrm{AM}^{2}$, Ferres M.,2 
${ }^{1}$ Departamento de infectologia e inmunología pediatrica División de Pediatría de la Pontificia Universidad Católica de Chile. ${ }^{2}$ Laboratorio de Infectologia y Virologia Molecular. ${ }^{3}$ Centro del Cancer, Red de Salud UC Christus.

Introduction: Human Cytomegalovirus (HCMV) infection significantly contributes to morbidity and mortality in hematopoietic stem cell (HSCT) and in solid organ transplant (SOT) patients. CMV naïve SOT recipients from a CMV positive donor are at the highest risk of CMV-related complication. Meanwhile, CMV positive recipients in HSCT with naive donor present a higher risk of reactivation. The specific immune response against HCMV, particularly during the first month after transplantation, is impaired and preemptive or prophylactic anti HCMV strategies are needed. However, these strategies need close monitoring of viral load and are associated with viral resistance and drug toxicity. At the same time, immunosuppressive drugs induce the loss of immune control over HCMV and frequently are associated with impaired CD8 T cell function. QuantiFERON-CMV ${ }^{\circledR}$ is able to detect HCMV specific T lymphocytes in blood by measuring IFNY production with an ELISA test. QuantiFERON-CMV ${ }^{\circledR}$ has been used in immunocompromised adults to address immune specific response against HCMV, but there is limited information about its use in children after transplantation. Objective: To establish QuantiFERON ${ }^{\circledR}$-CMV levels in children with HCMV infection during the first year after HSCT or SOT. Methods: We included children after 6 weeks of HSCT and 3 month of SOT, with HCMV sero-positive status in donor and/or recipient. QuantiFERON-CMV ${ }^{\circledR}$ was performed every month for HSCT and every two months for SOT, during the first year post transplant. The results were expressed as optic density (OD) obtained with HCMV antigens stimulation minus OD obtained from negative control (nil), as recommended by manufacturer: HCMV minus nil $\geq 0.2 \mathrm{UI} / \mathrm{ml}$ was interpreted as a reactive test. When were available, we registered the following laboratory parameters: HCMV viral load, lymphocyte count and tacrolimus or cyclosporine blood levels. Results: Three patients receiving an HSCT were included ( 2 umbilical cord blood and 1 related donor). All receptors had a seropositive HCMV status and the related donor was negative. Two patients with cardiac transplant were included, both donors had positive HCMV IgG and one receptor was negative. Among HSCT recipients, one patient with a seronegative HCMV related donor had QuantiFERON ${ }^{\circledR}-\mathrm{CMV}$ levels below $0.2 \mathrm{UI} / \mathrm{ml}$ during the first 8 months of follow up, despite of which no HCMV reactivation was observed. The second patient presented a reactive QuantiFERON ${ }^{\circledR}-C M V$ after 3 months of transplantation. However, the test showed levels below $0.2 \mathrm{UI} / \mathrm{ml}$ from the 4th until 6th month after transplantation without $\mathrm{HCMV}$ reactivation. The third patient presented an indeterminate result at 6 weeks after transplantation, but with undetectable HCMV viral load. Among SOT recipients, one patient presented a reactive QuantiFERON ${ }^{\circledR}-\mathrm{CMV}$ since the 3rd month after transplantation and with no HCMV reactivation. The patient with seronegative IgG presented QuantiFERON ${ }^{\circledR}-{ }^{-C M V}$ levels below $0.2 \mathrm{UI} / \mathrm{ml}$ from the 3rd month to the 6th months after transplantation, with concomitant positive HCMV viral loads, requiring preemptive therapy with gancyclovir and foscarnet. At 7th month, QuantiFERON ${ }^{\circledR}-C M V$ levels was $0.26 \mathrm{UI} / \mathrm{ml}$ and HCMV viral load was undetectable with no therapy. Even if there was a tendency of higher QuantiFERON ${ }^{\circledR}$-CMV levels in patients with higher lymphocyte counts and/or lower immunosuppressive drugs levels, no significant correlation was observed between these parameters. Conclusions: No HCMV reactivation was observed in this pediatric population with reactive QuantiFERON ${ }^{\circledR}-\mathrm{CMV}$ (levels above $0.2 \mathrm{UI} /$ $\mathrm{ml}$ as recommended by the provider). Finding HCMV specific and functional lymphocytes using QuantiFERON ${ }^{\circledR}-C^{-} M V$ seems to depend on donor and recipient CMV sero-status and immunosuppressive drugs levels. More patients need to be recruited and followed in order to confirm this hypothesis.

Presentado en: IV Intl Clinical Virology Sym \& Advances in Vaccines, BBAA

Fuente de financiamiento: Fundación Nuestros Hijos, División

Pediatría Hospital Clínico Pontificia Universidad Católica de Chile

\section{Diagnóstico nutricional en lactantes menores con cardiopatía congénita: comparación de dos clasificaciones antropométricas.}

Le Roy C, Larios G, Springmüller D, Clavería C

Departamento de Gastroenterología y Nutrición Pediátrica, Departamento de cardiología y Enfermedades Respiratorias Pediátricas, División de Pediatría, Escuela de Medicina, Pontificia Universidad Católica de Chile.

Introducción: Los niños con cardiopatía congénita (CC) presentan un alto porcentaje de malnutrición por déficit y talla baja, siendo difícil la interpretación del estado nutricional. Objetivo: Describir el estado nutricional de lactantes con CC utilizando dos diferentes clasificaciones nutricionales y realizar una comparación entre ellas. Pacientes y método: Estudio de cohorte no concurrente. Se estudiaron menores de 12 meses, desde enero del 2009 a diciembre del 2013, sometidos a cirugía de su CC del Centro Cardioquirúrgico del Hospital Clínico de la Pontificia Universidad Católica de Chile. Criterios de exclusión: prematurez, pequeño para la edad gestacional, 
poseer un síndrome genético u otra enfermedad que comprometa el estado nutricional. Se registraron datos demográficos, edad al momento de la cirugía, diagnóstico de CC, peso y talla del ingreso. Se realizó evaluación nutricional según criterios MINSAL y una clasificación antropométrica integrada (CAI) que define desnutrición si $Z T / E<-2 D S$ y/o ZP/T<-2DS, riesgo de desnutrición ZP/T entre -1 a -1,9DS, eutrofia ZP/T entre -0,9 a +0,9DS, sobrepeso entre +1 a +1,9DS y obesidad ZP/T >+2DS. Se utilizaron estándares OMS. Resultados: Se incluyeron 387 intervenciones, 219(56,6\%) fueron varones, mediana de edad de 3,1 meses (RIC:0,4;6,4). Las CC más frecuentes fueron comunicación interventricular 78(20,2\%), Sindrome Ventrículo Izquierdo hipoplásico (SVIH) 74(19,1\%) y Tetralogia de Fallot 48 (12,4\%).Tuvieron más de una intervención 49 niños, siendo el diagnóstico más frecuente el SVIH (46,6\%). Se encontró una mediana para ZP/E de -1,2(RIC: -2,2;-0,2) y un promedio para ZP/T de -0,5+1,6DS. El ZT/E tuvo una mediana de -1,2(RIC:-2,0;-0,4), 102 sujetos $(26,4 \%)$ presentaron talla baja (ZT/E<-2DS). Al realizar el diagnóstico nutricional según criterios MINSAL 55 sujetos presentaron dos diagnósticos por superposición entre ZP/E y ZP/T, se priorizó ZP/E sobre ZP/T para diagnosticar deficiencia y para exceso ZP/T sobre eutrofia según ZP/E. Al utilizar CAI ninguno tuvo más de un diagnóstico nutricional. Al comparar MINSAL con CAI se encontró diferencia en desnutrición 112(28,9\%) versus $149(38,5 \%) \mathrm{p}=0,001$, riesgo de desnutrición $106(27,4 \%)$ versus $63(16,3 \%) p=0,01$ y obesidad $19(4,9 \%)$ versus $13(3,3 \%) p=0,03$ respectivamente. Se encontró correlación positiva entre $Z P / E$ y $Z P / T$ con un $r=0,6(p<0,001)$ y también entre $Z P / E$ y $Z T / E r=0,6$ $(p<0,001)$, destacándose que presentaron talla baja el 55,4\% de los niños con $Z P / E<-2 D S$, el 30,2\% de los niños con ZP/E entre $-1,9$ a $-1 D S$ y $5 \%$ de los niños con ZP/E entre -0,9 a +0,9DS. Conclusiones: Los niños con CC presentan un alto porcentaje de desnutrición y talla baja. Utilizando las mismas mediciones antropométricas la clasificación CAI no presentó superposición de diagnósticos, fue más completa y detectó mayor porcentaje de desnutrición. El $\mathrm{P} / \mathrm{E}$ es útil como herramienta de screening nutricional, pero sería insuficiente en niños con malnutrición crónica.

Presentado en: Congreso de Sociedad Chilena de Pediatría 2016 Fuente de financiamiento: Sin necesidad de financiamiento

\section{Evaluación ecocardiográfica funcional con strain en pacientes pediátricos luego de trasplante cardíaco ortotópico.}

Trincado C, Urcelay G, Dellepiane P, Molina V

Unidad de Cardiología de la División de Pediatría de la Pontificia Universidad Católica de Chile
INTRODUCCIÓN El trasplante cardiaco es la terapia final de la falla cardiaca irreversible por cardiopatía congénita o adquirida. En el caso de los pacientes pediátricos, a las complejidades propias del trasplante cardíaco se suma la dificultad de encontrar donantes de peso adecuado al receptor. Tras un trasplante exitoso es necesario lograr una adecuada inmunosupresión a fin de evitar el rechazo. En caso de producirse, la detección precoz del rechazo es crucial para maximizar las probabilidades de éxito de su manejo. La evaluación ecocardiográfica es una herramienta diagnostica útil de seguimiento e intenta pesquisar en forma oportuna y consistente el rechazo, manifestado como disfunción miocárdica. Al no existir parámetros únicos de rechazo es necesaria la evaluación con múltiples parámetros. Se propone la evaluación de estos pacientes mediante un protocolo funcional de seguimiento que incluye la medición de strain longitudinal global (SLG). OBJETIVOS Detallar los hallazgos de la evaluación funcional ecocardiográfica con SLG en niños sometidos a trasplante cardíaco en la fase alejada (al menos 6 meses post-trasplante) y reconocer su estatus funcional actual. MATERIAL Y PACIENTES Estudio retrospectivo, descriptivo. Se analizaron registros clínicos y ecocardiográficos del grupo pediátrico sometido a trasplante cardíaco ortotópico en la PUC desde el 2001 a la fecha. Se realizó una evaluación ecocardiográfica anatómica y funcional, mediante un protocolo que incluye parámetros clásicos de función sistólica ventricular izquierda y derecha, y SLG de ventrículo izquierdo. Se consignó el resultado de la biopsia endomicárdica contemporánea a la evaluación ecocardiográfica. RESULTADOS Desde el 2001 se han trasplantado 14 pacientes, 10 de los cuales están vivos y adhieren al tratamiento, en capacidad funcional 1. Los 4 pacientes fallecidos se excluyeron del análisis por tener clara las causas de sus muertes: 1 por infección post-trasplante y 3 por suspensión de tratamiento. La mediana de edad al momento del trasplante fue de 13 años (3-15). Todos los diámetros ventriculares izquierdos, así como el grosor de las paredes son de tamaño normal. La fracción de acortamiento, la velocidad de acortamiento circunferencial y la fracción de eyección fueron normales en 8/10 pacientes. Uno de los pacientes con alteración de función sistólica por parámetros clásicos presentaba insuficiencia aórtica severa y disquinesia antero-septal. En relación a la evaluación con SLG, sólo 1 paciente presentó valores normales. No se observó una asociación clara entre la presencia de disfunción sistólica mediante SLG o parámetros clásicos y la presencia de rechazo. La función sistólica ventricular derecha medida por TAPSE fue normal en 2/9 pacientes, y en 3/9 pacientes al evaluarla mediante $S^{\prime}$ tricuspídea. En un paciente (cursando infección por citomegalovirus) se encontró derrame pericárdico. COMENTARIOS La evaluación ecocardiográfíca funcional en este grupo de pacientes trasplantados pediátricos nos permite ver una discrepancia entre parámetros clásicos y SLG. No hay una clara relación entre las al- 
teraciones ecocardiográficas y la presencia de rechazo. La función ventricular derecha se altera frecuentemente en estos pacientes, hecho reportado en la literatura. Es necesario un seguimiento de estos pacientes mediante el protocolo funcional reportado, a fin de definir la persistencia de las alteraciones descritas en el tiempo y su relación con la evolución clínica.

Presentado en: XXVI Congreso anual de la Sociedad Interamericana de Cardiología y Cirugía Cardiovascular

Fuente de financiamiento: No se declaran fuentes de financiamiento

\section{Caracterización de la evaluación clínica y videofluoroscopica de la deglución, en un grupo de pacientes con enfermedades neuromusculares pediatricas}

Salinas, L , González C, Beytia M, Ávila D y Escobar R.

'Programa de Enfermedades Neuromusculares, Unidad de Neurodesarrollo, Hospital Clínico, Red de Salud UC-CHRISTUS; 2) Unidad de Neurología, División de Pediatría, Escuela de Medicina. Pontificia Universidad Católica de Chile; 3) Escuela de Fonoaudiología. Pontificia Universidad Católica de Chile.

Introducción: Las Enfermedades Neuromusculares (ENM) pueden determinar Trastornos de Deglución (TD), y ello causar importante morbilidad asociada. Un diagnóstico adecuado y precoz de TD en ENM es necesario. Objetivo: Determinar utilidad de escala clínica de evaluación de la deglución (ECEDUC) en pacientes pediátricos con ENM. Método: Estudio prospectivo analítico de cohorte en pacientes que asisten regularmente al Policlínico de ENM pediátricas del Hospital Clínico de la P. Universidad Católica de Chile. Evaluación Clinica de Deglución se hizo con pauta ad hoc (ECDUC) y Escala clínica de Fujishima (FILS), además se evaluó deglución con Videofluoroscopia (VDF). Deglución se clasificó como normal (sin TD), TD leve (TDL), TD moderado (TDM) o TD grave (TDG). Resultados: Hasta julio 2016 se evaluaron 45 pacientes $(33$ hombres, 12 mujeres), edad promedio: 9 años 2 meses (rango: 1 a 21 años). Las ENM fueron: 14 DMD, 1 DMB, 2 FSH, 4 DMC, 15 Miopatías Congénitas, 3 AME III, 2 CMT, 2 DM1, 2 Miastenias. A los 45 pacientes se les evaluó con ECDUC y FILS y a 15 con VDF. En evaluación con ECDUC 35 fueron clasificados como normal, 9TDL, 1 TDM y 3 TDG. El nivel de concordancia de ECDUC con FILS fue alto (a de Cronbach $=0,799, p<0,001$ ) y también con VDF ( $a$ de Cronbach $=0,984, p<$ 0,001). Comparando EDCUC con VDF la sensibilidad fue de $100 \%$ y la especificidad 87,5\%. Conclusión: La evaluación clínica a través de la pauta de evaluación ECEUC, muestra ser un buen instrumento clínico para evaluar deglución en pacientes pediátricos portadores de enfermedades neuromusculares.

Presentado en: Sopnia 2016

Fuente de financiamiento: Propios

\section{Utilidad clínica del tromboelastograma en distintas patologías en pacientes pediátricos}

Sepúlveda P, Zúñiga P

Unidad de Hematología-Oncología Pediátrica de la Pontificia Universidad Católica de Chile

Introducción: La tromboelastografía (TEG) es un test de coagulación global que mide las propiedades viscoelásticas de la sangre al lado de la cama del paciente (point of care). Permite conocer la interacción de los distintos componentes de la coagulación, evaluando factores de coagulación e inhibidores (Tiempo R), generación de trombina y formación del coágulo (tiempo Ky ángulo alfa), interacción plaquetas y fibrinógeno (amplitud máxima (MA)) y la fibrinólisis mediante la rapidez de destrucción del coágulo. Su aporte es mostrar una idea global de la fisiología de la hemostasia en coagulopatías complejas, ya que la determinación de estas alteraciones resulta complicada con pruebas de coagulación convencionales (TP y TTPa, recuento de plaquetas y fibrinógeno) que evalúan la coagulación en forma parcial. En adultos se ha demostrado su utilidad en coagulopatías por trauma, cirugía cardiaca, trasplante hepático y cirugía ortopédica mayor. En pacientes pediátricos existe escasa evidencia sobre su utilidad y su uso es limitado. En nuestro centro se comenzó a utilizar hace 2 años en pacientes pediátricos que cursaban con patologías graves, experiencia a mostrar en este trabajo. Objetivo: Describir nuestra experiencia con uso de TEG en distintas patologías en unidad de cuidados intensivos pediátrica (UCIP) y neonatal (UCIN) Materiales: Estudio Descriptivo. Se revisaron los TEG realizados entre junio 2015 y junio 2016 en pacientes menores de 18 años hospitalizados en UCIP y UCIN, extraídos desde la base de datos de TEG, selecionándose aquellos que tuvieran en forma simultánea estudio de la coagulación convencional. Se tabuló y analizó los datos con SPSS $23^{\circledR}$. Se correlacionó con Spearman-rank distintos parámetros de TEG con los valores de los exámenes habitualmente solicitados para evaluar la coagulación (pruebas de coagulación, plaquetas y fibrinógeno). Significancia estadística $p<0,05$. Resultados: Se revisó un total de 68 TEG realizados a 20 pacientes con diversas patologías,con edades entre 6 días de vida hasta 17 años (Media de 61 meses). Los resultados de las 
correlaciones ( $\mathrm{r}$ ) fueron: tiempo R alterado (> $8 \mathrm{~min}$ ) versus TTPa (73 \pm 40 segundos $(s)): r$ 0,55 ( $p=0,027)$; tiempo $R$ normal versus $\operatorname{TTPa}(51 \pm 28(\mathrm{~s}))$ r 0,45 ( $<<0,01)$. Para MA y recuento de plaquetas disminuido $\left(<150.000 / \mathrm{mm}^{3}\right)$ : $r$ 0,54 $(\mathrm{p}<0,01)$. Para MA y recuento de plaquetas normal $\left(150.000-400.000 / \mathrm{mm}^{3}\right)$ : $r$ de 0,62 $(p<0,01)$ Para MA y fibrinógeno disminuido ( $<200 \mathrm{mg} / \mathrm{dL})$ : $\mathrm{r} 0,59(\mathrm{p}<0,01)$ y para MA con fibrinógeno normal: $r 0,1(p=0,7)$ Conclusiones: Si bien es un grupo pequeño de pacientes, con patología heterogénea, el análisis de 1 año de experiencia nos permite ver la baja correlación que existe entre las pruebas convencionales de coagulación con TEG. Esto se explica porque los elementos con que contamos habitualmente (TP, TTPa, recuento de plaquetas y fibrinógeno) entregan información parcializada y que no muestra el rebalance hemostático que se produce en muchas situaciones clínicas que se manejan en cuidados intensivos.

Presentado en: Sociedad Chilena de Pediatría

Fuente de financiamiento: sin financiamiento

\section{Novel insight into Andes Hantavirus-host relationship; from basic to translational science.}

López-Lastra M

Departamento de Infectología e Inmunología Pediatrico, Instituto Milenio de Inmunología e Inmunoterapia, Laboratorio de Virología Molecular, Escuela de Medicina, Pontificia Universidad Católica de Chile, Santiago, Chile.

Andes virus (ANDV), a rodent-borne hantavirus member of the Bunyaviridae family of viruses endemic in Argentina and Chile, is the major etiological agent of hantavirus cardiopulmonary syndrome (HCPS) in South America. ANDV is the only known Hantavirus to be transmissible from human to human. In this presentation novel aspects of ANDV replication will be discussed. Special focus will be given to the analysis of the ANDV small messenger RNA (SmRNA), which in contrast to most cellular mRNA lacks a poly(A) tail. Additionally, the SmRNA encodes two proteins the nucleocapsid (N) protein and also a non-structural protein (NSs) using a non-canonical cap-dependent translation initiation mechanism. These and other features will be analyzed. Finally, the relationships between ANDV induced disease and the infected hosts' genotype will be discussed.

Presentado en: SI

Fuente de financiamiento: Comisión Nacional de Investigación Científica y Tecnológica de Chile (CONICYT) through Programa Investigación Asociativa (PIA) ACT1408 and P09/016-F of Iniciativa Científica Milenio del Ministerio de Economía, Fomento y Turismo

\section{La síntesis de las proteínas SpHBZ y UsHBZ del Virus linfotropico humano de tipo 1 (HTLV-1) esta sujeta a control traduccional por distintos mecanismos de inicio de la traducción}

Cáceres, C. Joaquín', Olivares, Eduardo', Angulo, Jenniffer', Contreras, Nataly', Pino, Karla', López-Lastra, Marcelo',

'Laboratorio de Virologia Molecular, Departamento de Enfermedades Infecciosas e Inmunología Pediátrica, Instituto Milenio de Inmunología e Inmunoterapia, Centro de Investigaciones Médicas. , Escuela de medicina, Pontificia Universidad Católica De Chile

HTLV-1 is a retrovirus, which is the etiological agent of Adult T-cell leukemia (ATL) and HTLV-1-Associated Myelopathy/Tropical Spastic Paraparesis (HAM/TSP). During its replication HTLV-1 synthesizes two antisense messenger RNAs (mRNAs) that encode for two different versions of the HBZ protein. HBZ is critical for the viral replicative cycle and has been directly associated with HTLV-1 pathogenicity. One of these mRNAs corresponds to a splice version (SpHBZ) while the other is an unspliced mRNA (UsHBZ). Both mRNAs are different only in their $5^{\prime}$ untranslated regions ( $5^{\prime}$ UTR) and both mRNAs are equally expressed in blood cells recovered from ATL patients. Strikingly, the SpHBZ protein is more abundant in cells than the UsHBZ protein, suggesting a possible regulation at the level of mRNA translation initiation. In this study, we show that the SpHBZ mRNAs is translated with higher efficiency than the UsHBZ mRNA. Results suggest that the $5^{\prime} \mathrm{UTR}$ SpHBZ can recruit the $40 \mathrm{~S}$ ribosomal subunit internally. Additionally, we show that the recruitment of the $40 S$ ribosome subunit by SpHBZ 5'UTR is sensitive to edeine suggesting that SpHBZ 5'UTR recruit the 40 S ribosome subunit upstream the start codon. Together, these results indicate that the expression of the different forms of the HTLV-1 HBZ protein is regulated at the level of translation initiation

Presentado en: SI

Fuente de financiamiento: FONDECYT 1130270 and grant P09/016-F de la Iniciativa Científica Milenio del Ministerio de Economía, Fomento y Turismo de Chile. CJC and NC are supported by CONICYT doctoral fellowships 


\section{A " Nuclear Experience " is required for retroviral mRNA IRES-dependent translation initiation}

Olguín, Valeria'., Olivares, Eduardo'., López-Lastra, Marcelo',

'Enfermedades Infecciosas e Inmunología Pediátrica, Medicina, Pontificia Universidad Católica De Chile.

Retroviral mRNAs including those of the human immunodeficiency virus type 1 (HIV-1), human T-cell lymphotropic virus type 1 (HTLV1 ), and the mouse mammary tumor virus (MMTV) can initiate translation using an internal ribosome entry sites (IRES). Retroviral IRESs require cellular proteins, termed IRES trans-acting factors (ITAFs) for their function. A number of ITAFs are well characterized nuclear-cytoplasmic shuttling proteins that primary reside in the nucleus. Based on this observation, we propose that certain ITAFs are recruited to the viral mRNA in the nucleus, and are delocalized to the cytoplasm as part of a ribonucleoprotein complex in association with the viral mRNA, enabling IRES-dependent translation initiation. If so, we predict that when found in the cytoplasm retroviral IRES would be functional only if the mRNA has had a passage through the cell nucleus. On the contrary, if a nuclear experience is not an absolute requirement for ITAFs loading, the ribonucleoprotein complex would form in the cytoplasm allowing IRES-mediated translation initiation to occur even when the viral mRNA has not had a passage through the cell nucleus. In this study we evaluated whether IRES from the mRNAs of retroviruses requires a nuclear experience to be functional. For this IRES-dependent translation initiation of HIV-1, HTLV-1 and MMTV was assessed using in vitro synthesized bicistronic mRNAs or in cell transcribed bicistronic mRNAs. Results show that IRES-elements are functional only when the bicistronic mRNA is synthesized in cells. These results strongly suggest that a nuclear experience is necessary for the functionality of the evaluated retroviral IRES.

Presentado en: SI

Fuente de financiamiento: FONDECYT 1130270, P09/016-F de la Iniciativa Científica Milenio del Ministerio de Economía, Fomento y Turismo. VO is a CONICYT Doctoral Fellow

\section{Functional gastrointestinal disorders in children from low socioeconomic status and Helicobacter pylori infection.}

\author{
Jaime F, Villagrán A, Hernández C, Ortiz M, Troncoso P, Harris P.
}

Departamento de Gastroenterología y Nutrición Pediátrica de la Pontificia Universidad Católica de Chile

Objectives and study: Most studies on functional gastrointestinal disorders (FGIDs) in children are based on data from the northern hemisphere. There is scarce literature on South American population, and even less on children from low socioeconomic status (SES) where Helicobacter pylori infection is endemic. The aim of this study is to determine the frequency of FGIDs in school children from low socioeconomic status, as well as evaluating demographic factors associated and the relationship between these disorders and $\mathrm{H}$. pylori infection. Methods: Between October and December 2013, students from three public schools in Chile with low SES were included. Exclusion Criteria included use of antibiotics, proton pump inhibitors or histamine receptor inhibitors in the last month. To evaluate the presence of FGIDs according to Rome III criteria, participants and/or their parents completed the Rome III Diagnostic Questionnaire for the Pediatric FGIDs in its Spanish version provided by The Rome Foundation and a survey that included: number of people living in the same house, educational level of the head of household, history of breastfeeding (in months), family history of gastric cancer, and symptoms within the last three months: fever and weight loss. These symptoms were considered as warning signs, so those who presented them were excluded in the evaluation of FGIDs. In those participants who also accepted to do so, the presence or absence of $\mathrm{H}$. pylori infection through $13 \mathrm{C}$ urea breath test (UBT) and 13C Infrared Spectrometer was determined, considering positive tests those with a delta over baseline $\geq 4 \%$ o. This project had approval of the Institutional Review Board (n'13-342) from the local University and complies with the Declaration of Helsinki. Results: 506 children were included, $48 \%$ were male, with a median age of 15.7 years (range 7.1-19.6). In the overall sample, 190 students (37.5\%) had alarm signs, and were excluded for the assessment of FGIDs. $20 \%$ of the sample ( $95 \% \mathrm{Cl} 16.7-23.7)$ met criteria for a FGIDs. The most frequent were: functional constipation $6.7 \%$, aerophagia $6.3 \%$, Irritable bowel syndrome $4.9 \%$ and abdominal migraine 4.6\%. Of those who met diagnostic criteria for any FGIDs, $29.7 \%$ met criteria for more than one. In multivariate analysis, variables associated with the presence of FGIDs were: educational level of the household head (primary or less) (adjusted OR 2.64, 95\% Cl: 1.50-4.66), family history of gastric cancer (yes) (adjusted OR 2.38, 
95\% Cl: 1.21-4.69) and months of breastfeeding (adjusted OR 1.02, $95 \% \mathrm{Cl}$ : 1.004-1.049). A total of 358 participants (70.8\% of overall sample) performed $13 \mathrm{C}$ UBT. Of these, $55.9 \%$ had a positive result (95\% Cl 50.7-60.9). In multivariate analysis, only the presence of abdominal pain (yes or no) was associated with increased likelihood of infection by $\mathrm{H}$. pylori (OR 1.58, 95\% Cl 1.04-2.41) and not the presence of FGIDs in general and/or its subgroups. Conclusion: FGIDs are common in low SES students. A low educational level of the household head was the most strongly associated risk factor to develop FGIDs. In this study, there was no relationship between the presence of $\mathrm{H}$. pylori and FGIDs.

Presentado en: Congreso Europeo de Gastroenterología y Nutrición Pediátrica (ESPGHAN)

Fuente de financiamiento: Proyecto Puente UC \#15/2013 y Fondecyt \#1130387

\section{Riesgo cardiovascular en niños y adolescentes con parálisis cerebral}

\section{Le Roy C, Sepúlveda C, Guzmán ML, Olivarez M, Figueroa MJ,} Barja S

Departamento de Gastroenterología y Nutrición Pediátrica, División de Pediatría, Facultad de Medicina Pontificia Universidad Católica de Chile, Programa NINEAS Hosp. Padre Hurtado, Fac. Medicina U. Del Desarrollo, Programa NINEAS, Hospital Sótero del Río.

Introducción: Existe una prevalencia creciente de malnutrición por exceso en pacientes con parálisis cerebral (PC), pero es escasa la información de los factores de riesgo cardiovascular asociados. Objetivo: Estudiar las complicaciones metabólicas de la obesidad en niños y adolescentes con PC y su asociación a diferentes condicionantes. Pacientes y método: Estudio transversal en 69 niños con PC controlados en los programas NINEAS de los Hospitales Padre Hurtado y Sotero del Río, Santiago, Chile. Se obtuvieron datos demográficos, se realizó antropometría y se evaluó el estado nutricional según patrones de Brooks y col. La función motora gruesa se clasificó según la escala internacional de Gross Motor Function Classification System (GMFCS), definiendo Grado I, II y III como leve y grado IV y V moderado-severo. Se obtuvo una muestra de sangre venosa de ayunas para: trigliceridemia (TG) definiendo TG altos: $\geq 110 \mathrm{mg} / \mathrm{dL}$ en $<9$ años y para $>10$ años $>130 \mathrm{mg} / \mathrm{dL}$, colesterol total (CT) siendo CT alto $\geq 200 \mathrm{mg} / \mathrm{dL}$, glicemia (Gli) definiendo Gli elevada $\geq 100 \mathrm{mg} / \mathrm{dL}$, insulinemia y se calculó índice HOMA considerándose elevada $>3$. Se estudiaron frecuencias y asociación de los parámetros metabólicos con edad, sexo, estado nutricional,
GMFCS y uso de anticonvulsivantes. Este estudio fue aprobado por Comité de Ética SSMSO, los padres firmaron un consentimiento informado. Resultados: La edad tuvo un promedio de 11,1+4,9 años, el 62,3\% fueron hombres. El 81,2\% tuvo una función motora moderada-severa. Utilizaban sonda nasogástrica o gastrostomía $50,7 \%$ y $83,9 \%$ recibía anticonvulsivantes. Presentaron IMC/E $<$ p 10 el 15,4\%, entre p10-75 el 73,8\% y >p75 el 10,8\%. Tuvieron $20,3 \%$ de los pacientes TG alto, 18,8\% HOMA elevado, 5,8\% con CT alto y 4,3\% Gli elevada. Se encontró asociación entre TG alto y mayor grado de GMFCS (Fisher, $\mathrm{p}=0,013$ ), correlación directa entre IMC y $\mathrm{CT}$ (Spearman $\mathrm{r}=0,4, \mathrm{p}=0,016$ ) y correlación entre TG y CT (Spearman $r=0,3, p=0,006)$. El HOMA elevado tuvo diferencia según sexo, en mujeres mediana de 2,2(RIC:1.2,3.4) versus hombres 1,7(RIC:1,2.2) (Mann Whitney, $\mathrm{p}=0,047$ ) y presentó asociación con el uso de anticonvulsivantes (Fisher, $\mathrm{p}=0,01$ ). Conclusiones: La prevalencia de hipertrigliceridemia, resistencia insulínica (RI) e hipercolesterolemia es alta en esta muestra de niños con PC. La hipertrigliceridemia se asoció con mayor inmovilidad, la hipercolesterolemia con el exceso de peso y la RI fue más frecuente en las mujeres y usuarios de anticonvulsivantes. Considerando la baja prevalencia de exceso de peso en esta muestra, el presentar similar prevalencia de alteraciones metabólicas que la población general, sugiere una elevada adiposidad con posible mayor riesgo cardiovascular futuro.

Presentado en: Congreso de Sociedad Chilena de Pediatría Fuente de financiamiento: Concurso Rama de Nutrición SOCHIPE 2013-2015

\section{Estado nutricional según tipo de cardiopatía congénita}

\section{Oyarzún I,Claverías C,Larios G,Le Roy C}

Residente de Pediatría, División de Pediatría de la ontificia Universidad Católica de Chile, Departamento de Cardiología y Enfermedades respiratoria Pediátricas, Departamento de Gastroenterología y Nutrición Pediátrica, División de Pediatría de la Pontificia Universidad Católica de Chile

Introducción: El compromiso nutricional en niños con cardiopatías congénitas (CC) depende de su diagnóstico cardiológico y otros factores. Objetivo: Describir el estado nutricional en niños con CC operable y algunos factores asociados. Sujetos y métodos: Estudio transversal. Se evaluaron niños que ingresaron a cirugía de CC entre Abril 2015 a Abril 2016 al Hospital Clínico de la Pontificia Universidad Católica de Chile. Se incluyeron: Comunicación interventricular (CIV), Comunicación interauricular (CIA), Hipoplasia de 
Ventrículo Izquierdo (HVI), Tetralogía de Fallot (TOF) y Transposición de grandes arterias (dTGA). Se excluyeron síndromes genéticos. Se obtuvieron datos demográficos, riesgo quirúrgico (RACHS),fármacos, antropometría, soporte nutricional. Se hizo diagnóstico nutricional con estándares OMS, utilizando ZP/T en $<$ de 5 años y ZIMC/E en mayores. Talla baja $\leq 2 \mathrm{DS}$. Resultados: Se incluyeron 43 pacientes. 22 (47,8\%) hombres. Mediana de edad 8 meses (RIC: 4,28). 14,3\% prematuros. $28,6 \%$ pequeños para edad gestacional (PEG). $51 \%$ provenían de Región Metropolitana. 9 (20,9\%) con CIV, 8 (18,6\%) CIA,12 (27.9\%) HVI,9 (20,9\%) TOF y 5 (11,6\%) dTGA. Se encontró ZT/E -0.8 $\pm 1.2 \mathrm{DS}$. El menor valor $-1.8 \pm 1.6 \mathrm{DS}$ en CIV $\mathrm{y}-1.28 \pm 0.8 \mathrm{DS}$ en HVI. 8 (18\%) con talla baja, ninguno con CIA o dTGA. El ZP/T-IMC/E

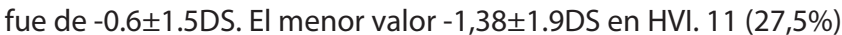
tuvieron malnutrición por déficit (<-1DS ZP/T-IMC/E), mayor en CIV (37.5\%) e HVI (36.3\%). Tuvieron seguimiento nutricional 20 (46\%) y 15 (34\%) utilizó SNG. RACHS complejo ( $\geq 3$ ) 15 (36\%). 26 (60\%) niños usaba fármacos, con diferencia según $\mathrm{CC}(\mathrm{p}=0,001)$, ninguno con $\mathrm{CIA}$ usaba fármacos. No se encontró diferencia significativa ni asociación según CC y sexo, prematuridad, PEG, ZT/E, talla baja, ZP/T-IMC/E ni con diagnóstico nutricional. Se encontró diferencia significativa entre edad y CC $(p=0,002)$, mayor en $\mathrm{CI}$, mediana de 58,5 meses (RIC:36,98.5) y menor en dTGA, mediana 0 meses (RIC:0,34). Hubo asociación entre seguimiento nutricional y CC $(p=0,001), 83 \%$ de niños con $\mathrm{HVI}$ y ninguno con $\mathrm{ClA}$. Hubo asociación entre CC y uso de SNG $(p=0,02)$, mayor en dTGA ( $40 \%)$ e HVI ( $25 \%)$ y ninguno en $\mathrm{CIA}$. Los pacientes AEG tuvieron mayor porcentaje de talla normal $(p=0,025)$. Hubo asociación entre RACHS y CC $(p=<0,001)$. Niños con talla baja usaban $>1$ fármaco $(p=0,02)$. No se encontró asociación entre variables estudiadas y diagnóstico nutricional. Se encontró correlación positiva débil entre ZP/T y ZT/E $(r=0,3, p=0,04)$ y entre $Z P / T$ y edad de cirugía $(r=0,4, p=0,02)$. Conclusiones: Se encontró alto porcentaje de malnutrición por déficit, talla baja, prematurez y PEG. La mitad tuvo seguimiento nutricional y un tercio usaron SNG. Mayor déficit nutricional en HVI y CIV. Existen diferencias según CC y edad de cirugía, seguimiento nutricional, usar SNG, RACHS y número de fármacos. El diagnóstico nutricional de ingreso no se asoció con las variables estudiadas. Se debe estudiar a futuro cómo influyen las variables que son diferentes según CC.

Presentado en: Congreso de Sociedad Chilena de Pediatría Fuente de financiamiento: Sin fuente de financiamiento

\section{Buenos indicadores en salud de niños y niñas con Síndrome de Down: Alta frecuencia de Lactancia Materna Exclusiva a los 6 meses}

\author{
Lorena Génova ${ }^{1, a}$, Catalina Correa² ${ }^{2}$ Natalia Vergara² , Jaime \\ Cerda $^{3}$, Macarena Lizama ${ }^{1,4}$
}

'División de Pediatría, Facultad de Medicina, Pontificia Universidad Católica de Chile, Santiago, Chile. a) Residente de Pediatría. 2) Programa Seguimiento NANEAS Centro Especialidades Pediátricas UC-Christus, 3) Departamento de Salud Pública. 4) Centro UC Síndrome de Down

Introducción: Los recién nacidos con síndrome de Down (SD) pueden tener patologías y malformaciones asociadas que interfieren con la lactancia materna (LM), la que además se puede ver afectada por factores maternos y condiciones asociadas a la atención en salud. Objetivos: determinar la frecuencia de LME en niños chilenos con SD y describir los factores asociados a su abandono. Materiales y Métodos: estudio descriptivo transversal del binomio madre-hijo/ hija, donde los hijos e hijas eran chilenos con SD, entre 6 meses y 2 años, en control en el Programa de Seguimiento en Salud de Personas con Síndrome de Down de la Red de Salud UC CHRISTUS o vinculados con el centro UC Síndrome de Down. Se utilizó un cuestionario on-line que incluyó la recolección de datos demográficos, patologías asociadas del hijo(a) y la experiencia en LM. Resultados: El total de la muestra obtenida fue de 76 binomios Madre-hijo e hija. EI 44,7\% (34/76) de las madres habían dado LME hasta los 6 meses o más. El 55,3\% (42/76) recibió apoyo en LM en clínica de lactancia o de parte de grupos de apoyo. El 65,8\% (50/76) de los hijos o hijas con SD había presentado alguna patología o malformación asociada que influía en el proceso de lactancia. De las madres que no dieron LME hasta los 6 meses, el 64,2\% (27/42) fue por motivos del hijo. La hospitalización durante los primeros 6 meses de vida fue el factor más significativo en el cese de LME antes de los 6 meses (OR=0,263). Conclusión: Primer estudio en Chile que describe prevalencia de LME a los 6 meses en niños con SD. La hospitalización pediátrica es un elemento que redujo la LME, por su parte, el acceso a seguimiento multidisciplinario especializado y a clínica de lactancia en la población estudiada, podría influir positivamente en los resultados obtenidos en este grupo. Los niños con síndrome de Down son capaces de recibir LME de forma similar a la población general con el apoyo y educación adecuada sobre lactancia. Se requiere de apoyo en lactancia durante hospitalizaciones pediátricas, de manera de intentar optimizar la LME en este grupo vulnerable.

Presentado en: 56 Congreso Chileno de Pediatría (premio a mejor trabajo categoría residente)

Fuente de financiamiento: No declara 


\section{Alta Frecuencia de Hipovitaminosis D en Pacientes con Síndrome de Down}

Eugenin MI', Borzutzky A', Paul MA'1', Cerda J², Lizama M'.

División de Pediatría (1) y Departamento de Salud Pública (2), Escuela de Medicina, Pontificia Universidad Católica de Chile.

Introducción: La vitamina D (VitD) juega un rol fundamental en el metabolismo óseo y durante los últimos años ha crecido el interés respecto a sus acciones extra-esqueléticas. A pesar de que los niños con síndrome de Down (SD) frecuentemente presentan factores de riesgo para hipovitaminosis D (ej: obesidad, menor actividad física, y exposición solar), existe muy escasa literatura respecto a la prevalencia de hipovitaminosis $\mathrm{D}$ en este grupo de pacientes. Objetivo: Describir los niveles de 25-hidroxi vitamina D (25OHD) en una cohorte de pacientes con SD. Métodos: Se revisaron las fichas clínicas de pacientes mayores de 1 año, en control en el Programa de Seguimiento de Personas con SD de la Red de Salud UC CHRISTUS, entre 2007-2016. Se registraron los niveles de 25OHD estacionalidad asociada a la toma de muestra, lugar de residencia, edad, sexo, estado nutricional y presencia de comorbilidades. En los casos de pacientes que contaban con más de 1 nivel de $250 \mathrm{HD}$ disponible, se registró el nivel más bajo. Resultados: Se revisaron fichas clínicas de 720 pacientes. 171 pacientes (23.8\%) tenían niveles disponibles de 25OHD. Algunos pacientes tuvieron más de un nivel disponible (rango 1-6), con un total de 276 niveles disponibles. El nivel promedio de 25OHD fue $22.9 \mathrm{ng} / \mathrm{ml}$ (DE \pm 8.2). El Gráfico 1 resume el estado de VitD. El promedio de edad de los pacientes con niveles suficientes fue menor en comparación que aquellos con niveles bajos de 25OHD (4.8 años $\pm 4.7 \mathrm{v} / \mathrm{s} 6.2$ años $\pm 4.0, \mathrm{p}=0.01$ ). $48 \%$ de los pacientes fueron hombres y no hubieron diferencias según sexo y niveles de $250 H D(p=0.67)$. No hubieron diferencias entre estaciones $(p=0.58)$, ni al comparar invierno $\mathrm{v} / \mathrm{s}$ resto estaciones $(p=0.19)$. No se encontraron diferencias según el lugar de residencia $(p=0.42$ ), sin embargo hubieron pocos casos de pacientes que vivían fuera de la región metropolitana (Tabla 1). La Tabla 2 resume el estado de VitD según comorbilidades, sin encontrar diferencias significativas. Conclusiones: La frecuencia de hipovitaminosis $D$ en niños y niñas con SD es alta (86.6\%), lo que es concordante con lo reportado para población pediátrica chilena. Considerando que se trata de un grupo de pacientes de alto riesgo para osteopenia y osteoporosis a largo plazo, sería importante incluir en el seguimiento de estos pacientes mediciones regulares de $250 \mathrm{HD}$ y eventualmente considerar profilaxis y/o tratamiento en los casos indicados.

Presentado en: 56 Congreso Chileno de Pediatría

Fuente de financiamiento: No declara

\section{Impacto de un programa de entrenamiento sobre trotadora en pacientes pediátricos con enfermedades respiratoria crónicas.}

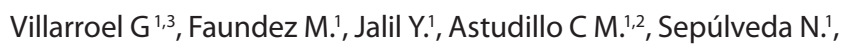
Mendez $\mathrm{M}^{1,2}$

${ }^{1}$ Hospital Josefina Martinez. ${ }^{2}$ Departamento de Enfermedades Cardiovasculares y Respiratorias del Niño. División de Pediatría Facultad de Medicina, Pontificia Universidad Católica de Chile. ${ }^{3}$ Carrera de Kinesiología, UDA Cs de la Salud, Facultad de Medicina, Pontificia Universidad Católica de Chile.

Introducción: En los últimos años ha existido un aumento de niños con enfermedades respiratorias crónicas (ERC) debido a factores vinculados al desarrollo tecnológico de la medicina, aplicación de estrategias sanitarias y estrategias terapéuticas más efectivos. La Rehabilitación Respiratoria (R.R.) ha sido uno de los tratamientos emergentes para esta población con el fin de minimizar los síntomas respiratorios, aumentar el rendimiento físico, promover la autonomía, la participación en las actividades de la vida diaria y por tanto la calidad de vida relacionada a la salud. Es por esto que en el Hospital Josefina Martínez se creo un programa de entrenamiento sobre trotadora para pacientes que poseen marcha estable. Objetivo: Evaluar el impacto de un programa de entrenamiento aeróbico sobre trotadora en pacientes pediátricos con enfermedades respiratorias crónicas. Metodología: Estudio observacional, descriptivo en base al registro de pacientes beneficiarios del programa de entrenamiento sobre trotadora. Los pacientes realizaron 24 sesiones 3 veces por semana sobre trotadora, con una duración de 35 minutos cada sesión utilizando cargas a intervalos. Se analizaron los registros de Test de marcha de 6 minutos y la carga máxima obtenida en el Test de Carga Incremental ( $\mathrm{TCl}$ ) previo y posterior a la ejecución del programa de entrenamiento. Se estableció un nivel de significancia de $\mathrm{p}<0,05$. Resultados: Se incluyeron 11 pacientes con una media de edad de 7,9 \pm 4,3 años. Los diagnósticos de los pacientes fueron agrupados en daño pulmonar crónico 8/11, enfermedad neuromuscular 2/11 y una obstrucción de la vía aérea superior. Tres pacientes eran usuario de ventilación mecánica continua, cuatro con ventilación mecánica intermitente y cuatro no utilizaban ventilación mecánica. Las medias de la distancia recorrida pre y post entrenamiento fueron de $378 \mathrm{~m} \pm 138.5 \mathrm{~m}$ y $450.1 \pm 134.3$ $m$ respectivamente. $(p=0.0000)$. Las medias de las velocidades máximas obtenidas en el TCl fueron de $4.2 \pm 1.1 \mathrm{k} / \mathrm{h}$ y $5.4 \pm 1.3$ k/h (p. 0.0001). No se encontraron diferencias estadísticamente significativas para las otras variables evaluadas. Conclusiones: La 
distancia recorrida en el test de marcha de 6 minutos y la capacidad máxima de trabajo obtenidas en el TCl mejoran de forma significativa con el entrenamiento sobre trotadora en los pacientes con enfermedad respiratoria crónica. Estas mejoras se lograron en todos los pacientes que fueron entrenados. De acuerdo a nuestros hallazgos sugerimos incorporar a un programa de entrenamiento aeróbico a aquellos pacientes con enfermedades respiratorias crónica que cumplan con los adecuados criterios de selección.

Presentado en: Sociedad Chilena de enfermedades respiratorias Fuente de financiamiento: No declara

\section{Situación Actual de Salud de Niños y Adolescentes con Síndrome de Down: Alta Frecuencia de Comorbilidad}

\author{
Lizama $\mathrm{M}^{1}$, Eugenin $\mathrm{Ml}^{1}$, Paul $\mathrm{MA}^{1}$, Cerda $\mathrm{J}^{2}$.
}

División de Pediatría y Departamento de Salud Pública², Escuela de Medicina, Pontificia Universidad Católica de Chile.

Introducción: Las personas con síndrome de Down (SD) presentan con mayor frecuencia problemas de salud. Presentamos los resultados de una serie histórica de 719 niños y adolescentes con SD en control en nuestro programa de seguimiento. Objetivo: Describir el perfil demográfico y de morbilidad de niños y adolescentes con SD. Métodos: Estudio descriptivo con reclutamiento retrospectivo realizado mediante la revisión de fichas médicas electrónicas de la última consulta ambulatoria de pacientes en control en el Programa de Seguimiento de Salud de Personas con SD de la Red de Salud UC-CHRISTUS entre los años 2007 a la fecha. El análisis estadístico se realizó utilizando excel y SPSS versión 15.0. Este estudio fue aprobado por el comité de ética de la Pontificia Universidad Católica de Chile. Resultados: Se revisó la ficha clínica de 719 pacientes en control. La mediana de edad de ingreso al Programa fue de 4.8 meses ( 1 día - 20.3 años). Se resume en la Tabla 1 las características demográficas y en la Figura 1 el perfil de morbilidad de nuestros pacientes. Resultados: Se reportan los resultados de la mayor serie chilena de niños y adolescentes con SD hasta la fecha. Existe una alta frecuencia de malformaciones congénitas y comorbilidades, la mayoría son condiciones tratables y comparables con lo reportado en la literatura internacional. El principal aporte de este estudio es evidenciar la alta vulnerabilidad médica de este grupo de pacientes, lo que exige una urgente planificación de un programa nacional de seguimiento de salud para personas con SD.

Presentado en: 56 Congreso Chileno de Pediatría

Fuente de financiamiento: Concurso división de pediatría 2014

\section{Relación costo beneficio de la prueba de unión a colágeno en estudio de Enfermedad von Willebrand en pacientes pediátricos}

\author{
Martínez J, Sepúlveda P, Muñoz G, Aguirre N, Zúñiga P
}

\section{Unidad de Hemato-Oncología Pediátrica}

Introducción La enfermedad de von Willebrand (EVW) es la enfermedad hemorragípara hereditaria más frecuente, siendo un $80 \%$ tipo 1. En nuestra institución el diagnóstico se realiza mediante: cuantificación factor von Willebrand (vWF:Ag) y factor VIII (FVIII:C), Cofactor Ristocetina (CoR) y prueba de unión a colágeno (CB), definido como estudio completo EVW (EC-EVW). Según datos publicados en adultos, CB aporta por sí mismo un 23\% al diagnóstico de EVW (Quiroga, 2014). En Chile CB no está codificada por el fondo nacional de salud (FONASA) lo cual encarece el costo del estudio. Objetivo Evaluar sí EC-EVW mejoró capacidad diagnóstica de EVW en pacientes pediátricos entre 0 y 18 años evaluados en laboratorio de hemostasia de la red de salud de la Universidad Católica de Chile (R-UC). Materiales y Métodos Estudio retrospectivo que revisó base de datos con resultados de EC-EVW durante los años 2008 a 2012. Se revisaron 617 EC-EVW, de los cuales se descartó las pesquisas de hemofilia $\mathrm{A}$ y los pacientes mayores de 18 años, quedando 464 registros. Con los resultados se clasificó según criterios diagnósticos de EVW presentados por Quiroga et al., con 2 de 3 variables bajo percentil 7,5 o bajo percentil 2,5, definiéndose cuatro categorías: Normal (N), Normal Bajo (NB), Posible EVW (p-EVW) y EVW. Datos tabulados y analizados con SPSS $23^{\circledR}$ Análisis estadístico: Test Exacto de Fisher para diferencias entre criterios y tets Spearman-rank para correlaciones. Significancia estadística: $p<0,05$. Resultados De los 464 registros de EC-EVW analizados la edad promedio fue 8,4 $\pm 4,7$ años. La proporción de mujeres fue 49,1\%. Los resultados EC-EVW fueron: N 306 (65,9\%); NB 74 (15,9\%); p-EVW 41 (8,8\%) y 43 (9,4\%) EVW. La correlación entre CoR y CB fue significativa en todos los grupos diagnósticos ( $N$ $R 2=0,73: p<0,001 ; \mathrm{Nb} R 2=0,50 \mathrm{p}<0,001 ; p-E V W R 2=0,87 ; p<0,001$; EVW R2 $=0,67 p<0,001)$. Al comparar aporte específico de CoR y CB para las categorías diagnósticas: no se observó diferencias en $\mathrm{N}(\mathrm{p}=1)$ ni EVW $(p=1)$; existiendo diferencia a favor de CoR en NB $(p=0,017)$ y a favor de CB en $p-E V W(p=0,017)$. Discusión Según los datos analizados, la CB por sí sola no aumentó la pesquisa de casos de EVW en pacientes pediátricos. Estos resultados difieren de los de Quiroga et al (2014) quien mostró que la CB mejora la pesquisa de EVW en un $23 \%$ en pacientes adultos. Lo anterior nos permite señalar que para diagnóstico de EVW en pacientes pediátricos la 
elección inicial puede omitir el estudio de CB, lo cual no altera la capacidad diagnóstica de EVW y disminuye el costo de este, dejando EC-EVW como estudio de segunda línea en casos de discordancia entre la clínica y el laboratorio. PALABRAS CLAVES: Enfermedad de von Willebrand, Cofactor Ristocetina, análisis costo beneficio.

Presentado en: LVI Congreso Chileno de Pediatría

Fuente de financiamiento: No declara

\section{Cytomegalovirus inmune response follow up using QUANTIFERON-cmv ${ }^{\circledR}$ in children during the first year after hematopoletic stem cell or solid organ TRANSPLANTATION; preliminary results}

Vizcaya C, Le Corre N, Martinez C, Barriga F, Urcelay G, Contreras M, Vidal M, Dellepiane P, Contreras AM, Ferres M

Departamento de Infectología, Inmunología y Reumatología Pediátrica, PUC. Laboratorio Infectología Y Virología Molecular. Oncología Pediétrica. Cardiología Pediátrica

Introduction: Human Cytomegalovirus (HCMV) infection significantly contributes to morbidity and mortality in hematopoietic stem cell (HSCT) and in solid organ transplant (SOT) patients. CMV naïve SOT recipients from a CMV positive donor are at the highest risk of CMV-related complication. Meanwhile, CMV positive recipients in HSCT with naive donor present a higher risk of reactivation. The specific immune response against HCMV, particularly during the first month after transplantation, is impaired and preemptive or prophylactic anti HCMV strategies are needed. However, these strategies need close monitoring of viral load and are associated with viral resistance and drug toxicity. At the same time, immunosuppressive drugs induce the loss of immune control over HCMV and frequently are associated with impaired CD8 T cell function. QuantiFERON-CMV ${ }^{\circledR}$ is able to detect HCMV specific T lymphocytes in blood by measuring IFNY production with an ELISA test. QuantiFERON-CMV ${ }^{\otimes}$ has been used in immunocompromised adults to address immune specific response against HCMV, but there is limited information about its use in children after transplantation. Objective: To establish QuantiFERON ${ }^{\circledR}$-CMV levels in children with HCMV infection during the first year after HSCT or SOT. Methods: We included children after 6 weeks of HSCT and 3 month of
SOT, with HCMV sero-positive status in donor and/or recipient. QuantiFERON-CMV ${ }^{\circledR}$ was performed every month for HSCT and every two months for SOT, during the first year post transplant. The results were expressed as optic density (OD) obtained with HCMV antigens stimulation minus OD obtained from negative control (nil), as recommended by manufacturer: HCMV minus nil $\geq 0.2 \mathrm{Ul} / \mathrm{ml}$ was interpreted as a reactive test. When were available, we registered the following laboratory parameters: HCMV viral load, lymphocyte count and tacrolimus or cyclosporine blood levels. Results: Three patients receiving an HSCT were included ( 2 umbilical cord blood and 1 related donor). All receptors had a seropositive HCMV status and the related donor was negative. Two patients with cardiac transplant were included, both donors had positive HCMV IgG and one receptor was negative. Among HSCT recipients, one patient with a seronegative HCMV related donor had QuantiFERON ${ }^{\circledR}-\mathrm{CMV}$ levels below $0.2 \mathrm{UI} / \mathrm{ml}$ during the first 8 months of follow up, despite of which no HCMV reactivation was observed. The second patient presented a reactive QuantiFERON ${ }^{\circledR}-\mathrm{CMV}$ after 3 months of transplantation. However, the test showed levels below $0.2 \mathrm{UI} / \mathrm{ml}$ from the 4th until 6th month after transplantation without HCMV reactivation. The third patient presented an indeterminate result at 6 weeks after transplantation, but with undetectable HCMV viral load. Among SOT recipients, one patient presented a reactive QuantiFERON ${ }^{\circledR}-C_{M V}$ since the 3rd month after transplantation and with no HCMV reactivation. The patient with seronegative IgG presented QuantiFERON ${ }^{\circledR}-{ }^{-C M V}$ levels below $0.2 \mathrm{UI} / \mathrm{ml}$ from the $3 \mathrm{rd}$ month to the 6 th months after transplantation, with concomitant positive HCMV viral loads, requiring preemptive therapy with gancyclovir and foscarnet. At 7th month, QuantiFERON ${ }^{\circledR}-\mathrm{CMV}$ levels was $0.26 \mathrm{UI} / \mathrm{ml}$ and HCMV viral load was undetectable with no therapy. Even if there was a tendency of higher QuantiFERON ${ }^{\circledR}$-CMV levels in patients with higher lymphocyte counts and/or lower immunosuppressive drugs levels, no significant correlation was observed between these parameters. Conclusions: No HCMV reactivation was observed in this pediatric

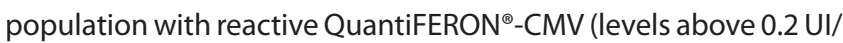
$\mathrm{ml}$ as recommended by the provider). Finding HCMV specific and functional lymphocytes using QuantiFERON ${ }^{\circledR}-C^{-} M V$ seems to depend on donor and recipient CMV sero-status and immunosuppressive drugs levels. More patients need to be recruited and followed in order to confirm this hypothesis

Presentado en: Infocus 2016

Fuente de financiamiento: Fundación Nuestros Hijos. Concurso División de Pediatría 


\section{Differential age-related expression of gastric matrix metaloproteases in Helicobacter pylori infected patients}

Hernández C, León MA, Vera M, Palma C, Cofre C, Harris P, Serrano C.

Laboratorio de Infección e Inmunología Gastrointestinal. Departamento de Gastroenterología y Nutrición Pediátrica. Escuela de Medicina. Pontificia Universidad Católica de Chile

Background and aims: H. pylori causes less inflammation and overall less mucosal damage in infected children in comparison to infected adults. Increased metalloprotease (MMPs) expression in the gastric mucosa has been correlated with CagA positive strain infection and gastric cancer progression. On the other hand loss of MMP-7 has been correlated with a reduction of $\mathrm{H}$. pylori induced gastric inflammation and cancer progression. Here we investigated if MMP expression patterns in $\mathrm{H}$. pylori infected in children differs from adults. Patients and methods: 36 symptomatic patients referred to upper Gl endoscopy by their physicians were included in this study. H. pylori infection was determined by Rapid Urease Test. MMP 1, 2, 7 and 9 mRNA expression was determined in gastric mucosa by qRT-PCR and normalized by GAPDH. Results: MMP-2, 7 and 9 expression levels were significantly increased in $\mathrm{H}$. pylori infected patients regardless of their age. Children with $\mathrm{H}$. pylori infection showed decreased expression of MMP-2 and 9 in comparison with infected adults. On the contrary MMP-7 showed higher levels of mRNA in infected children than in infected adults. Conclusion: Changes in MMPs expression patterns in childhood might contribute to the decreased mucosal damage observed in children infected by H. pylori.

Presentado en: Pan American Digestive Disease Week and VII International Symposium of Helicobacter pylori and Gastric Cancer. Fuente de financiamiento: Fondecyt \#11140232

\section{Descripción clínica de pacientes pediátricos controlados en policlínico de enfermedades neuromusculares.}

Soto C, Beytía M, Avila D, Escobar R.

Unidad de Neurología, División de Pediatría, Escuela de Medicina. Pontificia Universidad Católica de Chile. Unidad de Neurología Infantil, Complejo Asistencial Sótero del Río.
Introducción: Las Enfermedades Neuromusculares(ENM), grupo heterogéneo de patologías, constituyen causa importante de discapacidad. En Chile, no existen estudios descriptivos que señalen las características clínicas de pacientes pediátricos afectados por ENM. Objetivos: Caracterizar clínicamente a pacientes pediátricos en control periódico en uno de los policlínicos del Programa de ENM pediátricos UC-Complejo Asistencial Sótero del Río. Metodología: Estudio Prospectivo Observacional Descriptivo de pacientes atendidos en policlínico de ENM del Complejo Asistencial Sótero del Río, entre Enero 2012 y Diciembre 2015, con diagnóstico presuntivo o confirmado de ENM. Aprobado por el Comité de Ética Institucional. Resultados: Se reportan 150 pacientes (74 hombres; edad promedio 8 años, rango 0-18). Motivos de consulta más frecuentes: alteración de la marcha, hipotonía y retraso del desarrollo psicomotor. Morbilidad asociada: Discapacidad Intelectual(15\%), Trastorno Deglución(8\%), Requerimiento Ventilación Mecánica(8\%), Cardiopatía(4\%), Patologías traumatológicas(24\%), perdida de marcha(5\%). Técnicas diagnosticas utilizadas: EMG (66\%), Biopsia(27\%), Anticuerpo Anti receptor Acetilcolina(5\%), RM muscular(2\%), RM cerebro(23\%), Exámenes genéticos(32\%). Las etiologías fueron: hereditaria( $n=77)$, adquirida $(n=39)$ y en estudio(n=34). Los diagnósticos más frecuentes fueron: Distrofias musculares $(n=21)$, Trastornos Introducción: Las Enfermedades Neuromusculares(ENM), grupo heterogéneo de patologías, constituyen causa importante de discapacidad. En Chile, no existen estudios descriptivos que señalen las características clínicas de pacientes pediátricos afectados por ENM. Objetivos: Caracterizar clínicamente a pacientes pediátricos en control periódico en uno de los policlínicos del Programa de ENM pediátricos UC-Complejo Asistencial Sótero del Río. Metodología: Estudio Prospectivo Observacional Descriptivo de pacientes atendidos en policlínico de ENM del Complejo Asistencial Sótero del Río, entre Enero 2012 y Diciembre 2015, con diagnóstico presuntivo o confirmado de ENM. Aprobado por el Comité de Ética Institucional. Resultados: Se reportan 150 pacientes (74 hombres; edad promedio 8 años, rango 0-18). Motivos de consulta más frecuentes: alteración de la marcha, hipotonía y retraso del desarrollo psicomotor. Morbilidad asociada: Discapacidad Intelectual(15\%), Trastorno Deglución(8\%), Requerimiento Ventilación Mecánica(8\%), Cardiopatía(4\%), Patologías traumatológicas(24\%), perdida de marcha(5\%). Técnicas diagnosticas utilizadas: EMG (66\%), Biopsia(27\%), Anticuerpo Anti receptor Acetilcolina(5\%), RM muscular(2\%), RM cerebro(23\%), Exámenes genéticos(32\%). Las etiologías fueron: hereditaria( $n=77)$, adquirida( $n=39)$ y en estudio( $n=34)$. Los diagnósticos más frecuentes fueron: Distrofias musculares( $n=21)$, Trastornos miotónicos $(n=17)$, Polineuropatías Hereditarias( $n=16)$, Miopatías congénitas $(n=9)$, otras Polineuropatías $(n=9)$ y Miastenia gravis $(n=8)$. Se logró diagnóstico definitivo con estudio completo en $112 / 150$ casos. Dentro de los 
exámenes complementarios destacó que en 34\% de los pacientes con causa hereditaria tienen estudio genético confirmatorio. Conclusiones: En nuestro Centro es posible llegar a diagnóstico definitivo en $75 \%$ de los casos totales de ENM y en $34 \%$ de las patologías hereditarias se logró diagnóstico genético específico.

Presentado en: Congreso de Neurología y Psiquiatria Infantil(SOPNIA) Fuente de financiamiento: No declara

\section{Progression of Lung Disease in Preschool Patients with Cystic Fibrosis.}

Stanojevic S', Davis SD², Retsch-Bogart G ${ }^{3}$, Webster $\mathrm{H}^{4}$, Davis $\mathrm{M}^{5,6}$, Johnson $\mathrm{RC}^{7}$, Jensen $\mathrm{R}^{8}$, Pizarro ME9, Kane $\mathrm{M}^{10}$, Clem $\mathrm{CC}^{11}$, Schornick $L^{12}$, Subbarao $\mathrm{P}^{13}$, Ratjen $\mathrm{FA}^{14}$.

'Division of Respiratory Medicine, Hospital for Sick Children, Toronto, Canada ${ }^{2}$ Physiology and Experimental Medicine, Research Institute, Hospital for Sick Children, Toronto Canada ${ }^{3}$ Section of Pediatric Pulmonology, Allergy and Sleep Medicine; Department of Pediatrics; Riley Hospital for Children, Indiana University School of Medicine, Indianapolis IN, USA ${ }^{4}$ Division of Pediatric Pulmonology, University of North Carolina at Chapel Hill, Chapel Hill NC, USA ${ }^{5}$ Pontificia Universidad Catolica de Chile, Santiago Chile

La implementación de estrategias de intervención precoz para prevenir el daño pulmonar en pacientes con fibrosis quística (FC) requiere de mediciones objetivas de la evolución de la enfermedad pulmonar. OBJETIVO: Definir la utilidad del Lung Clearance Index $(\mathrm{LCl})$, medido a través de lavado de nitrógeno a múltiples respiraciones (MBW), como un medio para seguir la progresión de la enfermedad en niños en edad preescolar con FQ. MÉTODOS: Niños entre las edades de 2,5 y 6 años con un diagnóstico confirmado de CF y controles sanos pareados por edad se inscribieron en tres centros norteamericanos de CF. Se realizaron test de MBW al ingreso y luego a los 1, 3, 6 y 12 meses posterior al ingreso. Para de esta manera imitar los puntos de tiempo utilizados habitualmente en la atención clínica y los ensayos clínicos; También se realizó espirometría. En el analisis estadístico se utilizó un modelo generalizado de efectos mixtos lineales para distinguir los cambios de $\mathrm{LCl}$ asociados con el crecimiento y desarrollo normales (es decir, niños sanos) de la progresión de la enfermedad pulmonar en FQ. RESULTADOS: Se recogieron datos en 156 participantes con 800 mediciones $\mathrm{LCl}$. Aunque tanto el $\mathrm{LCl}$ como la espirometría discriminaron la salud de la enfermedad, sólo el LCI identificó deterioro significativo de la función pulmonar en la FC con el tiempo. El deterioro del LCl empeoró aún más durante los episodios de tos así como las exacerbaciones pulmonares, mientras que en los niños sanos con síntomas similares no se asociaron con valores aumentados de $\mathrm{LCl}$. CONCLUSIONES: LCl es un marcador útil para rastrear progresión temprana de la enfermedad y puede servir como una herramienta para guiar terapias en pacientes jóvenes con FQ.

Presentado en: No

Fuente de financiamiento: National Heart Lung and Blood Institute

\section{A Systematic Approach to Multiple Breath Nitrogen Washout Test Quality.}

Jensen $\mathrm{R}^{1}$, Stanojevic $\mathrm{S}^{1,2}$, Klingel M1', Pizarro $\mathrm{ME}^{1,3}$, Hall GL $\mathrm{L}^{4,5,6}$, Ramsey $K^{4,5,7}$, Foong $\mathrm{R}^{4,5}$, Saunders $\mathrm{C}^{8,9}$, Robinson PD ${ }^{10,11}$, Webster $\mathrm{H}^{1}$, Hardaker $\mathrm{K}^{10}$, Kane $\mathrm{M}^{1}$, Ratjen $\mathrm{F}^{1,2}$.

${ }^{1}$ Division of Respiratory Medicine, Hospital for Sick Children, Toronto, Canada. ${ }^{2}$ University of Toronto, Toronto, Canada. ${ }^{3}$ Pontificia Universidad Católica de Chile, Santiago, Chile. ${ }^{4}$ Telethon Kids Institute, Perth, Australia. ${ }^{5}$ Centre for Child Health Research, University of Western Australia, Perth, Australia. ${ }^{6}$ School of Physiotherapy and Exercise Science, Curtin University, Perth, Australia. ${ }^{7}$ University of North Carolina at Chapel Hill, Chapel Hill, United States of America. ${ }^{8}$ Royal Brompton \& Harefield NHS Foundation Trust, London, United Kingdom. ' Department of Gene Therapy, Imperial College London, London, United Kingdom. ${ }^{10}$ Department of Respiratory Medicine, The Children's Hospital at Westmead, Sydney, Australia. "'Discipline of Paediatrics and Child Health, University of Sydney, Sydney, Australia.

Para la estimación exacta de los resultados del lavado de nitrógeno de múltiples respiraciones (MBW) requiere de el funcionamiento correcto del dispositivo, la distracción apropiada del sujeto para asegurar que respiran a volumen corriente y relajado, e interpretación apropiada de los datos adquiridos. Basado en las recomendaciones disponibles para un test MBW aceptable, se desarrolló un protocolo para evaluar sistemáticamente MBW basadas en estos criterios. MÉTODOS: Se revisaron, por un observador experimentado, 50 test de MBW (aproximadamente 3 maniobras por estudio) evaluando elementos técnicos y si el patrón de respiración era adecuado. Posterior a esto se evaluó el impacto de criterios cualitativos y cuantitativos en los resultados obtenidos por 8 operadores revisando 20 de los 50 test de MBW. Se evaluó la concordancia entre operadores utilizando el test estadístico Kappa. RESULTADOS: Utilizando criterios cualitativos 46/168 maniobras fueron rechazadas: $16,6 \%$ eran técnicamente inaceptables y $10,7 \%$ fueron excluidos debido a un patrón de respiración inadecuado. El acuerdo entre los distintos evaluadores fue bueno utilizando criterios cualitativos y mejoró agregando criterios cuantitativos de $(\mathrm{k}=$ 0,53-0,83\%) a (к 0,73-0,97\%), pero requirió la exclusión maniobras 
de MBW de manera retrospectiva. CONCLUSIONES: La aplicación criterios cualitativos y cuantitativos mejoró la concordancia interobservadores pero no afectó los resultados reportados de MBW.

Presentado en: No

Fuente de financiamiento: Cystic Fibrosis Foundation to Felix Ratjen. Irwin Foundation to Felix Ratjen.

\section{Síndrome de Lesh-Nyhan y automutilación oral. Reporte de un caso}

Andrés Campolo González, Alex Vargas Díaz, Marta Hernández Chávez, Daniel Fontboté Riesco

Departamento de Cirugía oncológica, cabeza-cuello y maxilofacial. Unidad de Neurología Pediatrica, División de Pediatría; Odontología. Centro Médico San Joaquin. Escuela de Medicina, Pontificia Universidad Católica de Chile.

El síndrome de Lesch Nyhan (SLN) secundario a deficiencia de hipoxantina / guanina fosforribosil transferasa (HPRT) produce en los casos graves auto-mutilación compulsiva y movimientos anormales expresados como mordeduras en la mucosa bucal, labios, lengua, dedos y hombros. Desde el punto de vista odontológico, la extracción dental múltiple previene lesiones graves en la mucosa oral, labios y manos. Presentamos el caso de un niño de 7 años con Lesch Nyhan referido a la Unidad de Odontología del Centro Médico San Joaquin desde el Departamento de Neurología Pediátrica para la evaluación y manejo de heridas autoinfligidas en dedos, labios y mejillas, las cuales llevaron a pérdida de peso por disminución de la ingesta alimentaria. El procedimiento quirúrgico consistó en extracciones múltiples, y plastía de rebordes alveolares, lo cual se realizó en pabellón central bajo anestesia general, sin incidentes. Conclusión: La automutilación en el SLN provoca graves alteraciones en la calidad de vida del paciente, familia y entorno cercano la extracción temprana de piezas dentarias, parece ser la major alternativa como manejo inicial en aquellos casos graves. Lo anterior con el objetivo de lograr minimizar los daños por automutilacion y mejorar calidad de vida. Palabras clave: Síndrome de Lesch Nyhan; Labio/lesiones; Conducta autoagresiva/terapia; cuidado dental para niños; auto-mordida.

Presentado en: en vias de presentacion

Fuente de financiamiento: fondos propios

\section{The protein NSs of Andes virus is detected in lungs of experimentally infected golden Syrian Hamsters.}

Jorge Vera-Otarola', Fernando Lowy', Loretto Solis', Karla Pino', Carola Otth², Paula Padula ${ }^{3}$, and Marcelo López-Lastra1,".

'Laboratorio de Virología Molecular, Instituto Milenio de Inmunología e Inmunoterapia, Centro de Investigaciones Médicas, Departamento de Infectología e Inmunología Pediátrica, Escuela de Medicina, Pontificia Universidad Católica de Chile, Marcoleta 391, Santiago, Chile. 2Instituto de Microbiología Clínica, Facultad de Medicina, Universidad Austral de Chile, P. O. Box 567, Valdivia, Chile. ${ }^{3}$ Instituto Nacional de Enfermedades Infecciosas, Administración Nacional de Laboratorios e Institutos de Salud "Dr. C. G. Malbrán", Av Velez Sarsfiel 563 (1281) CABA Argentina, Buenos Aires, Argentina.

Andes virus (ANDV) is a rodent-borne hantavirus member of the Bunyaviridae family of viruses. ANDV is endemic in Argentina and Chile and is the major etiological agent of hantavirus cardiopulmonary syndrome (HCPS) in South America. ANDV mainly infects humans through aerosolized excreta and secrete from infected rodents inducing HCPS; a respiratory disease characterized by the development of a vascular leakage syndrome, eventually leading to massive pulmonary edema, shock and, in many cases, death. ANDV features a tripartite genome consisting of three negative polarity single-stranded RNA segments designated large $(\mathrm{L})$, medium (M) and small (S), packed into helical nucleocapsids. The $L$ and $\mathrm{M}$ messenger RNAs (mRNAs) encode the RNA polymerase and a glycoprotein precursor that is co-translationally processed to yield two envelope glycoproteins (Gc and Gn), respectively. The SmRNA encodes the nucleocapsid (N) protein. Recently, we described that an additional non-structural protein (NSs) is expressed in virus-infected VeroE6 cells from an overlapping $(+1)$ open reading frame (ORF) found in the ANDV SmRNA. In this study further our previous findings by showing that the ANDV-NSs protein is detected in the lungs of experimentally infected golden Syrian hamsters.

Presentado en: si

Fuente de financiamiento: Proyecto Instituto Milenio P09/016-F IMII, Financiado con fondos Programa ICM and the Poyecto Anillo ACT1408 to MLL, and FONDECYT Iniciación 11150611 to J.V-O. FL and LS were recipients of a CONICYT Doctoral fellowship. 


\section{Narcolepsia: caracterización clínica de 20 pacientes con inicio en la infancia y adolescencia.}

Riffo C', Ortiz V., Krakowiak M.J.', Rosso K. , Mesa T.

'Unidad de Neurologia Pediatrica. PUC

NARCOLEPSIA: CARACTERIZACIÓN CLINICA DE 20 PACIENTES CON INICIO EN LA INFANCIA Y ADOLESCENCIA. Riffo C., Ortiz V., Krakowiak M.J., Rosso K., Mesa T. Centro de Medicina del Sueño, División de Neurociencias y Pediatria. Pontificia Universidad Católica, Santiago, Chile. INTRODUCCIÓN: La Narcolepsia es una enfermedad crónica, cuyo diagnóstico habitual es entre los 10-20 años de edad, generalmente con varios años de latencia entre el incio de los síntomas y el diagnóstico. En este grupo etáreo se desconoce su incidencia, es sub-diagnosticada y las formas de presentación pueden ser atípicas. OBJETIVO: Caracterizar una serie de pacientes con diagnóstico en la infancia y en la adolescencia de Narcolepsia del Centro de medicina del Sueño Universidad Católica de Chile, entre los años 2008 y 2015. MATERIAL Y METODO: Análisis de ficha clínica de pacientes con diagnóstico de Narcolepsia antes de los 18 años. Se realizó examen neurológico -TLM (test de latencias múltiples) en el $100 \%$ de los pacientes y PSG (polisomnograma) en el 65\% de estos. RESULTADOS: 20 pacientes, 13 hombres (65\%). El promedio de edad al diagnóstico de 13 años (8-18 años), inicio de la sintomatología en promedio a los 13 años (8 -15). Motivo de consulta: $100 \%$ somnolencia diurna excesiva (ESD). Un 25\% derivado para evaluación desde psiquiatría por trastorno conductual y somnolencia diurna excesiva; 13 pacientes con cataplexia (65\%). Tres pacientes (15\%) se encontraban en tratamiento por epilepsia erróneamente. Alucinaciones hipnagógicas 4 (20\%); parálisis de sueño 4 (20\%). Examen neurológico 100\% normal. IMC promedio de $23,2 \mathrm{Kg} / \mathrm{mt}$. TLMS: Latencia promedio fue de 4,12 minutos (48 seg - 8,9 min). Promedio de SOREM de 3 (2- 5). 14 pacientes (74\%) presentan alteraciones del comportamiento, 5 en control con psiquiatría; 1 paciente presenta un familiar de primer grado con Narcolepsia. La principal comorbilidad fue trastorno conductual. Todos con terapia farmacológica para ESD, con buena respuesta. CONCLUSIÓN: Se debe considerar el diagnóstico de Narcolepsia en los niños con somnolencia diurna excesiva, sin esperar la tétrada clásica, considerar la cataplexia, en todas sus formas de presentación clínica.

Presentado en: no

Fuente de financiamiento: sin

\section{Transición de Adolescentes con Enfermedades Reumáticas: Caracterización de 40 pacientes}

\author{
Armstrong $\mathrm{M}^{1}$, Talesnik E², Borzutzky $\mathrm{A}^{2}$, Morales $\mathrm{P}^{2}$.
}

'Departamento de Inmunología Clínica y Reumatología de la División de Medicina Interna de la Pontificia Universidad Católica de Chile. ${ }^{2}$ Departamento de Enfermedades Infecciosas pediátricas, Inmunología, Alergia y Reumatología de la División de Pediatría de la Pontificia Universidad Católica de Chile.

Introducción: La transición es el proceso planificado, continuo y coordinado de traspaso de un adolescente portador de una enfermedad crónica, desde un sistema de salud pediátrico a un sistema de salud de adultos. Aborda aspectos psicosociales, vocacionales, educacionales, de la vida sexual y la adquisición de hábitos saludables con el fin de lograr la autonomía de los jóvenes. Finaliza cuando se alcanza la madurez física, cognitiva y psicosocial que les permite continuar sus atenciones en el sistema de adultos en forma autónoma. Objetivo: Reportar las características de los primeros 40 pacientes incluídos en el Programa de Transición de adolescentes de Reumatología en la Universidad Católica de Chile. Materiales y Métodos: Se incluyeron pacientes entre 15 y 23 años que fueron derivados desde Reumatología Pediátrica al Policlínico de Transición con diagnóstico de enfermedad reumatológica durante la infancia, entre Marzo del 2015 y Enero del 2017 en la Red de Salud UC - Christus. La primera evaluación incluyó al paciente y al familiar acompañante y en las consultas siguientes se dejó espacio para entrevista individual entre el paciente y el médico. Por una vez se alternaron consultas de Reumatología Pediátrica y Adultos. En todas las atenciones se aplicó la entrevista de adolescentes HEADDS, además de la evaluación propia de la enfermedad. La periodicidad de los controles médicos se fijó de acuerdo al diagnóstico y estado de actividad de la enfermedad. La adherencia a terapia farmacológica se definió como el cumplimiento del tratamiento, entrevistando a padres y pacientes y la adherencia a controles, si estos se cumplían de acuerdo al protocolo. Resultados: La edad promedio fue 18 años (rango 15 a 23 años), 35/40 del sexo femenino y la mayoría residentes en la Región Metropolitana. Predominó la Artritis idiopática juvenil (AIJ ) 21/40, seguida de Lupus eritematoso sistémico (LES) 9/40, Enfermedad Indiferenciada del Tejido Conectivo (EITC) 3/40, Uveítis 2/40, Fibromialgia 2/40, Síndrome Sjogren 2/40, Morfea 1/40, Uveítis 1/40, Policondritis Recidivante 1/40. 9/40 pacientes se encontraban con enfermedad activa al momento de la transición. Promedio de consulta por paciente $=3$. 
En la primera consulta 8/40 pacientes asistieron solos, todos mayores de 19 años. En la última visita 14/40 acudieron solos, entre 15 y 23 años, incremento de 15\% respecto a la primera atención. 10/40 pacientes fueron atendidos en forma intercalada en Pediatría y en Transición. 3/40 no han adherido a controles y 4 de 40 pacientes no adhirieron a terapia. Conclusión: Este es el primer reporte de pacientes atendidos en el Programa de Transición de Adolescentes en Reumatología, y muestra un proceso planificado que ha permitido la continuidad de la atención, adherencia a los controles y terapias en la mayoría de los pacientes incluidos en este estudio.

Presentado en: No

Fuente de financiamiento: No declara

\section{Recomendaciones para la atención en transición de adolescentes con enfermedades crónicas, desde servicios pediátricos a adultos.}

Tamara Zubarew' ${ }^{1}$, Loreto Correa', Paula Bedregal², Carolina Inostroza'

'División de Pediatría, Facultad de Medicina, Pontificia Universidad Católica; ${ }^{2}$ Departamento de Salud Pública, Facultad de Medicina, Pontificia Universidad Católica

En las últimas décadas hemos observado un incremento progresivo de la sobrevida de niños y adolescentes con enfermedades crónicas. Uno de cada 10 adolescentes es portador de una enfermedad crónica, y de éstos el 90\% sobrevive a la adultez. La transferencia no planificada desde servicios pediátricos a adultos impacta en su adherencia terapéutica determinando mayor morbimortalidad y un deterioro en la calidad de vida.

Se plantean recomendaciones de atención que se enmarcan en el Proyecto FONIS y VRI PUC realizado por la División de Pediatría de la P. Universidad Católica de Chile: “El proceso de transición de servicios pediátricos a adultos: visión de adolescentes portadores de enfermedades crónicas, sus cuidadores y los profesionales de salud", cuyo objetivo es describir la experiencia, barreras, puntos críticos y facilitadores percibidos por adolescentes portadores de enfermedades crónicas, cuidadores y profesionales de salud, en el proceso de transición. Acorde a estos resultados y en base a experiencias internacionales publicadas, se plantean recomendaciones para la implementación de procesos graduales y planificados de transición. Se discuten aspectos respecto a: diseño e implementación de políticas de transición con énfasis en la necesidad de prolongación de la edad pediátrica hasta los 18 años, constitución de equipos multidisciplinarios y coordinación entre equipos pediátricos y adultos, momento adecuado y etapas en la transferencia, fomento del autocuidado y autonomía, utilización de registros para la transferencia que apoyen la atención clínica, participación de familias y adolescentes, necesidad de apoyo emocional, aspectos éticos involucrados, importancia de la confidencialidad, necesidad de adecuación de los servicios hospitalarios y de capacitación profesional, y la necesidad de evaluación y mayor investigación en el tema.

Conclusiones: Como resultado de una transición programada y aplicación de estas recomendaciones se espera que adolescentes portadores de enfermedades crónicas logren acceso expedito a los servicios de salud, continuidad de su atención, mayor conocimiento y competencias en el manejo de su enfermedad, y a la vez refuercen habilidades de desarrollo personal como autoestima, autoeficacia y habilidades de comunicación. Esto incidirá en una mejor adherencia a controles, menor morbimortalidad y mejor calidad de vida, logrando su máximo potencial de desarrollo.

Presentado en:

Fuente de financiamiento:

\section{Relación entre parámetros nutricionales y monitoreo ambulatorio de presión arterial en pacientes pediátricos de Santiago de Chile}

Bofill L, Peredo MS, Carrillo D, Vogel A, Nardiello A, Andrade D, Gutiérrez A

Unidad de Nefrología de la División de Pediatría de la Pontificia Universidad Católica de Chile

Se realizó un estudio analítico transversal con el objetivo de buscar si existe asociación el estado nutricional y los resultados de monitoreo ambulatorio de presión arterial de pacientes, asociación descrita en la literatura, pero no caracterizada en pacientes chilenos. Para este fin, se usaron los datos de todos los pacientes que se tomaron monitoreo ambulatorio de presión arterial (MAPA) en la Red de Salud UC Christus entre Enero y Julio de 2015, considerando sólo un registro de MAPA por paciente. Se excluyeron aquellos registros de pacientes menores a 1,15 mt y que no fueran técnicamente satisfactorios. Para la evaluación del estado nutricional se utilizaron curvas CDC (2003) para talla/edad e índice de masa corporal por edad, usando el percentil por edad para ambas curvas. Se obtuvieron datos de 50 pacientes: 25 hombres (50\%) 


\section{Suplemento 1 año 2017}

y 25 mujeres (50\%). Como resultados destacamos la distribución por edad con mediana de 11 años RIC (8-14), 22 pacientes (44\%) obesos, 9 pacientes (18\%) con sobrepeso, percentil de talla/edad $78,5 \%$ RIC (37\%-94\%), y que el motivo de toma de MAPA fue por sospecha de hipertensión o hipertensión en 48 pacientes (96\%). De los resultados de MAPA destacamos presiones diurnas sistólicas y diastólicas de mediana $117,5 \mathrm{~mm} \mathrm{Hg}$ RIC (111-124) y de 71,5 mm Hg RIC (67-76), respectivamente; nocturnas sistólicas y diastólicas de 107,5 mm Hg RIC (101-114) y de 62 mm Hg RIC (58-66), respectivamente. En cuanto a sobrecargas diurnas sistólicas 11,6\% RIC (2,5\%-33,3\%), diastólicas de $11,25 \%$ RIC (5\%-23\%) y sobrecargas nocturnas sistólicas y diastólicas con medianas de $24,25 \%$ RIC (5,6\%-36,8\%) y $24,5 \%$ RIC (15\%-42,1\%) respectivamente. No se obtuvieron correlaciones estadísticamente significativas entre percentil de IMC/edad y talla/edad con sobrecargas y presiones medias y máximas (coef. Kendall para todos los casos entre - 0,1 y 0,1 con $p=N S$ ). Más investigación es necesaria en el área.

Presentado en: Il Congreso Nacional de Hipertensión

Fuente de financiamiento: Ninguno 


\section{PUBLICACIONES}

\section{DIVISIÓN DE PEDIATRÍA}

\section{Pontificia Universidad Católica de Chile}

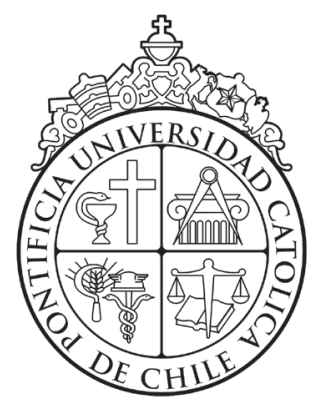


Abarca, K., Garate, D., López, J., \& Acosta-Jamett, G. (2016). Flea and ticks species from dogs in urban and rural areas in four districts in Chile. Archivos De Medicina Veterinaria, 48(2), 247-253.

Acuna, G., \& Perret, C. (2016). What is human infection with zika virus? Revista Médica De Chile, 144(10), 1322-1325.

Angulo, D., Bustos, E., Sánchez, A., \& Barja, S. (2016). Oral feeding rehabilitation in children with chronic respiratory diseases and long-term enteral nutrition. Nutrición Hospitalaria, 33(4), 765-770. doi:10.20960/nh.368

Asgari, S., McLaren, P. J., Peake, J., Wong, M., Wong, R., Bartha, I., ... Swiss Pediat Sepsis Study. (2016). Exome sequencing reveals primary immunodeficiencies in children with community-acquired pseudomonas aeruginosa sepsis. Frontiers in Immunology, 7 doi:10.3389/fimmu.2016.00357

Barriga, G. P., Boric-Bargetto, D., Martin, M. C., Neira, V., van Bakel, H., Thompsom, M., ... Medina, R. A. (2016). Avian influenza virus $\mathrm{H} 5$ strain with north american and eurasian lineage genes in an antarctic penguin. Emerging Infectious Diseases, 22(12), 2221-2223. doi:10.3201/eid2212.161076

Betancur Moreno, C., Bustos, C., Quezada, C., Bastidas, C., Pineda, C., Sanchez, T., \& Brockmann, P. (2016). Association between sleep features and hyperactivity and attention deficit in school children of the biobio region in chile. Journal of Sleep Research, 25(1, SI), 372.

Brockmann, P. E., Damiani, F., Smith, D. L., Castet, A., Nunez, F., ViIlarroel, L., \& Gozal, D. (2016). Metabolic consequences of snoring in adolescents and younger adults: A population study in Chile. International Journal of Obesity, 40(10), 1510-1514. doi:10.1038/ ijo.2016.133

Brockmann, P. E. (2016). When does the risk for obstructive sleep apnea start? The importance of perinatal factors. Sleep, 39(4), 721 722. doi: $10.5665 /$ sleep. 5610

Brockmann, P. E., Damiani, F., \& Gozal, D. (2016). Sleep-disordered breathing in adolescents and younger adults. A representative population-based survey in chile. Chest, 149(4), 981-990. doi:10.1378/ chest.15-2112

Brockmann, P. E., Damiani, F., Nunez, F., Moya, A., Pincheira, E., Paul, M. A., \& Lizama, M. (2016). Sleep-disordered breathing in children with down syndrome: Usefulness of home polysomnography. International Journal of Pediatric Otorhinolaryngology, 83(4), 47-50. doi:10.1016/j.ijporl.2016.01.030
Brockmann, P. E., Diaz, B., Damiani, F., Villarroel, L., Nunez, F., \& Bruni, O. (2016). Impact of television on the quality of sleep in preschool children. Sleep Medicine, 20, 140-144. doi:10.1016/j. sleep.2015.06.005

Brodlie, M., Gupta, A., Rodriguez-Martinez, C. E., Castro-Rodriguez, J. A., Ducharme, F. M., \& McKean, M. C. (2016). Leukotriene receptor antagonists as maintenance or intermittent treatment in pre-school children with episodic viral wheeze. Paediatric Respiratory Reviews, 17, 57-59. doi:10.1016/j.prrv.2015.10.007

Caceres, C. J., Contreras, N., Angulo, J., Vera-Otarola, J., Pino-Ajenjo, C., Llorian, M., ... Lopez-Lastra, M. (2016). Polypyrimidine tract-binding protein binds to the 5 untranslated region of the mouse mammary tumor virus mRNA and stimulates cap-independent translation initiation. Febs Journal, 283(10), 1880-1901. doi:10.1111/febs.13708

Campino, C., Hill, C., Baudrand, R., Martinez-Aguayo, A., Aglony, M., Carrasco, C. A., ... Fardella, C. E. (2016). Usefulness and pitfalls in sodium intake estimation: Comparison of dietary assessment and urinary excretion in chilean children and adults. American Journal of Hypertension, 29(10), 1212-1217. doi:10.1093/ajh/hpw056

Caniuguir, A., Krause, B. J., Hernandez, C., Uauy, R., \& Casanello, P. (2016). Markers of early endothelial dysfunction in intrauterine growth restriction-derived human umbilical vein endothelial cells revealed by 2D-DIGE and mass spectrometry analyses. Placenta, 41, 14-26. doi:10.1016/j.placenta.2016.02.016

Carcey, J., Garcia, P., Padilla, O., \& Castro-Rodriguez, J. A. (2016). Increased prevalence of mycoplasma pneumoniae serological positivity in chilean young children. Allergologia Et Immunopathologia, 44(5), 467-471. doi:10.1016/j.aller.2016.02.007

Cardenas, A., Paul, M. A., Correa, C., Valderrama, S., Cerda, J., \& Lizama, M. (2016). Morbidity profile among adolescents with down syndrome. Revista Medica De Chile, 144(8), 998-1005.

Carvajal, F., Vallejos, M., Walters, B., Contreras, N., Hertz, M. I., Olivares, E., ... Lopez-Lastra, M. (2016). Structural domains within the HIV-1 mRNA and the ribosomal protein S25 influence cap-independent translation initiation. Febs Journal, 283(13), 2508-2527. doi:10.1111/febs.13756

Castro-Rodriguez, J. A., Ramirez-Hernandez, M., Padilla, O., Pacheco-Gonzalez, R. M., Perez-Fernandez, V., \& Garcia-Marcos, L. (2016). Effect of foods and mediterranean diet during pregnancy and first years of life on wheezing, rhinitis and dermatitis in preschoolers. Allergologia Et Immunopathologia, 44(5), 400-409. doi:10.1016/j. aller.2015.12.002 
Castro-Rodriguez, J. A. (2016). A new childhood asthma phenotype: Obese with early menarche. Paediatric Respiratory Reviews, 18, 85-89. doi:10.1016/j.prrv.2015.10.006

Castro-Rodriguez, J. A., Beckhaus, A. A., \& Forno, E. (2016). Efficacy of oral corticosteroids in the treatment of acute wheezing episodes in asthmatic preschoolers: Systematic review with meta-analysis. Pediatric Pulmonology, 51(8), 868-876. doi:10.1002/ ppul.23429

Castro-Rodriguez, J. A., Forno, E., Rodriguez-Martinez, C. E., \& Celedon, J. C. (2016). Risk and protective factors for childhood asthma: What is the evidence? Journal of Allergy and Clinical Immunology-in Practice, 4(6), 1111-1122. doi:10.1016/j.jaip.2016.05.003

Castro-Rodriguez JA, Custovic A, Ducharme FM. Treatment of asthma in young children: evidence-based recommendations. Asthma Res Pract. 2016 Mar 2;2:5. Review.

Castro-Rodriguez JA, Brockmann PE, Marcus CL. Relation between asthma and sleep disordered breathing in children: is the association causal? Paediatr Respir Rev. 2016 Aug 21. pii: S1526-0542(16)300847. doi:10.1016/j.prrv.2016.08.010.

Castro-Rodríguez JA, Krause BJ, Uauy R, Casanello P. [Epigenetics in allergic diseases and asthma]. Rev Chil Pediatr. 2016 MarApr;87(2):88-95. doi: 10.1016/j.rchipe.2016.02.006.

Codner, E., Merino, P. M., Martinez, D., Lopez, P., Godoy, C., Iniguez, G.,... Perez-Bravo, F. (2016). C-reactive protein and insulin growth factor 1 serum levels during the menstrual cycle in adolescents with type 1 diabetes. Diabetic Medicine, 33(1), 70-76. doi:10.1111/ dme.12829

den Hartog, G., Chattopadhyay, R., Ablack, A., Hall, E. H., Butcher, L. D., Bhattacharyya, A., ... Crowe, S. E. (2016). Regulation of Rac1 and reactive oxygen species production in response to infection of gastrointestinal epithelia. Plos Pathogens, 12(1) doi:10.1371/ journal.ppat.1005382

Flores, J. C., Bohmwald, K., Espinoza, J., Jara, C., Pena, M., Hoyos-Bachiloglu, R., . . Borzutzky, A. (2016). Potential neurocognitive consequences of infection by human respiratory syncytial virus. Revista Chilena De Infectologia, 33(5), 537-542.

Galleguillos C, Galleguillos B, Larios G, Menchaca G, Bont L, Castro-Rodriguez JA. Down's syndrome is a risk factor for severe lower respiratory tract infection due to respiratory syncytial virus. Acta Paediatr. 2016 Nov;105(11):e531-e535. doi: 10.1111/apa.13552.
Goecke, C., Seiltgens, C., Mellado, C., Martinez-Aguayo, A., Garcia, C., \& Garcia, H. (2016). Short stature and hypothyroidism in a child with nail-patella syndrome. case report and review of the literature. Hormone Research in Paediatrics, 86(2), 58.

Gutierrez, V., Martinez-Valdebenito, C., Montecinos, L., Alarcon, R., Garate, C., \& Ferres, M. (2016). Parechovirus as etiologic agent of meningitis and/or sepsis like illness in infants. Revista Chilena De Infectologia, 33(4), 380-388.

Hansen, J., Seiltgens, C., Mellado, C., Garcia, C., \& Garcia, H. (2016). Use of growth hormone in a girl with cleidocranial dysplasia. Hormone Research in Paediatrics, 86(2), 78-79.

Herrera, E. A., Alegria, R., Farias, M., Diaz-Lopez, F., Hernandez, C., Uauy, R., ... Krause, B. J. (2016). Assessment of in vivo fetal growth and placental vascular function in a novel intrauterine growth restriction model of progressive uterine artery occlusion in guinea pigs. Journal of Physiology-London, 594(6), 1553-1561. doi:10.1113/JP271467

Hoyos-Bachiloglu, R., Garcia, A., Morales, P. S., Cerda, J., Talesnik, E., \& Borzutzky, A. (2016). Geographic distribution of Kawasaki disease throughout Chile. Revista Chilena De Infectologia, 33(1), 12-18.

Jensen, R., Stanojevic, S., Klingel, M., Pizarro, M. E., Hall, G. L., Ramsey, K., ... Ratjen, F. (2016). A systematic approach to multiple breath nitrogen washout test quality. Plos One, 11(6) doi:10.1371/journal.pone.0157523

Joaquin Caceres, C., Angulo, J., Contreras, N., Pino, K., Vera-Otarola, J., \& Lopez-Lastra, M. (2016). Targeting deoxyhypusine hydroxylase activity impairs cap-independent translation initiation driven by the 5'untranslated region of the HIV-1, HTLV-1, and MMTV mRNAs. Antiviral Research, 134, 192-206. doi:10.1016/j.antiviral.2016.09.006

Krause BJ, Castro-Rodríguez JA, Uauy R, Casanello P. [General concepts of epigenetics: Projections in paediatrics]. Rev Chil Pediatr. 2016 Jan-Feb;87(1):4-10. doi: 10.1016/j.rchipe.2015.12.002. Review.

Koltin, D., O'Gorman, C. S., Murphy, A., Ngan, B., Daneman, A., Navarro, O. M., ... Rachmiel, M. (2016). Pediatric thyroid nodules: Ultrasonographic characteristics and inter-observer variability in prediction of malignancy. Journal of Pediatric Endocrinology \& Metabolism, 29(7), 789-794. doi:10.1515/jpem-2015-0242

Krause, B. J., Herrera, E. A., Diaz-Lopez, F. A., Farias, M., Uauy, R., \& Casanello, P. (2016). Pre-gestational overweight in guinea pig sows induces fetal vascular dysfunction and increased rate of large and small fetuses. Journal of Developmental Origins of Health and Disease, 7(3), 237-243. doi:10.1017/S2040174415007266 
Krause, B. J., Hernandez, C., Caniuguir, A., Vasquez-Devaud, P., Carrasco-Wong, I., Uauy, R., \& Casanello, P. (2016). Arginase-2 is cooperatively up-regulated by nitric oxide and histone deacetylase inhibition in human umbilical artery endothelial cells. Biochemical Pharmacology, 99, 53-59. doi:10.1016/j.bcp.2015.10.018

Mardones, F., Rosso, P., Villarroel, L., Bacallao, J., Dominguez, A., Passi, A., ... Margozzini, P. (2016). Pregnancy outcomes and the use of two standards to assess adequacy of maternal body mass index in early gestation. Journal of Developmental Origins of Health and Disease, 7(1), 83-89. doi:10.1017/S204017441500714X

Martinez-Aguayo, A., Seiltgens, C., Campino, C., Vecchiola, A., Carvajal, C. A., Baudrand, R., .. F Fardella, C. E. (2016). Leptin is associated with serum aldosterone in paediatric subjects, independently of body mass index, blood pressure and plasma renin activity. Hormone Research in Paediatrics, 86(2), 18-19.

Martinez-Aguayo, A., Campino, C., Baudrand, R., Carvajal, C. A., Garcia, H., Aglony, M., . . F Fardella, C. E. (2016). Cortisol/cortisone ratio and matrix metalloproteinase- 9 activity are associated with pediatric primary hypertension. Journal of Hypertension, 34(9), 1808-1814. doi:10.1097/HJH.0000000000001017

Martinez-Aguayo, A., Campino, C., Baudrand, R., Carvajal, C., Grob, F., Garcia, H., ... Fardella, C. (2016). Leptin is associated with serum aldosterone in paediatric subjects, independently of body mass index, blood pressure and plasma renin activity. Hormone Research in Paediatrics, 86(1), 122.

Morales, M., Flores, C., Pino, K., Angulo, J., Lopez-Lastra, M., \& Castro-Rodriguez, J. A. (2016). Urinary leukotriene and bcl I polymorphism of glucocorticoid receptor gene in preschoolers with recurrent wheezing and high risk of asthma. Allergologia Et Immunopathologia, 44(1), 59-65. doi:10.1016/j.aller.2015.02.003

Mosso, C., Isabel Hodgson, M., Ortiz, T., \& Loreto Reyes, M. (2016). Bone mineral density in young chilean patients with type 1 diabetes mellitus. Journal of Pediatric Endocrinology \& Metabolism, 29(6), 731-736. doi:10.1515/jpem-2015-0097

Moya, A., Hernandez, M., \& Mellado, C. (2016). Prevalence of genetic diseases in admissions to a tertiary care hospital pediatric service. Revista Medica De Chile, 144(2), 188-193.

Navarrete-Dechent, C., Perez-Mateluna, G., Silva-Valenzuela, S., Vera-Kellet, C., \& Borzutzky, A. (2016). Humoral and cellular autoreactivity to epidermal proteins in atopic dermatitis. Archivum Immunologiae Et Therapiae Experimentalis, 64(6), 435-442. doi:10.1007/s00005-016-0400-3
Ontiveros, N., Valdez-Meza, E. E., Vergara-Jimenez, M. J., Canizalez-Roman, A., Borzutzky, A., \& Cabrera-Chavez, F. (2016). Parent-reported prevalence of food allergy in mexican schoolchildren: A population-based study. Allergologia Et Immunopathologia, 44(6), 563-570. doi:10.1016/j.aller.2016.03.003

Orellana-Manzano, A., O'Ryan, M. G., Lagomarcino, A. J., George, S., Munoz, M. S., Mamani, N., ... Quest, A. F. G. (2016). Helicobacter pylori infection is associated with decreased expression of SLC5A8, a cancer suppressor gene, in young children. Frontiers in Cellular and Infection Microbiology, 6 doi:10.3389/fcimb.2016.00121

Pena, A., Abarca, K., Weitzel, T., Gallegos, J., Cerda, J., Garcia, P., \& Lopez, J. (2016). One health in practice: A pilot project for integrated care of zoonotic infections in immunocompromised children and their pets in Chile.Zoonoses and Public Health, 63(5), 403-409. doi:10.1111/zph.12241

Poblete-Duran, N., Prades-Perez, Y., Vera-Otarola, J., Soto-Rifo, R., \&Valiente-Echeverria, F. (2016). Who regulates whom? An overview of RNA granules and viral infections. Viruses-Basel, 8(7) doi:10.3390/v8070180

Poli, C., Hoyos-Bachiloglu, R., \& Borzutzky, A. (2016). Primary immunodeficiency epidemiology in Chile evaluated through icd-10 coded hospital admissions. Journal of Clinical Immunology, 36(3), 242-243.

Putnam, L. R., Harting, M. T., Tsao, K., Morini, F., Yoder, B. A., Luco, M., . . Congenital Diaphragmatic Hernia. (2016). Congenital diaphragmatic hernia defect size and infant morbidity at discharge. Pediatrics, 138(5) doi:10.1542/peds.2016-2043

Retamal, J., Becker, P., Gonzalez, R., Ferres, M., Cerda, J., Riquelme, M. I., .. . Claveria, C. (2016). Surgical site infections in children undergoing cardiac surgery with delayed sternal closure. case-control study. Revista Chilena De Infectologia, 33(5), 495-500.

Rodriguez-Martinez, C. E., Sossa-Briceno, M. P., \& Castro-Rodriguez, J. A. (2016). Cost-utility analysis of once-daily versus twice-daily inhaled corticosteroid dosing for maintenance treatment of asthma in pediatric patients. Journal of Asthma, 53(5), 538-545. doi:10.31 09/02770903.2015.1116087

Sánchez T, Castro-Rodríguez JA, Brockmann PE. Sleep-disordered breathing in children with asthma: a systematic review on the impact of treatment. J Asthma Allergy. 2016 Apr 18;9:83-91. doi: 10.2147/JAA.S85624. Review.

Sandoval, C., Barrera, A., Ferres, M., Cerda, J., Retamal, J., Garcia-Sastre, A.,... Hirsch, T. (2016). Infection in health personnel with high and low levels of exposure in a hospital setting during the H1N1 2009 influenza A pandemic. Plos One, 11(1) doi:10.1371/journal.pone.0147271 
Seiltgens, C., Cristi, F., Iruretagoyena, M., Perez-Mateluna, G., Talesnik, E., Hogdson, I., .. Borzutzky, A. (2016). Role of PTPN22 C1858T gene polymorphism in pediatric polyautoimmunity. Hormone Research in Paediatrics, 86(1), 404-405.

Serrano, C. A., Villagran, A., Toledo, H., Crabtree, J. E., \& Harris, P. R. (2016). Iron deficiency and IL1 beta polymorphisms in helicobacter pylori-infected children. Helicobacter, 21(2), 124-130. doi:10.1111/hel.12247

Urbina, J., Sotelo, J. A., Springmuller, D., Montalba, C., Letelier, K., Tejos, C., ... Uribe, S. A. (2016). Realistic aortic phantom to study hemodynamics using MRI and cardiac catheterization in normal and aortic coarctation conditions. Journal of Magnetic Resonance Imaging, 44(3), 683-697. doi:10.1002/jmri.25208

Valdivia, C., Carvajal, C. A., Campino, C., Allende, F., Martinez-Aguayo, A., Baudrand, R., .. . Fardella, C. E. (2016). Citosine-adenine-repeat microsatellite of 11 beta-hydroxysteroid dehydrogenase 2 gene in hypertensive children. American Journal of Hypertension, 29(1), 25-32. doi:10.1093/ajh/hpv052
Verdaguer D, S., \& Gana A, J. C. (2016). Management of pediatric patients with esophageal varices. Revista Médica De Chile, 144(7), 879-885.

Weitzel, T., Dittrich, S., Lopez, J., Phuklia, W., Martinez-Valdebenito, C., Velasquez, K., ... Abarca, K. (2016). Endemic scrub typhus in South America. New England Journal of Medicine, 375(10), 954961. doi:10.1056/NEJMoa1603657

Weitzel, T., Lopez, J., Acosta-Jamett, G., Edouard, S., Parola, P., \& Abarca, K. (2016). Absence of convincing evidence of coxiella burnetii infection in Chile: A cross-sectional serosurvey among healthy adults in four different regions. Bmc Infectious Diseases, 16 doi:10.1186/s12879-016-1880-9

Zubizarreta, J. R., Lorch, S. A., Marshall, G., D'Apremont, I., Tapia, J. L., \& South Amer Neocosur Network. (2016). Effect of prophylactic CPAP in very low birth weight infants in South America. Journal of Perinatology, 36(8), 629-634. doi:10.1038/jp.2016.56 